\title{
ARE EXPECTATIONS ALONE ENOUGH? ESTIMATING THE EFFECT OF A MANDATORY COLLEGE-PREP CURRICULUM IN MICHIGAN
}

\author{
Brian Jacob \\ Susan Dynarski \\ Kenneth Frank \\ Barbara Schneider \\ Working Paper 22013 \\ http://www.nber.org/papers/w22013 \\ NATIONAL BUREAU OF ECONOMIC RESEARCH \\ 1050 Massachusetts Avenue \\ Cambridge, MA 02138 \\ February 2016
}

Thanks to our partners at the Michigan Department of Education (MDE) and Michigan's Center for Educational Performance and Information (CEPI), especially Thomas Howell, Venessa Keesler and Joseph Martineau. An army of research assistants worked to prepare these data and we are eternally grateful to them all. The Institute of Education Sciences provided generous support through Grant R305E100008. This research uses data structured and maintained by the Michigan Consortium for Educational Research (MCER). MCER data are modified for analysis using rules governed by MCER and are not identical to data collected and maintained by MDE and CEPI. Results, information and opinions are the authors' and do not reflect the views or positions of MDE or CEPI. The views expressed herein are those of the authors and do not necessarily reflect the views of the National Bureau of Economic Research.

NBER working papers are circulated for discussion and comment purposes. They have not been peerreviewed or been subject to the review by the NBER Board of Directors that accompanies official NBER publications.

(C) 2016 by Brian Jacob, Susan Dynarski, Kenneth Frank, and Barbara Schneider. All rights reserved. Short sections of text, not to exceed two paragraphs, may be quoted without explicit permission provided that full credit, including $(\mathcal{O}$ notice, is given to the source. 
Are Expectations Alone Enough? Estimating the Effect of a Mandatory College-Prep Curriculum in Michigan

Brian Jacob, Susan Dynarski, Kenneth Frank, and Barbara Schneider

NBER Working Paper No. 22013

February 2016

JEL No. I0,I21,I3

\begin{abstract}
This paper examines the impacts of the Michigan Merit Curriculum, a statewide college preparatory curriculum that applies to the high school graduating class of 2008 and later. We use a student, longitudinal database for all public school students in Michigan for the main analyses, and complement this with analyses from a state-year panel. The study employs several nonexperimental approaches, including a comparative interrupted time series and a synthetic control method. Our analyses suggest that the higher expectations embodied in the MMC has had little impact on student outcomes. Looking at student performance on the ACT, the only clear evidence of a change in academic performance comes in science. Our best estimates indicate that ACT science scores improved by 0.2 points (or roughly 0.04 standard deviations) as a result of the MMC. Students who entered high school with the weakest academic preparation saw the largest improvement, gaining 0.35 points ( 0.15 standard deviations) on the ACT composite score and 0.73 points (0.22 standard deviations) on the ACT science score. Our estimates for high school completion are very sensitive to the sample and methodology used. Some analysis suggests a small negative impact on high school graduation for students who entered high school with the weakest academic preparation, but other analysis finds no such effect.
\end{abstract}

Brian Jacob

Gerald R. Ford School of Public Policy

University of Michigan

735 South State Street

Ann Arbor, MI 48109

and NBER

bajacob@umich.edu

Susan Dynarski

University of Michigan

Weill Hall

735 South State Street

Ann Arbor, MI 48109-3091

and NBER

dynarski@umich.edu
Kenneth Frank

Room 462 Erickson Hall

Michigan State University

East Lansing, MI 48824-1034

kenfrank@msu.edu

Barbara Schneider

Erickson Hall

Michigan State University

East Lansing, MI 48824-1034

bschneid@msu.edu 


\section{INTRODUCTION}

Over the past two decades, the academic achievement of elementary students in the United States has risen substantially, but that of high school students has stagnated. Reading and math scores of 9- and 13-year-olds rose from the early 1970s through 2012, while those of 17year-olds barely budged (National Center for Education Statistics, 2013). Moreover, recent research indicates that, when calculated properly, the high school graduation rate of boys is flat over the past 40 years while that of girls has increased only slightly (Murnane, 2013). The United States consistently lags behind other industrialized countries on international tests of the academic performance of high school students. On the 2009 PISA exam, fifteen-year-olds in the United States scored seventeenth in math and twelfth in science relative to students in the other thirty-three OECD countries.

Spurred in part by these disappointing trends, there has been an intense, nationwide conversation about establishing uniform curricular standards in the US. The Common Core, which has now been adopted by 43 states and the District of Columbia, details the knowledge that should be expected of students in each grade. The expectation is that consistent standards will produce students who are better prepared for both college and work.

While it is far too early to measure the effect of the Common Core, it is possible to examine the effect of analogous initiatives in individual states. In this paper, we focus on the efforts of one state to impose consistent curricular standards across high schools. In 2007, Michigan implemented the Michigan Merit Curriculum, which established an ambitious set of standards for the state's high school students.

In order to graduate from high school, Michigan’s students must now take a set of classes that includes Algebra II, chemistry or physics, four years of English, and two years of a foreign 
language. While this set of courses is standard for any student planning to attend a four-year college, it is not at all typical of most high school graduates. In 2005, only 12\% of Michigan's high schools required Algebra II and even fewer required chemistry or physics. Among high school graduates nationwide in 2005, 68\% completed Algebra II and only 31\% completed physics. ${ }^{1}$

The intent of the Michigan Merit Curriculum is to increase academic preparation for college and enhance career readiness. But the theoretical effects of the initiative are ambiguous. When graduation standards are raised, it is plausible that fewer students will meet the new, higher standards required to graduate. However, the theory underlying the Michigan Merit Curriculum is that students, teachers, and schools will rise to the higher expectations, leading to an increase in academic achievement and attainment.

This paper evaluates the effect of the Michigan Merit Curriculum (MMC) on high school graduation rates and academic achievement. ${ }^{2}$ Like many large education policy changes, the MMC was implemented statewide and affected virtually all students at the same time, making it difficult to convincingly estimate the causal impact of the reforms. We take several approaches to evaluating the policy. To begin, we use student-level longitudinal data to estimate an interrupted time series that identifies the impact of the policy from deviations in pre-existing trends. We supplement this with an analysis of aggregate data that compares changes over time in Michigan to changes over the same time period in comparison states.

Looking at student performance on the ACT, the only clear evidence of a change in academic performance comes in science. Our best estimates indicate that ACT science scores

\footnotetext{
${ }^{1}$ See https://nces.ed.gov/programs/digest/d13/tables/dt13_225.40.asp

${ }^{2}$ In future work, as the affected cohorts age, we will also examine effects on postsecondary attainment, choice and achievement.
} 
improved by 0.2 points (or roughly 0.04 standard deviations) as a result of the MMC. Students who entered high school with the weakest academic preparation saw the largest improvement, gaining 0.35 points ( 0.15 standard deviations) on the ACT composite score and 0.73 points ( 0.22 standard deviations) on the ACT science score. Looking at student performance on the ACT, the only clear evidence of a change in academic performance comes in Science.

Our estimates for high school completion are very sensitive to the sample and methodology used. Overall, we find no clear evidence that the introduction of the new policy changed graduation rates. However, some of our analyses suggest that the new requirements may have had a small negative impact on the likelihood of high school graduation for students who entered high school with the weakest academic preparation.

These findings are consistent with much of the prior literature. A large body of research has found that increasing high school graduation requirements (whether in the form of additional courses or exit exams) results in lower graduation rates among the most disadvantaged students. There is less evidence on how such policies impact student achievement, but the existing research generally does not find large gains in student performance.

Our findings suggest several important lessons for policymakers. First, higher expectations alone are likely insufficient to generate substantial improvements in student outcomes. Second, higher expectations may have a downside in terms of pushing the least prepared students out of school.

The remainder of the paper proceeds as follows. In Section II, we describe the background of the Michigan Merit Curriculum. In Section III, we review prior literature on similar reform efforts. Section IV and V describe the empirical strategy and data respectively. Section VI presents results and we conclude in Section VII. 


\section{BACKGROUND}

While the Common Core is relatively new, there is a longer history of states imposing curricular standards on school districts. Forty-six states have at least some statewide requirements for high school graduation (American Association of State Colleges and Universities, 2006), and 25 states offer an optional, college-preparatory diploma (Dounay, 2006).

The American Diploma Project, an advocacy organization, has tracked state’s adherence to their recommended high-school curriculum, which includes math through Algebra II and four years of English. Since 2004, 36 states and the District of Columbia have raised graduation requirements to meet this set of standards, while an additional 14 states plan to do so in the next few years (Achieve, 2013).

Following this national trend, the Michigan legislature in 2006 passed a set of high school graduation requirements called the Michigan Merit Curriculum. The stated intent of the Michigan Merit Curriculum was to, by increasing the rigor of secondary school, better prepare students for college and career (Cherry Commission, 2004). The first students covered by the Michigan Merit Curriculum started high school in the fall of 2007. Students who started high school before that date were not bound by the new rules. The first cohort of freshmen affected by the Michigan Merit Curriculum graduated in the spring of 2011.

The Michigan Merit Curriculum emphasizes academic preparation in mathematics and science. Students are required to take Algebra I, Geometry, and Algebra II, as well as Biology and either Chemistry or Physics. Students must also take four years of English, two years of a foreign language, three courses in social studies, and one credit each of physical education, art, and online learning. The typical high school student will devote about half of her courses to meeting the requirements of the Michigan Merit Curriculum. 
Before these requirements were passed, Michigan had largely left curricular decisions to the districts. For high school students, the only state requirement was a single course in civics. ${ }^{3}$ The state still had influence on curricular content, however, in that it wrote and graded the standardized tests required by the federal No Child Left Behind Act. Since schools and districts faced sanctions if students performed poorly on these tests (given in $11^{\text {th }}$ grade, as well as grades three through eight) they had a strong incentive to teach the material contained in those tests. But the state imposed no constraints on the curricula that schools used to teach the material contained in the required tests.

Before the Michigan Merit Curriculum, districts varied considerably in the courses they required of high school students. According to a state-administered survey, only about a third of school districts required four years of math before the new curriculum was put in place; a similar proportion required three years of science. These requirements were reflected in students’ choices: only a quarter of high school students took physics, less than half took chemistry, and only one out of eight took Algebra II. By contrast, about 60 percent of districts required four years of English even before the Merit Curriculum was implemented. ${ }^{4}$ These statistics suggest that the new curriculum was particularly binding in the realms of science and math. Note that the new curriculum not only required students to take more rigorous classes, but also required schools to provide them; thus, many schools would need to hire teachers and schedule the courses students would now be required to take.

While the requirements of the Michigan Merit Curriculum are extensive, state oversight of compliance is relatively limited. The state does provide a detailed framework for each required course, including instructional guidelines. However, implementation of these standards

\footnotetext{
${ }^{3}$ See page 2 in http://www.michigan.gov/documents/mde/faq1_178592_7.pdf.

${ }^{4}$ Authors' calculations based on data provided by the Michigan Department of Education.
} 
and enforcement of the requirements of the curriculum are local responsibilities. A set of standardized, statewide, end-of-course exams was intended to accompany the new curriculum, but these were shelved in the face of budget constraints and district resistance. Districts and schools write and administer their own course assessments, which can consist of (for example) a final exam, a portfolio, a project, or a series of tests given throughout the course. The state does not audit these assessments or student transcripts to confirm that the Michigan Merit Curriculum is being followed. We therefore expect considerable variation across the state in the fidelity with which the curriculum is implemented and, therefore, in the impact of the Merit Curriculum on student learning.

The state does require that all students take the Michigan Merit Exam (MME) in 11th grade. The MME consists of the ACT college entrance examination, components of the ACT's WorkKeys job skills assessment, and Michigan-developed assessments in mathematics, science, and social studies. Graduation is not contingent on passing the MME.

\section{PRIOR LITERATURE}

A long literature documents the correlation between the rigor of courses that students take in high school and their future academic success. Successful completion of rigorous math and science courses is associated with improved academic and social outcomes in the short term (Frank et al., 2008). Those who take math and science are also more likely to attend college, especially four-year institutions (Adelman, 1999; Sells, 1973; Davis-Kean, Eccles, \& Simpkins, 2006; Sadler \& Tai, 2007, Schneider, Swanson, \& Riegle-Crumb 1997; Riegle-Crumb, 2006). This may be because requiring a set of college-preparatory courses raises students' college aspirations (Bryk, Lee, \& Holland, 1993; Lee, 2002). 
A small but growing body of research shows that taking certain core courses, especially those in math and science, can have significant, positive effects on long-term labor-market outcomes (Cortes, Goodman, \& Nomi, forthcoming; Goodman, 2012, Levine \& Zimmerman, 1995; Betts \& Rose, 2004). This evidence suggests that requiring more rigorous courses of Michigan's students could improve their earnings and employment as adults. In theory, this effect could operate both through an increase in educational attainment and through enhanced skills among those with a given level of education. We will therefore examine the effects of the Michigan Merit Curriculum on educational attainment as well as on standardized test scores. In later work, as the cohort ages and if the requisite data are made available, we hope to examine labor market effects.

Evidence based on courses students choose to take, however, may not predict the effects of a policy that requires all students to take those same courses. The effects of taking a given course are almost certainly heterogeneous. Standard economic theory would predict that those who choose to take a course are those who expect to benefit most from it, and that forcing others to take it would produce smaller benefits or even harm. However, the standard assumptions underlying this prediction may well be violated in this context. Students, as well as parents, teachers and counselors, may be uninformed about the benefits of such courses, especially since they largely arrive far in the future. Under such conditions, those induced to take the classes by the Michigan Merit Curriculum could actually benefit more than the students who took them voluntarily. ${ }^{5}$

It is also possible that the imposition of the curricular requirements could harm students who voluntarily would have taken the required courses. Schools may shift teachers out of

\footnotetext{
${ }^{5}$ Analogously, a large body of evidence now indicates that students forced to stay in high school by compulsory schooling and child labor laws benefit from the additional schooling (Angrist and Krueger 1991; Acemoglu and Angrist, 2001; Oreopoulos, 2006; Oreopoulos, 2007.
} 
courses tailored to high-achieving students in order to staff the newly required classes. A school might scale back its AP science offerings, for example, so that teachers can be deployed to other science courses required by the Michigan Merit Curriculum. Peer effects and class size are additional channels through which high-achieving students could be harmed, as their classes expand to include less-eager classmates. Depending on the nature of classroom peer effects and instruction, the lower-achieving students, by contrast, could benefit from sharing more classes with their high-achieving classmates. ${ }^{6}$

What is the evidence on the effect of requiring high school students to take more rigorous courses? The results to date are mixed. There is some evidence that increased coursetaking boosts student performance and high school completion (Achieve, 2009; Balfanz \& West, 2009). But there is countervailing evidence that higher course requirements are associated with decreases in high school completion (DeCicca \& Lillard, 2001). Moreover, there is substantial evidence that high school exit exams, a closely related policy, increase dropout rates, particularly among low-income students (Jacob 2001; Jenkins, Kulick, \&Warren, 2006; Dee \& Jacob 2007; Papay, Murnane, and Willets, 2010) and little evidence that they improve student achievement (Grodsky, Kalogrides, \& Warren 2009; Dee \& Jacob 2007).

Two evaluations in Illinois are particularly relevant to the present paper. In 1997, the Chicago Public Schools enacted a reform that mandated a college-preparatory curriculum, including four years of specific English courses, three years of specific math courses (algebra, geometry and advanced algebra), three years of laboratory science (biology, earth or space or environmental science, and chemistry or physics), and three years of social science. As part of this policy, students were required to take Algebra I and English I in ninth grade (rather than lower-level math and English courses). In a series of papers, researchers at the Consortium on

\footnotetext{
${ }^{6}$ Many of the same issues are raised in the literature on ability tracking.
} 
Chicago School Research investigated the impact of these requirements on a wide variety of short- and long-run outcomes (Allensworth et al., 2009; Allensworth et al., 2010; Montgomery and Allensworth, 2010). The result was a convergence in the courses taken by students of differing race and baseline achievement. However, grades in Algebra I grades went down and more students failed the course. Further, affected students were no more likely to take math courses beyond Algebra II. There was no effect on test scores or college attendance. In addition, the research documented a sharp decline in high school graduation rates in the first few years following the introduction of the policy, although graduation rates subsequently recovered and returned to pre-policy levels. ${ }^{7}$

In 2005, Illinois passed legislation requiring three years of math and two years of science for high school graduation. Buddin and Croft (2014) use cross-district variation in baseline requirements to implement a differences-in-differences strategy, with districts that had the requirements in place prior to the legislation serving as the control group and other districts as the treatment group. Their findings indicate that students took slightly more science courses as a result of the policy, but there was no change in math courses or college attendance. Despite the increase in science coursework, science scores did not rise, and actually dropped for students with the lowest baseline achievement.

\footnotetext{
${ }^{7}$ In a related set of analyses, researchers studied a program of "double-dose" algebra that Chicago implemented in an effort to improve outcomes among low-performing students. In 2003, Chicago required students with belowaverage math scores to take two periods of algebra. Researchers found that test scores increased among students targeted for this "double dose" as well as those who were not. But, at the same time, failure rates increased among students who were not targeted for the double dose (Nomi and Allensworth 2009; see also Cortes, Goodman, \& Nomi, forthcoming ). Subsequent research indicated that the double-dose policy led schools to sort students into math classes based on ability to a greater extent than they had previously. As a result, some students who were just above the average were sorted into classes with higher performing peers and more rigorous standards. This contributed to the improvement in their scores, but also led to higher failure rates for this group (Nomi and Allensworth, 2014). Nomi (2012) documents that the double-dose policy led to more mixed-ability classes and a subsequent decline of high-performing students.
} 


\section{RESEARCH METHODOLOGY}

The Michigan Merit Curriculum was implemented statewide in a single year. Before the new legislation, Michigan had few school districts with requirements resembling those of the Michigan Merit Curriculum. This precludes the construction of a straightforward within-state control group of schools that were not bound by the new requirements, as was used in the analysis of Illinois (Buddin and Croft, 2014). For this reason, we utilize several complementary methods to estimate the impact of the Michigan Merit Curriculum on student outcomes.

Our primary approach is to estimate an interrupted time series (ITS) using rich, studentlevel, longitudinal data. In the ITS approach, post-policy deviations from pre-policy trends in outcomes are attributed to the policy. ${ }^{8}$ Specifically, we estimate a model of the form:

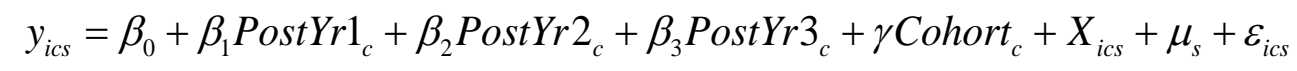

Here, subscripts index student $i$ in school $s$ in ninth grade cohort $c$. The dependent variable is a measure of educational attainment or achievement. The variable Cohort is a continuous variable indicating the year a student starts high school, and serves to estimate our trend. The three Post variables are dummies that are set to one for the first, second and third cohorts bound by the new policy. The coefficients on these dummies estimate cohort-specific deviations from the pre-policy trend in the dependent variable. We present the weighted average of the coefficients on these dummies as a summary measure of the policy impact.

The key identifying assumption of an ITS is that, absent the policy, the outcome of interest would have continued on its pre-policy trend. Since we are undertaking a cohort analysis, the key threats to identification are cohort-specific shocks. These shocks could include changes in the composition of Michigan's students, economic shocks that affect labor market prospects

\footnotetext{
${ }^{8}$ The ITS approach has been used by a number of researchers to evaluate district- and state-initiated reforms, including comprehensive Accelerated Schools (Bloom et al., 2001), Talent Development (Herlihy, Kemple, \& Smith, 2005), and district-wide high-stakes testing (Jacob, 2005).
} 
and family income, and other shifts in education policy affecting the same cohorts as the new curriculum. Our detailed longitudinal data will allow us to control for a rich set of student, school and district characteristics, included in the vector $\boldsymbol{X}$ in the equation above. These include student race, sex, eligibility for subsidized meals, and baseline test scores. In addition, we include fixed effects that indicate the school at which a student was a freshman, along with cohort-specific measures that capture the average characteristics of a school's freshman class.

During the first years of the Michigan Merit Curriculum, economic conditions in Michigan (as in the rest of the country) were rapidly deteriorating. The effect of the Great Recession on educational attainment and achievement is ambiguous. Dismal labor market conditions reduce the opportunity cost of schooling, but deteriorating family income may negatively affect the ability of children to succeed in school. To control for such variation in economic conditions across time, as well as across the state, we include measures of the local unemployment rate during the time a student was enrolled in high school. Since these economic shocks may have also affected schools' financial resources, we also control for annual, per-pupil expenditures at the level of the school and district.

One concern that we cannot address with such controls involves the context of the reforms in Michigan. As noted above, the Cherry Commission report released in 2004 signaled a renewed focus on high school reform in the state, with a focus on both academic skill as well as educational attainment. The MMC legislation passed in 2006 reinforced the emphasis on high school reform, and incorporated more tangible changes such as the mandate that all $11^{\text {th }}$ graders take the ACT exam (see Hyman, forthcoming, for a discussion of this policy and its potential impact) along with the introduction of a new Michigan-specific high school assessment, the Michigan Merit Exam. These changes took place prior to the actual MMC requirements that are 
the focus of this paper. To the extent that we see improvements in student outcomes prior to the new requirements themselves, the ITS assumes that such improvements would have continued on the same trend. If we expect that the improvement generated by these non-curricular high school reforms would have declined (or accelerated) of their own accord, the ITS results might be misleading.

This may be particularly relevant for examining ACT scores. It is well documented in the education literature that scores tend to fall after the introduction of a new exam, but then rise as teachers and students gain familiarity with its content and format (Koretz, 2002). The ACT was mandated statewide in Michigan just a few years before the implementation of the Michigan Merit Curriculum. This would predict that ACT scores would rise sharply for a few years before the Merit Curriculum and then flatten out, even if the curriculum had zero causal effect on scores. In this scenario, the inclusion of a pre-trend in the ACT analysis would lead us to understate any benefits of the policy. For this reason, we will present all of our results both with and without the pre-trend.

When analyzing high school graduation outcomes, we supplement the ITS analysis with a cross-state analysis. We will present estimates from standard panel data models (with controls for state and year fixed effects as well as time-varying state-level controls) as well as from the synthetic control methods suggested by Abadie et al. (2010). We discuss the details of this data and analysis below.

When analyzing high school achievement, we take advantage of the national scope of the ACT exam to implement something like a comparative interrupted time series approach. During our analysis period, Illinois required all $11^{\text {th }}$ grade public school students in the state to take the 
ACT. ${ }^{9}$ While we do not have student-level data from Illinois, we obtained the distribution of ACT scores in Illinois by year. That is, for each year, we know the Illinois state percentile corresponding to each possible ACT score on each subtest. We use this information to normalize the ACT scores of Michigan students by year. ${ }^{10}$ This normalization implicitly controls for changes in the scaling of the ACT as well as trends in student performance in Illinois, due to compositional changes, economic conditions, educational policies or other factors. We estimate equation (1.1) using this Illinois-normalized ACT score. In all equations, standard errors are clustered by the school at which a student was a freshman.

\section{DATA}

Our estimation relies on a student-level, longitudinal data file that includes multiple cohorts of Michigan public school students. We have merged administrative datasets from the state’s Center for Educational Performance and Information and its Department of Education. This yields a student-level, longitudinal file that includes information on demographics, standardized test scores, school attended, and high school completion. We drop the roughly 5\% of students in this group who attended a nontraditional school. In addition, for our main analyses, we focus on the subset of students with a non-missing eighth grade test score in the year prior to high school entry. This provides us with a key covariate for our analysis, but results in the exclusion of roughly 16-19 percent of each ninth grade cohort, most of which stems from students who were not in the Michigan public school system prior to high school or took an alternative assessment for students with special needs. If we include this set of students and

\footnotetext{
${ }^{9}$ Colorado also had mandatory ACT over this period. We chose to focus exclusively on Illinois because it is more similar to Michigan on a variety of dimensions, and thus likely a better comparison. Several other states later adapted mandatory ACT policies. For more information on these, see Hyman (forthcoming).

${ }^{10}$ For example, a student who scored 23 on the ACT math would be at the $71^{\text {st }}$ percentile of the Illinois distribution if she were in the 2005 cohort and the $67^{\text {th }}$ percentile if she were in the 2010 cohort.
} 
assign them imputed scores based on their own demographics and their peers eighth grade scores, our results do not change (see appendices).

For the analysis of student achievement, our sample consists of six cohorts of students who entered high school in fall 2004 though fall 2009. The first three cohorts were not bound by the Michigan Merit Curriculum, while the second three were. We will refer to these cohorts by the spring in which they were freshmen: the pre-policy cohorts are denoted 2005, 2006 and 2007, while the post-policy cohorts are denoted 2008, 2009 and 2010. The first cohort bound by the Michigan Merit Curriculum would have been scheduled to graduate in spring 2011.

The relevant high school exam during our analysis period is the Michigan Merit Exam (MME). As part of the Michigan Merit Exam, all students take the ACT, a nationally-normed, college-entrance exam. The ACT includes subtests in math, science, reading, writing and social studies. While the state provides each student with an overall MME score, students are able to use the resulting ACT score independently for purposes such as college admissions and scholarship applications. That is, the Michigan exam is structured so that the ACT score the students obtain is a complete and "regular" ACT score, comparable to what students would receive had they taken the exam outside of the state testing context. The MME replaced the older Michigan high school test, with both being administered to eleventh graders in spring 2007, which corresponds to the ninth grade cohort of 2005. We begin our analysis period with this cohort to avoid the need to equate across two quite different high school exams.

In the analysis that follows, we focus on the ACT scores rather than other components of the Michigan Merit Exam because the ACT is nationally normed and highly relevant for critical student outcomes such as college admissions. In the small set of cases in which students have multiple ACT scores, we use the score from the first time the student took the exam. 
For our analysis of high school completion, we are able to include two additional prepolicy cohorts - students entering high school in fall 2002 and fall 2003 - although we have somewhat less confidence in the data for the fall 2002 cohort because the fraction missing $8^{\text {th }}$ grade scores is about 5 percentage points more than in subsequent cohorts. ${ }^{11}$

Graduation from a public high school in Michigan is captured by our longitudinal data, which follows students as long as they remain in the public-school system. We are confident in the data on graduation, since it is audited by the state for accountability purposes. We are less confident in the other "exit code" values provided in the state data. The exit code represents a school's best guess of what a student will be doing the following year, e.g., dropping out, transferring to a private school or leaving the state. Our inspection of the longitudinal data indicates that these exit codes are periodically wrong. For example, many students who were expected to re-enroll or transfer to another public school in Michigan never again appear in the state data.

Hence, for most of our analysis, we focus on a three-category measure that we have coded using the longitudinal data: graduated from a Michigan public high school, still enrolled in a Michigan public school, and everything else. Our primary outcome will be an indicator for high school graduation, which is set to zero for all other students, who may have dropped out, transferred to a private school, or left the state. ${ }^{12}$

Students in Michigan take standardized tests in grades three through eight, as well as in the junior year of high school. The high school test will serve as our measure of academic

\footnotetext{
${ }^{11}$ The student longitudinal data system officially began with the 2002-03 academic year. We obtain the 2001-02 $8^{\text {th }}$ grade test scores for the first cohort in our sample by matching older test score files to the longitudinal data via a fuzzy match using name, sex, race, and school district. Match rates were 93 percent, meaning that we were able to match 93 percent of students in the test score files to the SLDS. Note that we would not expect all to match because some students will have left the Michigan Public Schools between 2001-02 and 2002-03.

${ }^{12}$ The state, when calculating its high school graduation rates for each cohort of freshmen, uses a federal formula that excludes students who transfer to private school or leave the state. We do not exclude such students from the analytic sample, so our measures will differ slightly from officially published graduation rates.
} 
achievement, while math scores from fourth and eighth grades will serve as baseline controls. The choice of exams for use as baseline achievement controls is dictated by data availability. Given the rollout of standardized exams in different grades and subjects in the state, fourth and eighth grade math were the only cases in which we had consistent elementary test score measures for all cohorts in our sample.

We define all student-specific demographic variables, as well as variables indicating program participation, by their values when the student started high school. These include dummies indicating a student's eligibility for free or reduced priced lunch, special-education status, migrant status, and English-learner status.

\section{Sample Statistics}

Tables 1A (demographics and school characteristics) and 1B (outcomes) provide sample means, reported separately for each entering freshman cohort. The size of the entering ninthgrade cohort in Michigan public schools declined steadily, from 112,201 students in the cohort starting high school in 2005 to 114,491 for the cohort entering in 2010. This reflects the population loss experienced by the state during this period. The number of high schools in the analysis fluctuates across cohorts, from as few as 674 to as many as 717 schools.

Demographic shifts in the sample over this period were relatively minor, with the exception of the share of students eligible for free and reduced-price lunch (FRPL), which increased from 22 percent for the 2003 cohort to 35 percent for the 2010 cohort, a result of the nationwide recession on Michigan’s students.

We construct standardized scores across all cohorts by subtracting the 2005 mean score and dividing by the 2005 standard deviation, creating a measure that is standardized relative to the 2005 cohort. Fourth and eighth grade math scores appear to have been increasing somewhat 
throughout the time period, consistent with national trends and the findings of Dee and Jacob (2011) with regard to NCLB. However, there is an extremely large (0.31 standard deviation) jump in eighth grade scores for the ninth grade cohort of 2009. Despite extensive investigations of the underlying data and conversations with state officials, we cannot find any explanation for what seems like an extremely large one-year increase, although the fact that the 2010 cohort mean is even larger suggests the 2009 value was not an anomaly. ${ }^{13} 14$

Graduation rates are also rising across time during the period before the MMC was put in effect. Among the cohort starting high school in 2003, 75 percent graduated high school within four years and 78 percent within five years; the corresponding statistics for those entering in 2007 are 76 percent and 79 percent, respectively. The statewide four- and five-year graduation rate for those students who enter the Michigan system in ninth grade is $72.3 \%$ and $75.4 \%$ respectively.

The fraction of students taking the 11th grade test increased during the sample period, likely reflecting the ramp-up of test-taking in the first years of the new high school test, the MME, before the MMC took effect. Both MME and ACT scores increase over the sample period.

\section{RESULTS ON HIGH SCHOOL ACHIEVEMENT}

The primary goal of the MMC was to ensure that students were prepared for college and a $21^{\text {st }}$ century labor market, with a focus on enhancing skills in math and science. To explore what, if any, impact the new course requirements had on student achievement, Figures 1-5 show

\footnotetext{
${ }^{13}$ Relative to the 2008 cohort, the 2009 had higher scores in 8th grade science ( 0.17 s.d.) and 7 th grade English (0.11 s.d.) and reading $(0.19$ s.d.) but lower scores in 7 th grade writing $(0.07$ s.d.).

${ }^{14}$ As a sensitivity analyses, we estimate all models excluding the $8^{\text {th }}$ grade test score (but keeping the $4^{\text {th }}$ grade scores) and obtain comparable results.
} 
trends in the ACT composite and subtest scores in Michigan from the 2005 cohort through the 2010 cohort.

The solid line in each figure shows the unadjusted trends, normalized to zero in 2005. In order to control for other factors that might have changed over this time period, we estimate a variant of equation (1.1), but include indicators for cohorts 2006 through 2010 instead of the linear trend or post-policy indicators. The dashed line in each figure indicates the point estimates on these cohort indicators from regressions with all of the controls described above except for the prior test scores (both at the individual student and the school-cohort level). The 2005 cohort serves as the omitted category and so all estimates are relative to this group. The dotted line in each figure tracks the cohort effects from a regression that also controls for prior test scores. Specifically, we control for individual fourth and eighth grade math scores as well as the mean and standard deviation of fourth and eighth grade in the individual's school-cohort (i.e., the student's high school peers).

Figure 1 shows that composite scores increased over the sample period. For example, students in the 2010 cohort scored roughly 1.1 points higher than students in the 2005 cohort. It is interesting to note that the dashed line, which controls for demographics, is notably steeper than the solid line, which shows the unconditional achievement trend. This difference reflects the fact that the student population in Michigan was becoming more disadvantaged over the recession period. Controls for prior achievement flatten the trend somewhat because, despite the economic conditions, student performance on fourth and eighth grade exams grew over this period. Most notably, we see a sharp drop in the dotted line in 2009 and 2010, reflecting the substantially higher eighth grade math scores for these cohorts. 
While a simple before-after analysis would suggest a positive impact of the MMC, the growth we observe does not deviate sharply from the existing growth once the new curricular requirements are introduced. Scores on the Math and English tests follow trends similar to the composite score. In contrast, scores in science and reading appear to increase more sharply, indicating that the policy may have had a positive impact on achievement in these subjects.

Table 2 presents regression estimates of the relationship between the Merit Curriculum and ACT scores. In order to illustrate the importance of pre-existing trends, we show estimates without them (columns 1-2) as well as with them (columns 3-4). All estimates control for school fixed effects, fourth grade math scores and a full set of student, school and district covariates. The models in columns 2 and 4 also control for eighth grade math scores. ${ }^{15}$

Across the estimates in Table 2, several patterns emerge. First, as shown in the figures, the effects are stronger in science and reading than in math or English. Second, accounting for pre-existing trends and eighth grade math scores both independently (and jointly) reduce the size of the estimates. Third, all of the estimates are quite small relative to the pre-policy level of ACT scores. For example, the coefficient estimate of 0.389 points for science in column 3 corresponds to an increase of only 0.04 standard deviations. Finally, conditional on observable student and school characteristics, the introduction of the new curriculum is associated with a slight reduction in the proportion of students taking the ACT. ${ }^{16}$ However, as we discuss below, this modest sample attrition does not meaningfully bias our estimates.

\footnotetext{
${ }^{15}$ As discussed above, we believe eighth grade scores should be a control in our model. However, Table 1a shows an extremely large ( 0.27 standard deviation) increase in $8^{\text {th }}$ grade math scores between the 2008 and 2009 cohort. Given the strong relationship between eighth grade test scores and ACT scores, the inclusion of eighth grade controls have a noticeable influence on our estimates. For this reason, we show results with and without these grade 8 controls.

${ }^{16}$ This is not due to the policy-induced reduction in high school completion documented above. In results available upon request, we find comparable impacts on test-taking if we limit the analysis to students who attended $11^{\text {th }}$ grade and/or graduated a Michigan public high school.
} 
In an effort to account for changes in the scaling of the ACT over time, as well as any unobserved factors common to public schools in the Midwest, Table 3 shows results for ACT scores normed to the Illinois distribution (see Data section). While the estimates are slightly more positive than those in Table 2, the conclusions are similar. In column 4, our preferred model, we see small but significant increases in science and reading scores. For example, the estimate of 2.1 for science indicates a 2 percentile-point increase (from a baseline of the $47^{\text {th }}$ percentile). The math effect is very small (0.6 percentile points) and only marginally significant. The English effect is not significantly different than zero.

Table 4 shows results separately by the quintile of the student's eighth grade math score, using the specification from column 4 of Table 2. Appendix Figures 1-5 show the trends in ACT scores by subject for each of the quintiles. Models that do not control for grade 8 scores and/or use the Illinois percentiles of student ACT scores as the outcome yield comparable results and are shown in Appendix Tables 1-2. The final row of Table 4 shows the difference between the impacts of the MMC on the top and bottom quintiles. Across each subject area in our models with a pre-policy trend, the impact on the lowest-prepared students is larger than that for the highest-prepared students by a statistically significant margin. These comparatively larger effects mean that even when we lack clear evidence of growth in student scores, there is a clear narrowing of the achievement gap between the highest and lowest quintiles.

These results suggest that the set of students who entered high school with weak academic skills may have benefited from the new requirements, at least in terms of science and reading achievement. The estimate of 0.726 on science scores for bottom quintile students (from the model that includes a pre-policy trend) is equivalent to about 0.22 standard deviations; the corresponding estimate for the composite score translates to an effect of roughly 0.15 standard 
deviations. Conversely, there is some evidence that students who entered high school with the strongest academic skills experienced a decline in performance relative to what would have been expected in the absence of the policy. It should be noted, however, that these results are particularly sensitive to the inclusion of the pre-policy trend.

To the extent that these high-achieving students were most likely to have been taking college-prep courses in earlier years, one might not have expected the policy to have a sizeable impact on their performance. On the other hand, the introduction of the MMC necessitated staffing changes within schools that might have influenced the performance of higher-achieving students. For example, principals may have shifted the most talented math or science teachers to courses taken by less well prepared students who were newly required to take the college-prep courses. Or staffing shortages may have led class sizes in upper level math and science courses to increase. We plan to explore both of these potential pathways in subsequent research that utilizes individual student transcript data.

Table 5 shows analogous results where the outcome is the standardized Michigan Merit Exam score, and covariates include a pre-policy trend as well as fourth and eighth grade math scores at the student and school-cohort level. To reiterate, this exam is based in part on the ACT and in part on Michigan-specific test items. Unfortunately, scores based solely on the Michiganspecific items are not available. The results are generally comparable to the ACT-only estimates discussed above. Science scores show some modest positive effects across most quintiles. For example, students entering high school in the bottom quintile of achievement improved roughly 0.1 standard deviations after the introduction of the MMC. Conditional on prior trends, math and reading scores show no change for most quintiles. 


\section{Sensitivity of Results to Selection in Test-Taking}

The introduction of the MMC corresponds to a statistically significant decrease of about two percentage points in the likelihood that students take the ACT (Table 2) relative to a baseline of 85 percent. If this difference in test-taking is associated with unobservable factors that also influence student outcomes, then the estimates we present in Tables 2-4 could be biased.

To explore how differential selection into testing might influence our ACT estimates, we use a bounding technique outlined in Lee (2009). This technique involves "trimming” observations from either the top or the bottom of the treatment group's distribution of outcomes, where the percent trimmed is equivalent to the difference in response rates between treatment and control groups.

In order to improve the precision of these bounds, we implement what Lee (2009) describes as "tightened" bounds. For each ACT subtest, we predict student scores using all of the covariates in our primary specification, restricting our sample to the pre-policy cohorts. We split our sample into deciles based on these predicted scores. We then conduct the trimming exercise within each of these deciles. Lee (2009) shows that this technique is valid under relatively weak monotonicity assumptions, and typically produces tighter bounds than traditional "Manski” or “worst-case" bounds.

Appendix Table 3 shows the results of this bounding exercise. In column 1, we present the estimates from our primary specification. These are analogous to those shown in column 4 of Table $2 .{ }^{17}$ To provide an even better basis for comparison with the bounds, in column 2 we show estimates from a model that replaces the full set of controls in the main specification with fixed effects for the deciles we use in the bounding procedure. These estimates show the same general

\footnotetext{
${ }^{17}$ The results in column 1 here differ slightly from those in the main text because we exclude schools that appear in only the post-MMC cohorts since we cannot estimate the tightened Lee bounds for students in these schools.
} 
results as those in column 1 , although as expected, they are not identical. Columns 3 and 4 show the lower and upper Lee bounds respectively. With the exception of reading, the bounds exclude zero, indicating that any bias resulting from differential test-taking would not change the inferences one should draw about the sign of the impact. In the case of reading, the main point estimate is small and statistically significant, so in this way the bounding is consistent with our findings for this subject as well. In results available upon request, we conduct a similar exercise separately by eighth grade math quintile and find that the estimated Lee bounds would not change the inferences drawn from the analyses presented in Table 4.

\section{Cross-State Analysis}

As an additional test, we compare achievement trends in Michigan to other states. Given the difficulty of comparing state-specific exams with each other, and the many changes in testing regime within state, we choose instead to focus on ACT scores. However, in most states the average ACT score is highly dependent on the fraction of students in the state who take the exam (Hyman, forthcoming). For this reason, we limit our analysis to two other states that had mandatory ACT over our analysis period: Colorado and Illinois, both of which started requiring the ACT for students in the class of 2001. Appendix Figures 6-9 show these trends for math, English, science and reading respectively. While it is difficult to draw any strong conclusions from these figures, they are at least consistent with the effects described above - namely, potentially positive impacts for science but not for math.

\section{Advanced Placement Course-Taking}

The Merit Curriculum could harm high-performing students by diverting resources from them. For this reason we examine whether students were less likely to take AP exams after the introduction of the new policy. Table 6 shows impact on AP course taking separately for students 
in the top three quintiles of their cohort's eighth grade math distribution. ${ }^{18}$ As with the ACT and MME estimates, these models include controls for fourth and eighth grade math scores at the student and school-cohort level. We see a very small increase in the number of AP exams taken among students in the top quintile (0.17 exams, which is equivalent to 0.09 standard deviations). In results not shown here, we document that there was no increase in AP math exams taken, but a small increase in science that was not significant at conventional levels (coef $=0.047$, se $=0.031)$. Importantly, passing rates on AP science exams increased somewhat at the same time. For example, among students in the top quintile, the fraction of students scoring at least a 3 on an AP science exam increased by 3.6 percentage points relative to a 16.3 percent pre-policy mean. For students in quintiles 3 , the proportion scoring at least a 3 increased 0.005 percentage points from a baseline of 0.006 .

\section{RESULTS FOR HIGH SCHOOL ATTAINMENT}

The analysis above suggests that the introduction of the new course requirements had little impact on high school achievement for the average student, but may have improved ACT scores for students entering high school with the weakest academic preparation. However, the concern with policies like the MMC is that by placing additional barriers to a high school diploma, these policies might lead the least prepared students to drop out.

To begin to explore this issue, we present a variety of figures that track high school completion for Michigan ninth graders in 2003 through 2010. Figure 6 shows five-year rates for the full analysis sample. ${ }^{19}$ As in the ACT figures, the solid lines show the unadjusted trends, normalized to zero in 2003. The dashed lines show adjusted trends that controls for all student

\footnotetext{
${ }^{18}$ Essentially no students in the bottom two quintiles take AP exams.

19 The trends in four-year graduation results look virtually identical.
} 
and school characteristics with the exception of prior test scores. The dotted lines show adjusted trends that additionally control for fourth and eighth grade math scores at both the student and school-cohort level.

Several patterns stand out. First, unadjusted graduation rates declined somewhat between 2003 and 2005, then grew slightly until 2007, and finally leveled out for cohorts after 2008 that were affected by the new course requirements. When we control for student demographics and economic conditions (dashed line), completion rates look worse in the early years, but better in the later years. This largely reflects the influence of the dramatically worsening economic conditions over the period, which would have been expected to decrease high school completion. The dotted trend line, which further adjusts for prior student achievement, accentuates this pattern. The reason is that elementary school achievement scores were increasing over this time period, which would have been expected to increase high school completion in the absence of other factors.

From the perspective of the interrupted time series design, the non-linearity of the prepolicy trend substantially complicates the analysis. If we limit the analysis to the 2005-2010 cohorts, in an effort to match the achievement sample, the sharp upward trajectory before 2008 implies that we will find a negative impact of the reforms using the ITS design. If we use the entire 2003-2007 period to estimate the pre-reform trajectory, these figures suggest that we will find zero or even slightly positive effects. However, the fact that the trend from 2003-2007 is clearly non-linear implies that the ITS with a linear pre-trend is mis-specified. Finally, the existence of notable trends prior to the policy reform (at least in certain samples) suggests that the ITS estimates may differ substantially from simple difference-in-difference estimates. 
Given the likely sensitivity of our results to the choice of sample and specification, Table 7 presents the full range of estimates. As suggested by the figure, estimated impact of the MMC on high school graduation ranges from negative five percentage points to positive three percentage points. In results that are available upon request, we find a similar pattern of estimates for both four- and six-year graduation rates. This suggests that any effects we find are not merely a result of students taking longer to graduate high school.

However, as discussed earlier, the prior literature and the details of the MMC in particular suggest that the reform should have affected students differently based on their prior academic preparation. We hypothesized that it would have little, if any, impact on highly prepared students, many of whom would have been taking the rigorous math and science courses prior to the new requirements and have always had extremely high graduation rates. On the other hand, we expect it might have a negative impact on the least prepared students.

To examine this type of heterogeneity, Figures 7-11 show the five-year graduation trends separately for quintiles of a student's 8th grade performance on the standardized math exam. These quintiles are constructed separately by cohort, so they measure a student's relative position in the cohort's distribution and abstract from changes in the entire distribution over time. While there is some variation across the quintiles, each group shows a similar pattern whereby adjusted graduation rates decline over the first few years, rise sharply immediately before the reform, and then level off or drop for the cohorts to whom the new course requirements applied.

Table 8 presents five-year completion separately by quintile of eighth grade score. ${ }^{20}$ Looking across the quintiles and across the two specifications, we see that the graduation estimates are consistently smaller for the bottom quintiles. For example, the DD (ITS) estimates

\footnotetext{
${ }^{20}$ There are fewer than 100 unique values of the $8^{\text {th }}$ grade raw scores, which is the reason that the number of observations per quintile differ somewhat.
} 
suggest that the new course requirements increased graduation rates for students in the top quintile by roughly 2.0 (4.8) percentage points (off a baseline of 91.8 percent), compared with $0.01(0.00)$ percentage points for students in the bottom quintile. Again we show the difference between the $1^{\text {st }}$ and $5^{\text {th }}$ quintile impacts in the final row of this table. In this case, the difference reveals a widening gap in high school completion rate that is statistically significant and substantively large, with the top students receiving a 4.9 percentage point boost to their graduation rates from the MMC compared with no increase resulting from the policy for the lowest achieving group.

To the extent that one believes that the large positive coefficient for top quintile students is due to unobserved state-time specific factors unrelated to the MMC, one might consider the difference between top and bottom quintile students as the causal impact of the MMC from a comparative interrupted time series (CITS) design. This may be a reasonable assumption because the majority of students in this top quintile took MMC-mandated math and science courses prior to the new requirements, and nearly over 90 percent of students in this group graduated high school prior to the reform. Using the top quintile as a counterfactual for each of the lower quintiles, we would conclude that the new policy led to a modest reduction in high school graduation among students in the bottom quintiles. For students in the bottom quintile, for example, DDD and CITS estimates are -0.029 and -0.049 , respectively. Given the pre-reform completion rate of 58.6 percent, these effects are noticeable but modest.

Appendix Table 4 shows comparable estimates for a sample that excludes 2003 and 2004 cohorts to match the sample for which we have ACT scores. As suggested by the figures, the impacts for this sample are considerably more negative. For example, the ITS model for this sample indicates the MMC reduced graduation rates by 8.6 percentage points, and even the DD 
model indicates a reduction of 2 percentage points (though this estimate is not significantly

different from zero). ${ }^{21}$

\section{Cross-State Analysis}

Given the sensitivity of the graduation results presented thus far, we turn to a cross state analysis that allows us to control for common time effects that could confound the difference-indifference and interrupted time series analyses. In recent years, several states have adopted graduation policies similar to Michigan. We consider a state to have a comparable policy if its high school graduation requirements included both Algebra 1 and Geometry, and at least two of the three core science classes (Biology, Chemistry, and Physics) during our sample period. Appendix Table 6 lists graduation requirements in each state during this period, and indicates those states with policies similar to Michigan. ${ }^{22}$ We exclude all states with similar policies from our set of potential comparison states in the analyses described below.

A key challenge in this approach is to find a reliable state-year measure of high school graduation. Heckman and LaFontaine (2010) document a number of substantial biases inherent in the commonly used sources of data. They conclude that the decennial census (and more recently American Community Survey) provides the most accurate estimates of educational

\footnotetext{
${ }^{21}$ Given the large decline in graduation rates implied by the ITS estimates above, it is useful to examine what might have happened to the bottom quintile students under the MMC. With the caveats regard data quality discussed above, Appendix Table 5 presents estimates of how the reforms influenced the following outcomes: dropping out, leaving Michigan public schools, and a catch-all "other" category, which includes completion other than graduation (e.g., GED, completion of a special-education track that does not result in a diploma), incarceration, enlistment in the military, enrollment in home schooling and death. These results indicate that the bulk of the decrease in graduation is accounted for by an increase in outcomes captured in the "other" category.

${ }_{22}$ States other than Michigan that met this definition are Arizona, Arkansas, Delaware, District of Columbia, Georgia, Idaho, Illinois, Indiana, Kansas, Kentucky, Louisiana, Minnesota, Mississippi, Oklahoma, South Dakota, Tennessee, Texas, Utah, and West Virginia. Several of these states' requirements were implemented in different years for math and science. For example, the math requirement in Arkansas was binding for the graduating class of 2009, while the science requirement was binding for the class of 2010. In this case, the earlier year was coded as the beginning of the treatment period. In addition, 9 states had policies that were similar to MMC for either Math or Science, but not both.
} 
attainment at a national level. Unfortunately, it is not possible to reliably link individuals to the state (or year) in which they attended high school with this data.

After exploring various options, we chose to use the log of the average freshman graduation rate (AFGR) calculated by the National Center for Education Statistics (NCES) and reported in the Common Core of Data (CCD). The AFGR is a proxy measure of the graduation rate created by using the diploma count to estimate the number of graduates (the numerator) and an estimated freshman class size to determine the number of possible graduates (the denominator). While less accurate than the adjusted cohort graduation rate (ACGR) that directly measures high school completion with student-level data, the AFGR is the only available national-level measure of state graduation rates covering the period in which we are interested. We use the AFGR data for the cohorts graduating in 2004 through 2012, which correspond to $9^{\text {th }}$ grade cohorts 2001-2009. ${ }^{23}$ The CCD provides AFGRs for both the overall graduation rates as well as several subgroups. However, an inspection of the data suggested that the subgroup AFGR statistics were frequently missing and/or included implausible values in many states. For this reason, we limit our analysis to the state's overall AFGR. ${ }^{24}$

We adopt the synthetic control method of constructing a comparison group proposed by Abadie et al. (2010), which provides a formal method for constructing a comparison in cases where few units receive treatment. This approach uses information on pre-policy trends in the outcome measure as well as other covariates to create the best comparison for the treatment unit. State-year controls include racial composition, unemployment, logged median household income, average per-pupil expenditures for public K-12 schools, and fraction of elementary and

\footnotetext{
${ }^{23}$ The AFGR is not available after 2012, which means that we cannot include our final cohort in the cross-state analysis.

${ }^{24}$ AFGR was missing in 7 state-year observations. In these cases, we use an interpolated value to replace the missing.
} 
secondary age children enrolled in private schools, along with the outcome measure (log AFGR) in 2004, 2006, 2008 and $2010 . .^{25}$

Figure 12 shows the trends in Michigan and the synthetic control group, which consists of Alabama (weight 0.42), Alaska (weight 0.12), Connecticut (weight 0.28) and Vermont (weight 0.18). Michigan and the control states track each other quite closely from 2004 through 2010, but then diverge in 2011, the first class affected by the new graduation requirements. The fact that the two trend lines are so similar prior to 2011 reflects the fact that the procedure was effective in finding a good "match" for Michigan.

Table 9 presents corresponding regression estimates. Columns 1-3 all utilize the synthetic control states (and weights) identified above (along with Michigan), with each column showing point estimates from a specification that includes different control variables. The point estimates indicate that the MMC is associated with a roughly 5 percent decline in the graduation rate in Michigan. As a further robustness test, columns 4-6 show estimates from a more standard panel data regression in which all states are included and equally weighted. While the estimates vary a bit across specifications, the qualitative conclusion is the same - namely, the introduction of the MMC was associated with a small reduction in high school graduation. Our preferred model, column 6, indicates a roughly 3 percent reduction.

Given the small number of states and the fact that only one state (Michigan) is in the treatment group, standard methods of statistical inference are not appropriate. Instead, we adopt the exact inference test described by Abadie et al. (2010). We calculate the effect of a placebo treatment on all nontreated comparison states, and then produce p-values for the likelihood of Type I error by calculating the percentage of these effects that are as or more extreme than the

\footnotetext{
${ }^{25}$ Appendix Table 7 presents summary statistics
} 
effect we estimate for Michigan. ${ }^{26}$ The point estimate for Michigan is smaller than all of the 29 other states in the first two specifications (columns 1-2) which translates to a p-value of 0.000 . For the third specification (column 3), the point estimate for Michigan is smaller than 24 of the 29 other states, generating an implied p-value of 0.17 . The implied p-values for the specifications using all non-reform states as controls (equally weighted) are 0.10, 0.10 and 0.00 respectively.

While the outcome of AFGR is imperfect and our estimates are necessarily imprecise given the modest number of control states, we believe that this analysis provides suggestive evidence that the introduction of the new course requirements in Michigan led to a small reduction in high school completion.

\section{DISCUSSION \& CONCLUSIONS}

The Michigan Merit Curriculum implemented a standardized curriculum across the state, which closely resembled the core set of classes commonly required for college admittance. Among the changes the policy required was an increase in the number of math and science courses needed for graduation. The assumption of the policy was that having students take more rigorous courses would better prepare them for college and the workplace.

We find that the introduction of the policy had relatively little impact on either student achievement or educational attainment. There is some evidence that the new course requirements led to an increase in science achievement, which is reflected in higher scores on both the ACT exam as well as AP courses. In science and other subjects, the evidence suggests that students who entered high school with the weakest academic preparation may have experienced the largest benefits of the policy. However, even for the bottom quintile group in science, where we 
see the largest effects, the impact was modest: an increase of 0.73 ACT scale points, relative to a baseline of roughly 15 points.

Our results for high school completion are more sensitive to the choice of sample and specification. If we use ninth grade cohorts from 2003 through 2010, the ITS estimate suggests a 3.3 percentage point (4 percent) increase in graduate rates; if we focus instead on the 2005-2010 cohorts, we find a 5 percentage point (6.4 percent) decline in graduation rates. The difference is due to the highly non-linear pre-reform trend in high school completion, especially the sharp increase in graduation rates for the cohort immediately prior to the reform. Our cross-state analysis, which relies on cohorts back to 2001, suggests the MMC was associated with a 3-5 percent reduction in high school completion.

As with the achievement analysis, we find larger impacts among the students with the weakest academic preparation entering high school. In the case of completion, however, we find that these lower-achieving students experience the largest reductions in the likelihood of graduation under the new policy. We suspect that this was caused by higher failure rates among low performing students pushed into more difficult courses by the new requirement, a claim which we will investigate in subsequent analyses of student transcript data.

A sizeable portion of the decrease in high school graduation rates can be explained by an increase in dropout rates captured in the state administrative data. The remaining decrease in high school graduation rates may also be due to dropouts that are not captured in the state data, or to a variety of other factors such as students obtaining a GED, enlisting in the military, etc. Unfortunately, the available state administrative data do not allow us to reliably explore these other outcomes. 
Given recent trends of district and states adopting more rigorous high school curriculum requirements (Domina \& Saldana, 2012), it is critical to understand how such changes influence student outcomes. Our results suggest that higher standards alone will have, at best, a limited impact on student performance. Future research will allow us to examine if the policy did had an impact on college attendance and degree completion. It will also allow us to better pin down the mechanisms responsible for any reduction in high school graduation and the pattern of achievement effects across students with different initial achievement levels. With a deeper understanding of these mechanisms, policymakers will be able to adapt the policy to enhance its benefits and mitigate its costs. 


\section{References}

Abadie, A., Diamond, A., \& Hainmueller, J. (2010). Synthetic control methods for comparative case studies: Estimating the effect of California's tobacco control program. Journal of the American Statistical Association, 105(490).

Acemoglu, D., \& Angrist, J. (2001). How large are human-capital externalities? Evidence from compulsory-schooling laws. In NBER Macroeconomics Annual 2000, Volume 15 (pp. 9-74). MIT Press.

Achieve, Inc (2013). Closing the Expectations Gap: An Annual 50-state Progress Report on the Alignment of High School Policies With the Demands of College and Careers.

Achieve, Inc (2009). Closing the Expectations Gap: An Annual 50-state Progress Report on the Alignment of High School Policies With the Demands of College and Careers.

Adelman, C. (1999). Answers in the Tool Box. Academic Intensity, Attendance Patters, and Bachelor's Degree Attainment. National Institute on Postsecondary Education, Libraries, and Lifelong Learning.

Allensworth, E., Lee, V. E., Montgomery, N., and Nomi, T. (2009). College Preparatory Curriculum for All: Academic Consequences of Requiring Algebra and English I for Ninth Graders in Chicago. Educational Evaluation and Policy Analysis, 31(4): 367-391.

Allensworth, E., Nomi, Takako, Montgomery, Nicholas, Lee, V. E., and Mazzeo, Christopher (2010). “College Prep for All? What We’ve Learned from Chicago’s Efforts.” Policy Brief, Consortium on Chicago School Research, August 2010.

American Association of State Colleges and Universities, 2006.

Angrist, J. D., \& Krueger, A. B. (1991). Does Compulsory School Attendance Affect Schooling and Earnings?. The Quarterly Journal of Economics, 106(4), 979-1014.

Balfanz, R. and West, T. C. (2009). Raising Graduation Rates: A Series of Data Briefs. The Everyone Graduates Center. Johns Hopkins University.

Betts, J. R. and Rose, H. (2004). The Effect of High School Courses on Earnings. The Review of Economics and Statistics, 86(2): 497-513.

Bloom, H. S., Ham, S., Melton, L., \& O'Brien, J. (2001). Evaluating the Accelerated Schools Approach: A Look at Early Implementation and Impacts on Student Achievement in Eight Elementary Schools.

Bryk, A. S., Holland, P. B., and Lee, V. E. (1993). Catholic Schools and the Common Good. Harvard University Press. 
Buddin, R. \& Croft, M. (2014). Do stricter high school graduation requirements improve college readiness? ACT Working Paper Series working paper WP-2014-1.

Cherry, J. D. (2004). Final Report of the Lt. Governor's Commission on Higher Education \& Economic Growth. Governor’s Office, Michigan. Available at: www.cherrycommission.org.

Cortes, K. E., Goodman, J., and Nomi, T. (forthcoming). Intensive Math Instruction and Educational Attainment: Long-run Impacts of Double-Dose Algebra. Journal of Human Resources.

Davis-Kean, P. E., Eccles, J. S., Simpkins, S. D. (2006). Math and Science Motivation: A Longitudinal Examination of the Links Between Choices and Beliefs. Developmental Psychology, 42(1): 70-83.

DeCicca, P. P. and Lillard, D. R. (2001). Higher Standards, More Dropouts? Evidence Within and Across Time. Economics of Education Review, 20(5): 459-473.

Dee, T.S. and Jacob, B.A. (2007). "Do High School Exit Exams Influence Educational Attainment or Labor Market Performance?” In Adam Gamoran, ed., Standards-Based Reform and the Poverty Gap: Lessons for No Child Left Behind Washington, D.C.: Brookings University Press.

Dee, T. S. and Jacob, B. (2011). The Impact of No Child Left Behind on Student Achievement. Journal of Policy Analysis and Management, 30(3): 418-446.

Domina, T. \& Saldana, J. (2012) "Does Raising the Bar Level the Playing Field?: Mathematics Curricula Intensification and Inequality in American High Schools, 1982-2004” American Educational Research Journal, vol. 49, No. 4, pp.685-708.

Dounay, J. (2006). Embedding College Readiness Indicators in High School Curriculum and Assessments. Education Commission of the States.

Frank, K. A., Muller, C., Schiller, K. S., Riegle-Crumb, C., Mueller, A. S., Crosnoe, R., \& Pearson, J. (2008). The social dynamics of mathematics course-taking in high school. AJS; American journal of sociology, 113(6), 1645.

Goodman, J. S. (2012). The labor of division: Returns to compulsory math coursework. Mimeo.

Grodsky, E., Kalogrides, D., and Warren, J. R. (2009). State High School Exit Examinations and NAEP Long-Term Trends in Reading and Mathematics, 1971-2004. Education Policy, 23(4): 589-614.

Heckman, J. \& LaFontaine, P. (2010). "The American High School Graduation Rate: Trends and Levels," The Review of Economics and Statistics, 92(2), pages 244-262, 
Herlihy, C. M., Kemple, J. J., and Smith, T. J. (2005). Making Progress Toward Graduation: Evidence From the Talent Development High School Model. MDRC.

Hyman, Joshua (forthcoming). "ACT for All: The Effect of Mandatory College Entrance Exams on Postsecondary Attainment and Choice.” Education Finance and Policy.

Jenkins, K. N., Kulick, R. B., and Warren, J. R. (2006). High School Exit Examinations and State-Level Completion and GED Rates, 1975 Through 2002. Educational Evaluation and Policy Analysis, 28(2): 131-152.

Jacob, B. (2001). Getting tough? The Impact of High School Graduation Exams. Educational Evaluation and Policy Analysis, 23(2): 99-121.

Jacob, B. (2005). Accountability, Incentives and Behavior: The Impact of High-Stakes Testing in Chicago Public Schools. Journal of Public Economics, 89(5-6): 761-796.

Koretz, D. (2002). Limitations in the use of achievement tests as measures of educators' productivity. In E. Hanushek, J. Heckman, and D. Neal (Eds.), Designing Incentives to Promote Human Capital. Special issue of The Journal of Human Resources, 37(4, Fall), 752-777.

Lee, D. S. (2002). Trimming for Bounds on Treatment Effects with Missing Outcomes. NBER Technical Working Paper No. 77, June 2002.

Lee, D. S. (2009). Training, wages, and sample selection: Estimating sharp bounds on treatment effects. The Review of Economic Studies, 76(3), 1071-1102.

Levine, P. B. and Zimmerman, D. J. (1995). An Empirical Analysis of the Welfare Magnet Debate Using NLSY. NBER Working Paper No. 5264, National Bureau of Economic Research.

Montgomery, N., \& Allensworth, E. M. (2010). Passing through Science: The Effects of Raising Graduation Requirements in Science on Course-Taking and Academic Achievement in Chicago. Research Report. Consortium on Chicago School Research. 1313 East 60th Street, Chicago, IL 60637.

Murnane, R. J. (2013). US High School Graduation Rates: Patterns and Explanations. Journal of Economic Literature, 51(2), 370-422.

National Center for Education Statistics (2013). The Nation's Report Card: Trends in Academic Progress 2012 (NCES 2013 456). Institute of Education Sciences, U.S. Department of Education, Washington, D.C.

Nomi, T. (2012). "The unintended consequences of an algebra-for-all policy on high-skill students: The effects on instructional organization and sutdents' academic outcomes.” Educational Evaluation and Policy Analysis, 34(4): 489-505. 
Nomi, T. and Allensworth, E. (2009). Double-dose algebra as an alternative strategy to remediation: Effects on students' academic outcomes. Journal of Research on Educational Effectiveness, 2(2): 111-148.

Nomi, T. and Allensworth, E. (2014). Skill-Based Sorting in the Era of College Prep for All. University of Chicago Consortium on Chicago School Research Research Brief, March 2014.

Oreopoulos, P. (2006). Estimating average and local average treatment effects of education when compulsory schooling laws really matter. The American Economic Review, 152-175.

Oreopoulos, P. (2007). Do dropouts drop out too soon? Wealth, health and happiness from compulsory schooling. Journal of public Economics, 91(11), 2213-2229.

Papay, J. P., Murnane, R. J., \& Willett, J. B. (2010). The consequences of high school exit examinations for low-performing urban students: Evidence from Massachusetts. Educational Evaluation and Policy Analysis, 32(1), 5-23.

Riegle-Crumb, C. (2006). The Path Through Math: Course Sequences and Academic Performance Intersection of Race-Ethnicity and Gender. American Journal of Education, 113(1): 101-122.

Sadler, P.M. and Tai, R. H. (2007). The Two High-School Pillars Supporting College Science. Science, 317(5837): 457.

Schneider, B., Swanson, C. B., and Riegle-Crumb, C. (1997). Opportunities for Learning: Course Sequences and Positional Advantages. Social Psychology of Education, 2(1): 25-53.

Sells, L. W. (1973). High school mathematics as the critical filter in the job market. Developing opportunities for minorities in graduate education, 37-39. 
Figure 1: Impact of MMC on ACT composite scores

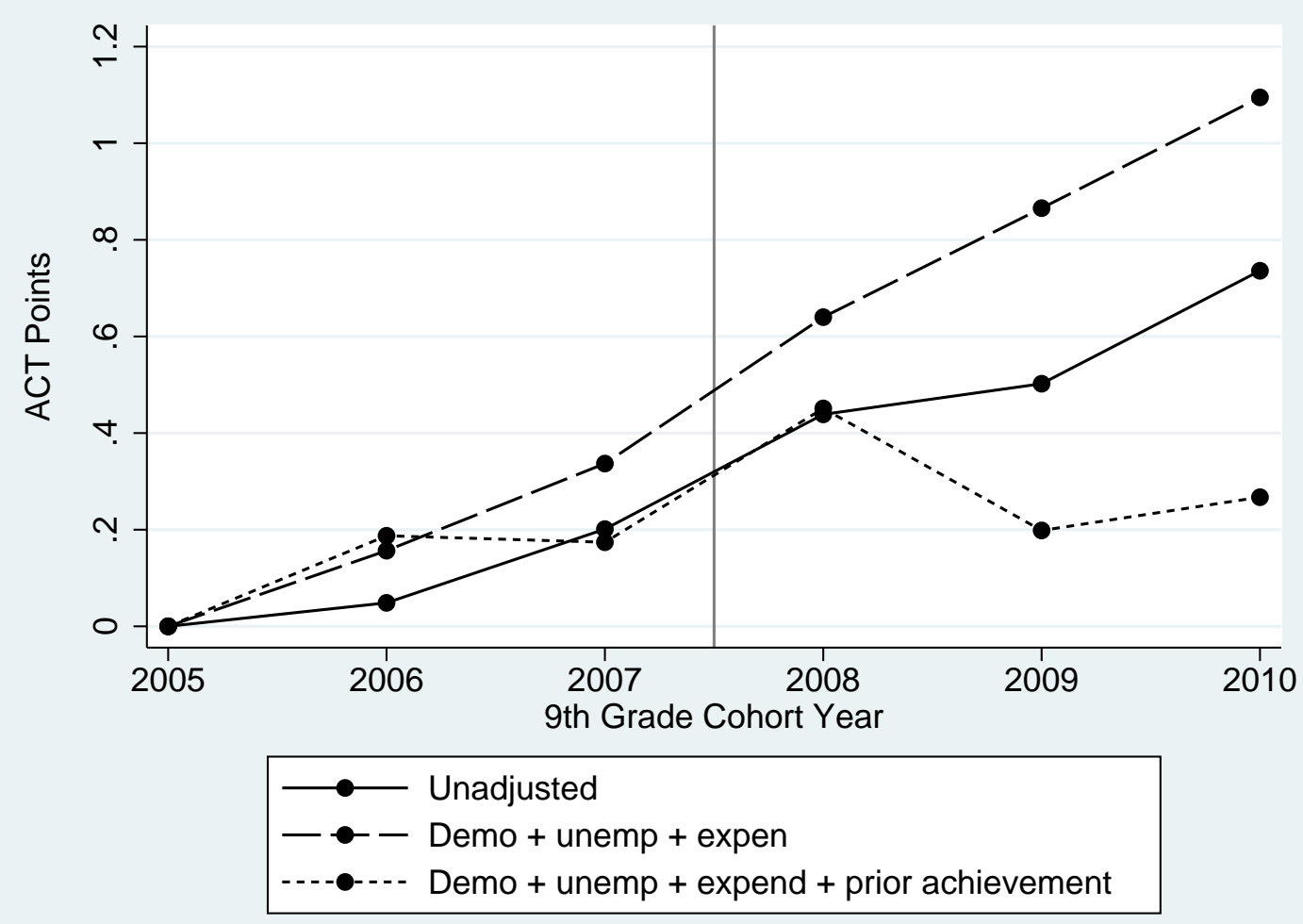

Figure 2: Impact of MMC on ACT math scores

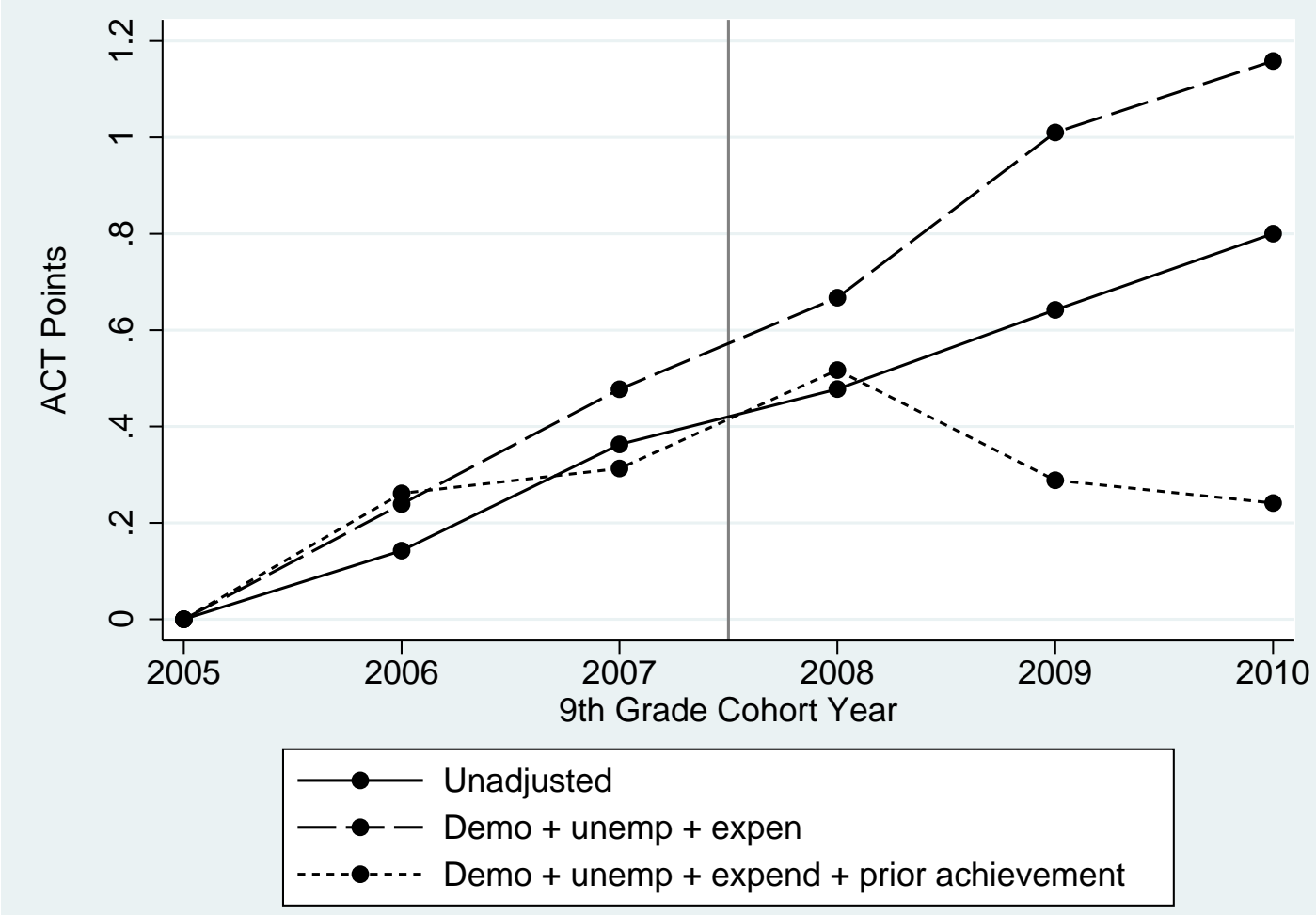


Figure 3: Impact of MMC on ACT science scores

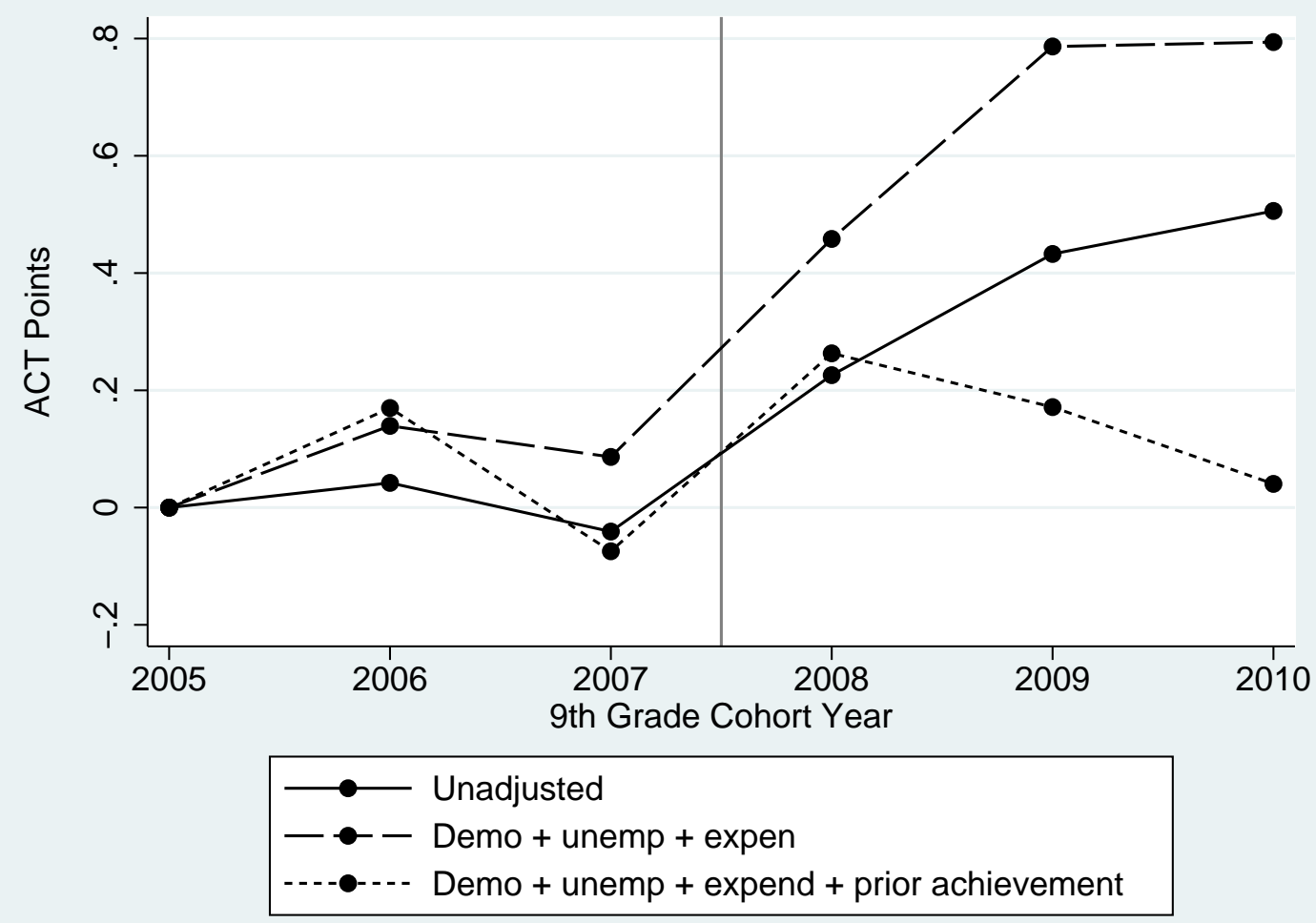

Figure 4: Impact of MMC on ACT reading scores

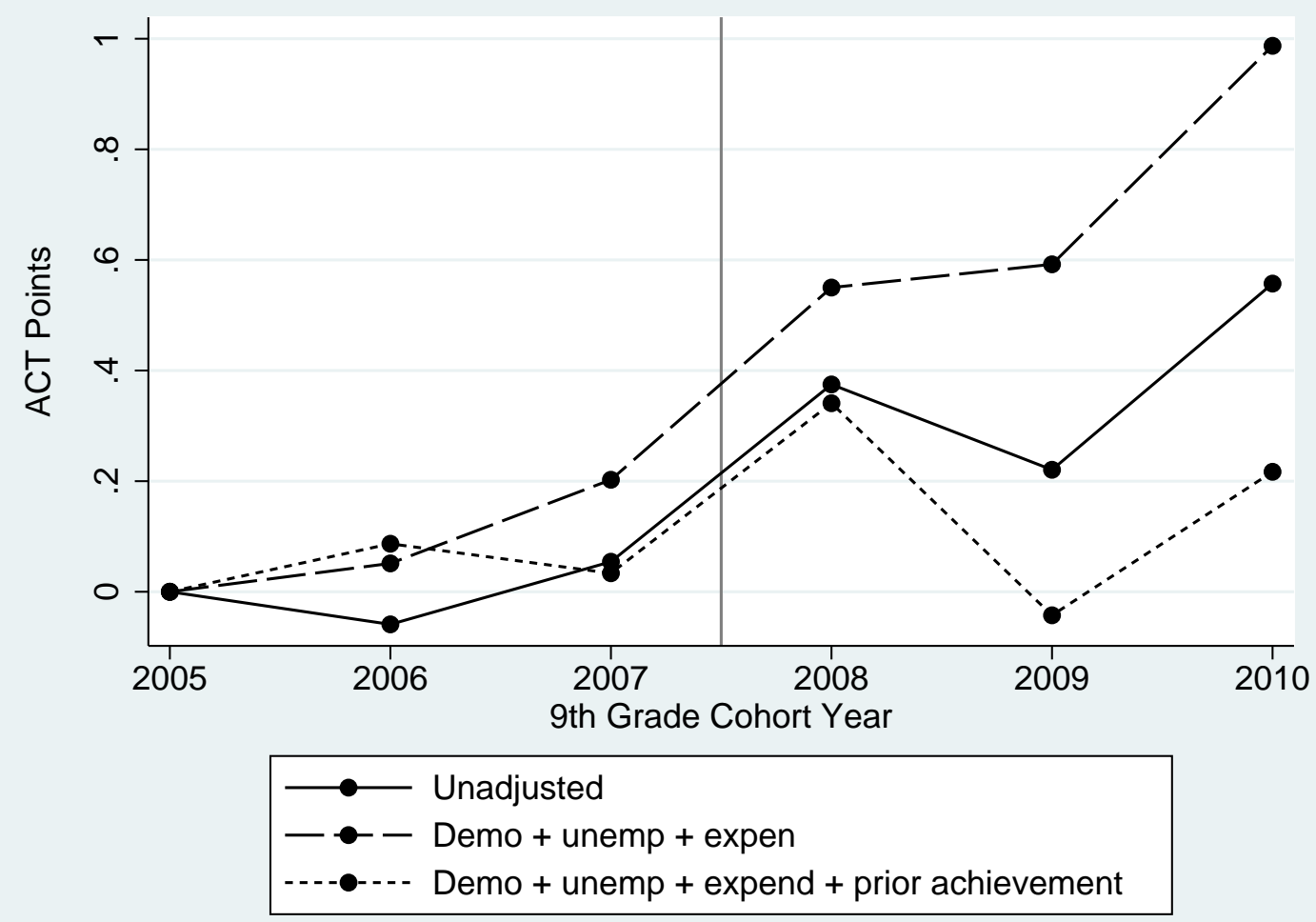


Figure 5: Impact of MMC on ACT English scores

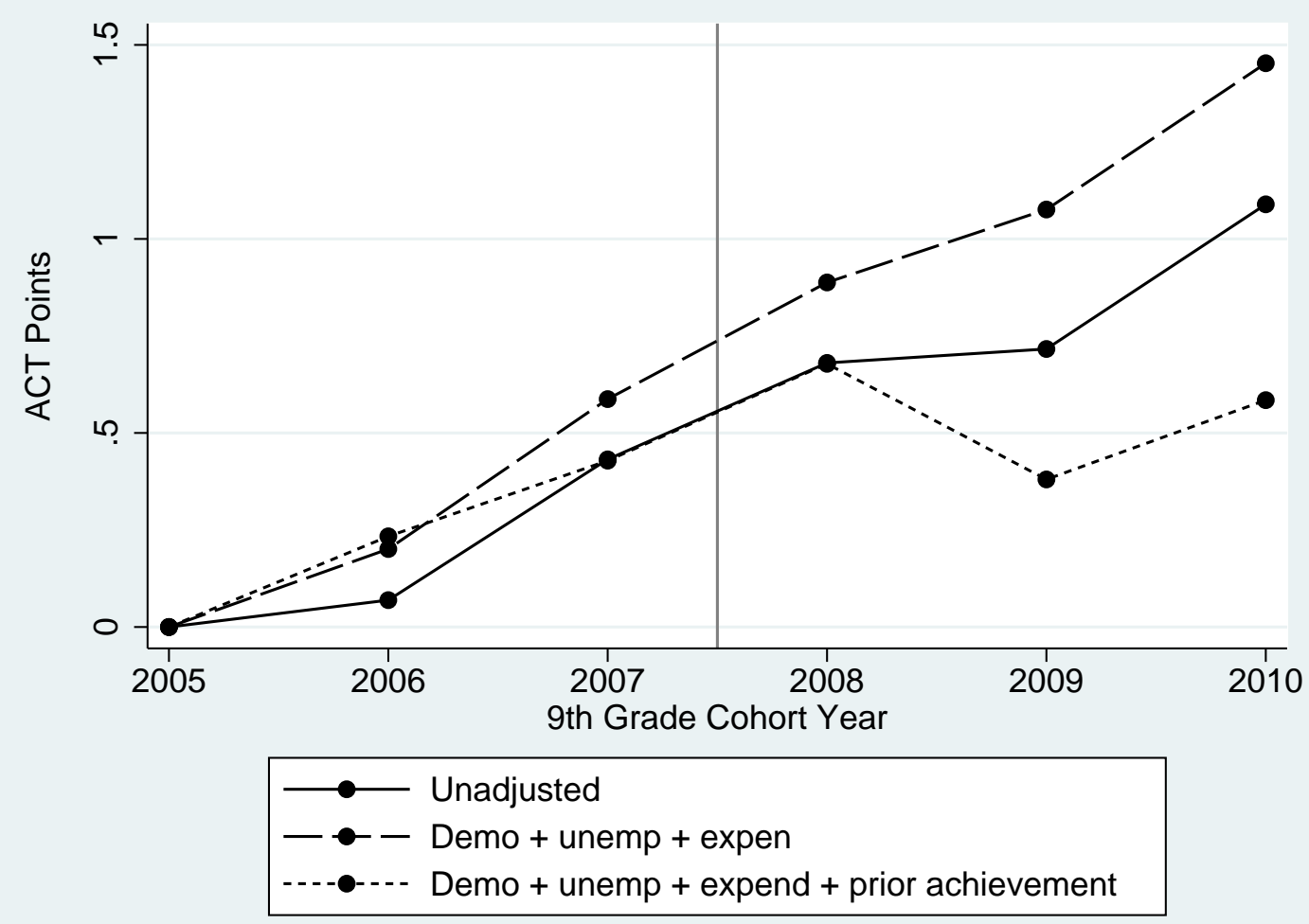

Figure 6: Impact of MMC on five-years graduation rates

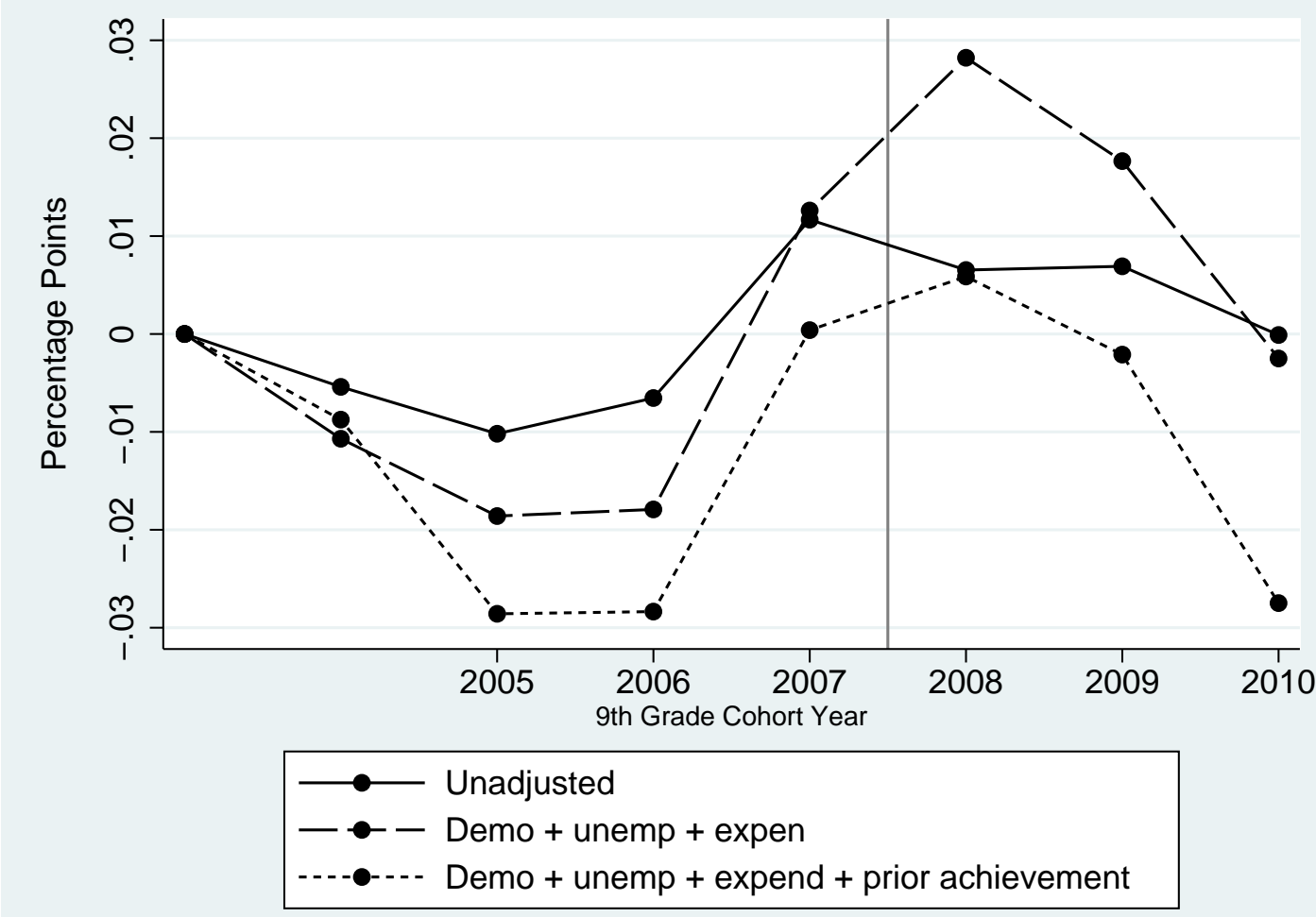


Figure 7: Impact of MMC on five-years graduation rates (Quintile 1)

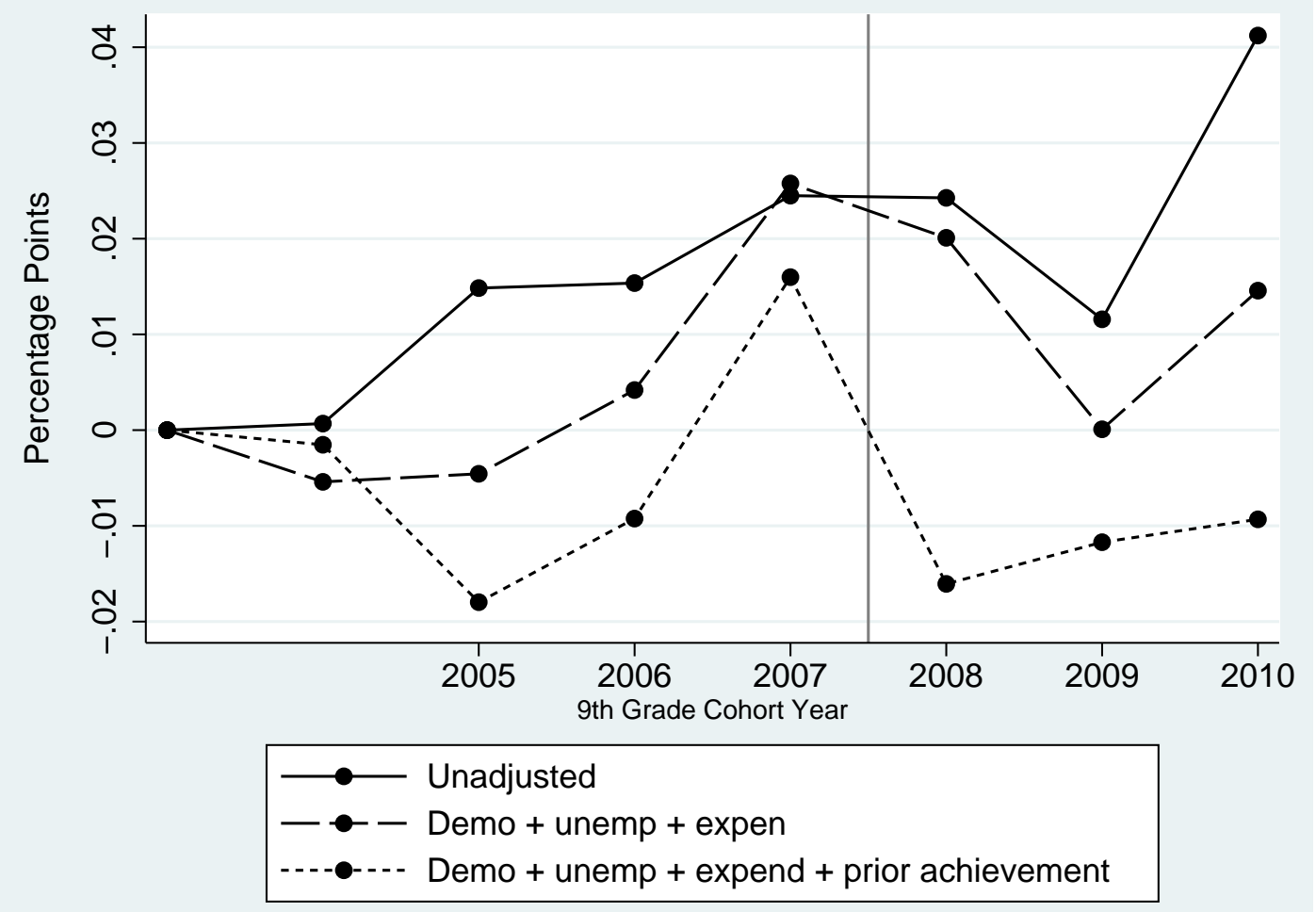

Figure 8: Impact of MMC on five-years graduation rates (Quintile 2)

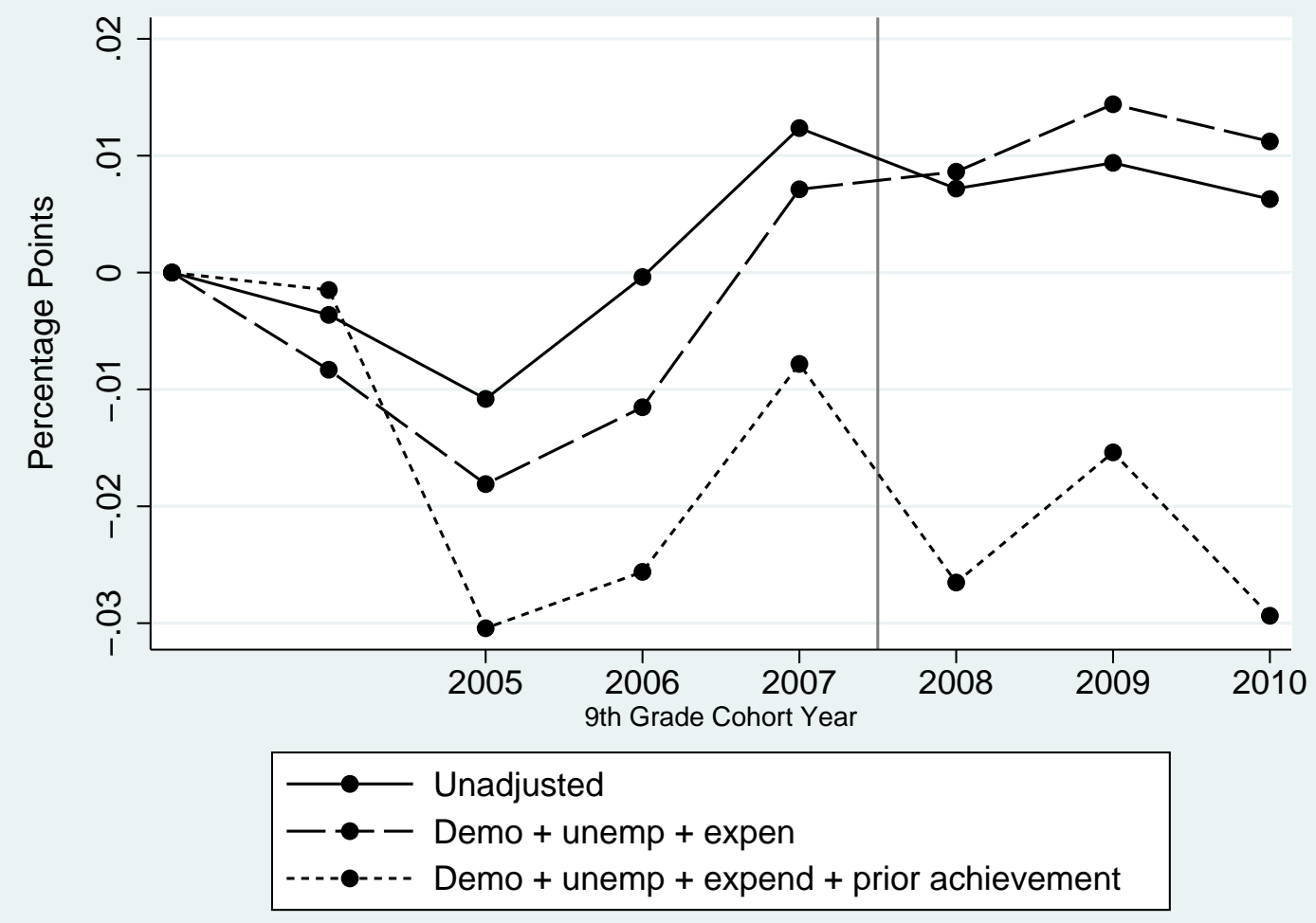


Figure 9: Impact of MMC on five-years graduation rates (Quintile 3)

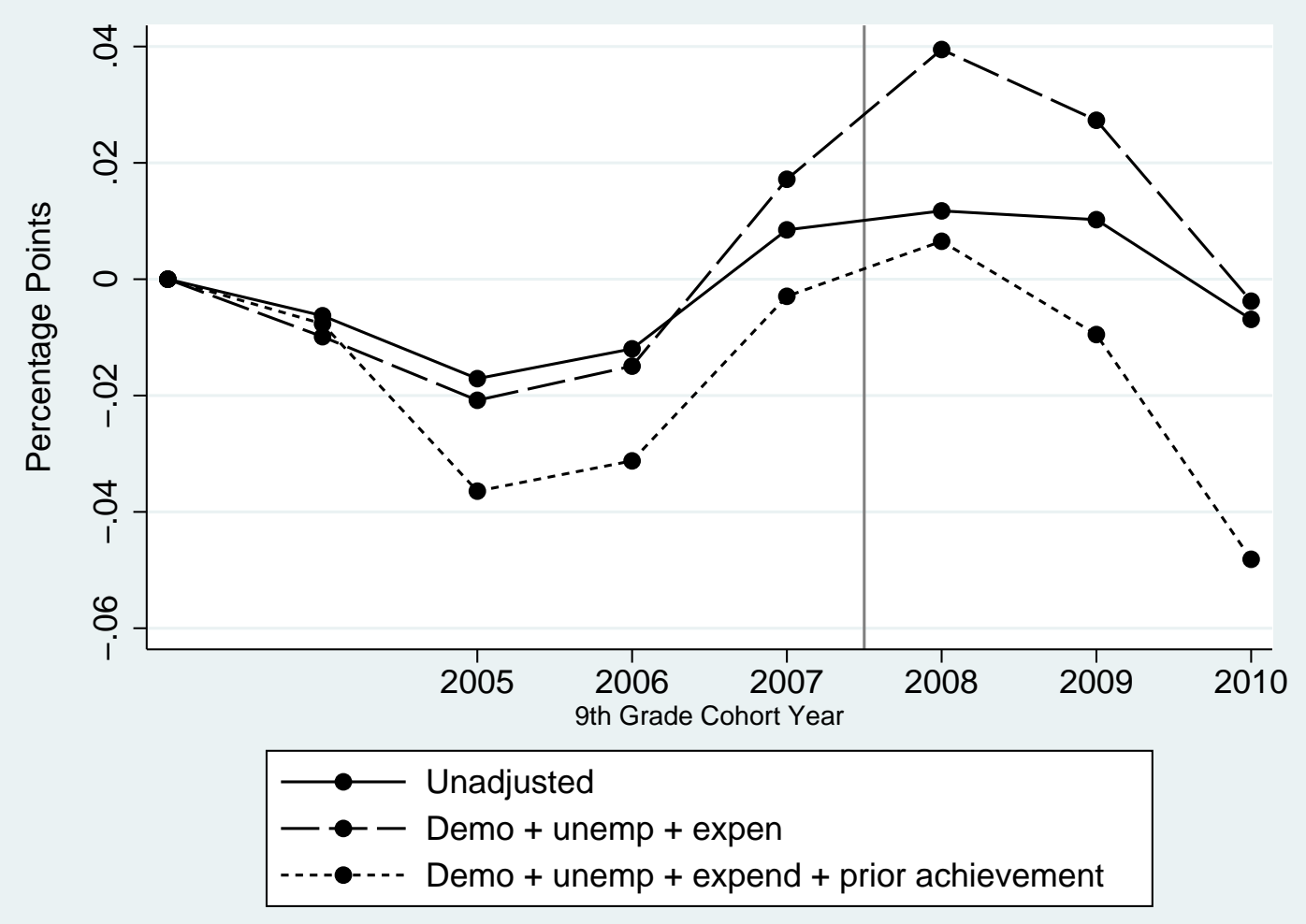

Figure 10: Impact of MMC on five-years graduation rates (Quintile 4)

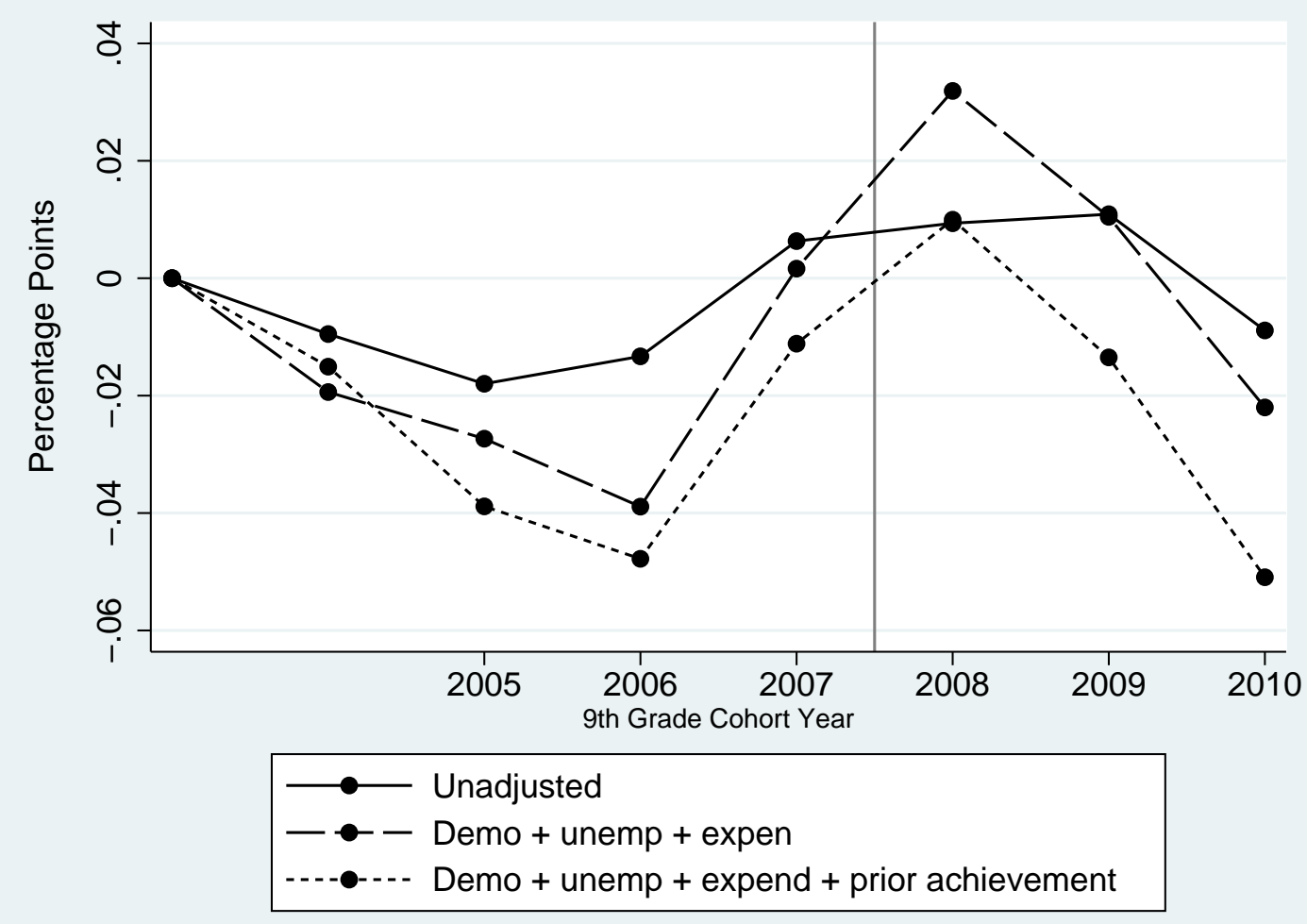


Figure 11: Impact of MMC on five-years graduation rates (Quintile 5)

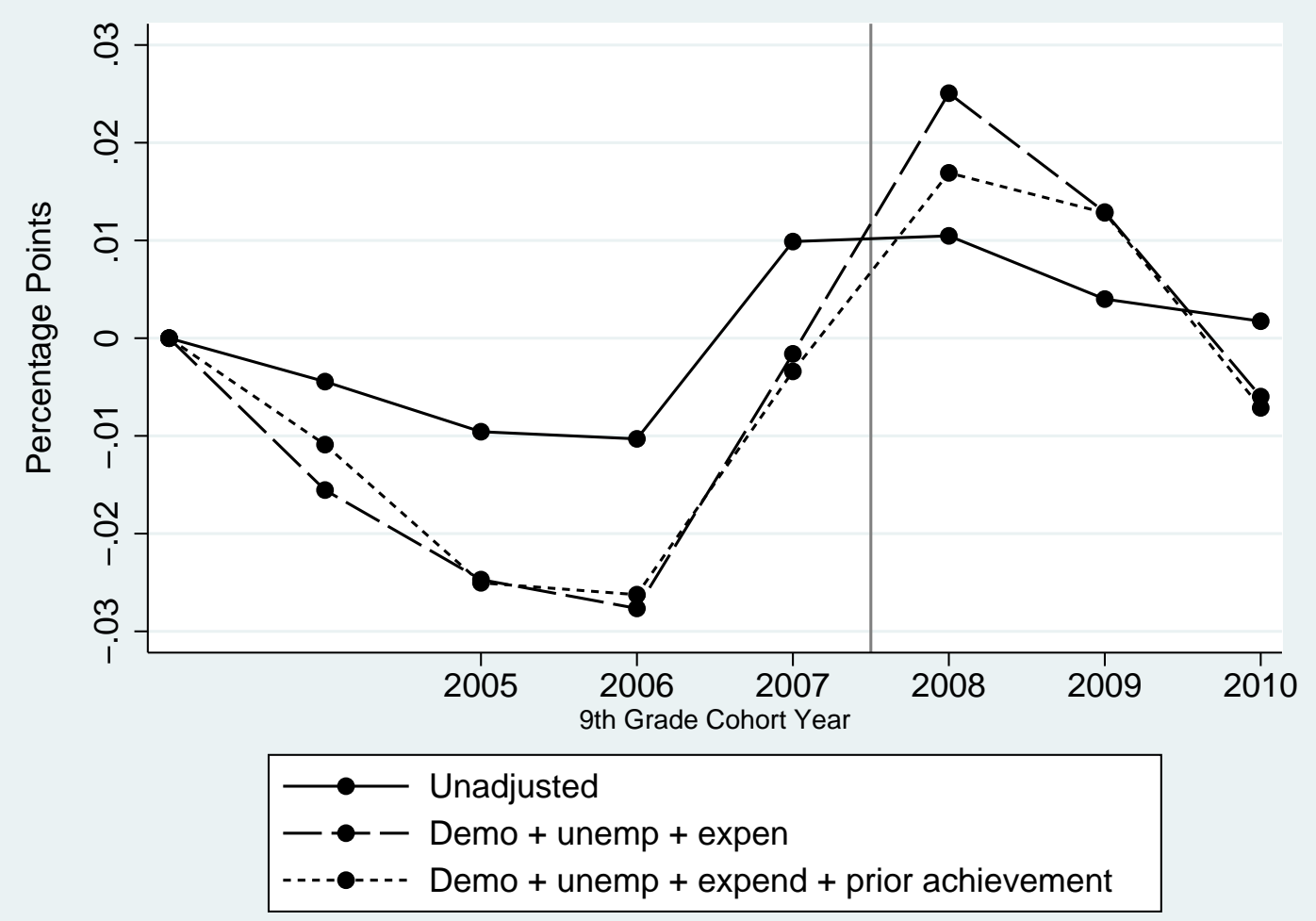

Figure 12: Impact of MMC on four-years graduation rates (synthetic control)

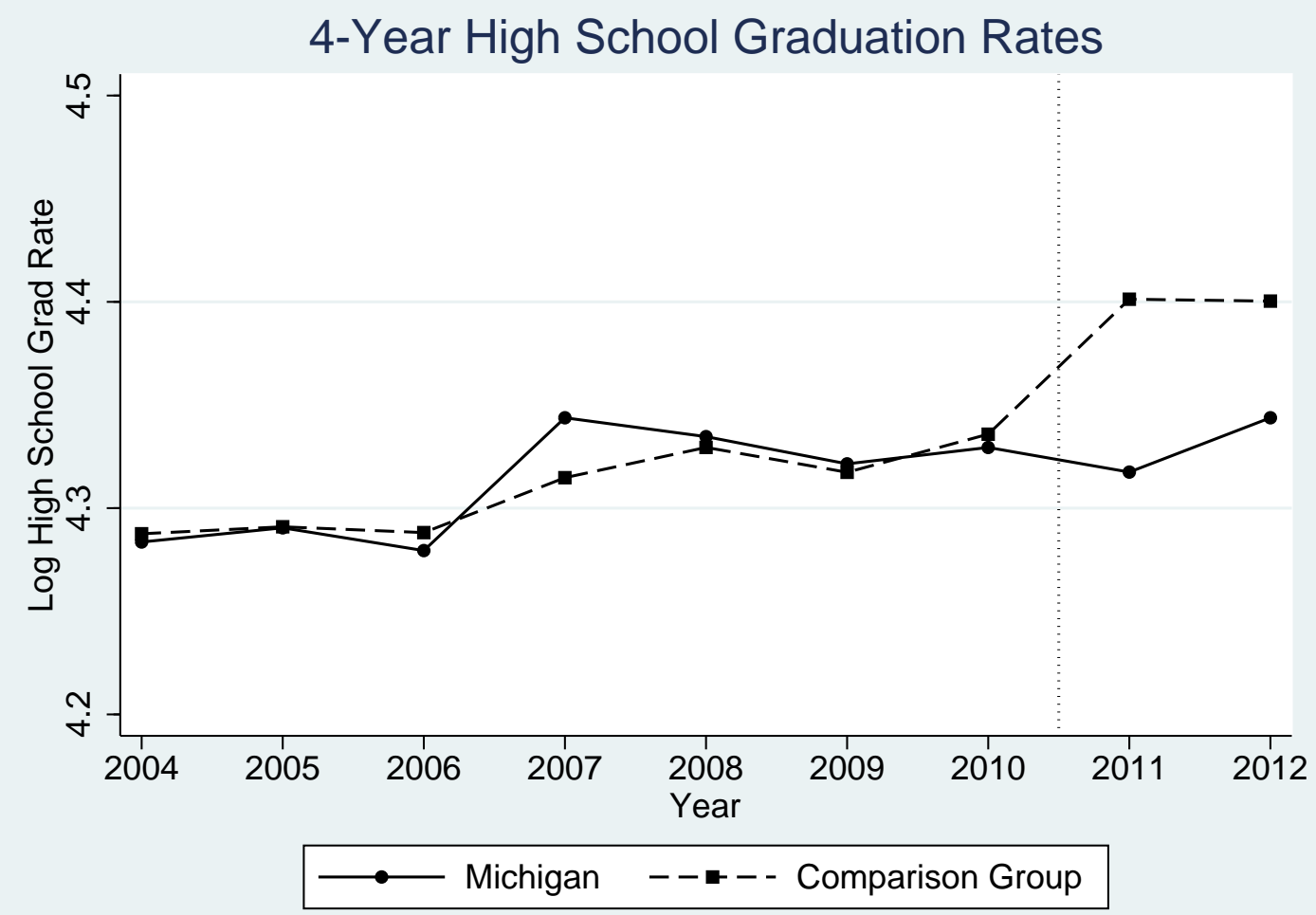


Table 1a - Summary Statistics on Student and School Background Characteristics

\begin{tabular}{|c|c|c|c|c|c|c|c|c|}
\hline \multirow[b]{2}{*}{ Variable } & \multicolumn{8}{|c|}{$\underline{\text { Year of Grade } 9}$} \\
\hline & 2003 & 2004 & 2005 & 2006 & 2007 & 2008 & 2009 & 2010 \\
\hline \multicolumn{9}{|l|}{ Demographics } \\
\hline \% White & $76.4 \%$ & $75.5 \%$ & $74.6 \%$ & $73.8 \%$ & $73.5 \%$ & $73.2 \%$ & $72.9 \%$ & $73.2 \%$ \\
\hline \% black & $17.0 \%$ & $18.1 \%$ & $19.0 \%$ & $19.4 \%$ & $19.4 \%$ & $19.3 \%$ & $19.3 \%$ & $18.4 \%$ \\
\hline \% Hispanic & $3.3 \%$ & $3.3 \%$ & $3.4 \%$ & $3.8 \%$ & $4.0 \%$ & $4.2 \%$ & $4.5 \%$ & $4.9 \%$ \\
\hline \% Asian & $2.0 \%$ & $1.9 \%$ & $1.9 \%$ & $1.9 \%$ & $2.1 \%$ & $2.1 \%$ & $2.2 \%$ & $2.4 \%$ \\
\hline \% migrant & $0.2 \%$ & $0.1 \%$ & $0.2 \%$ & $0.2 \%$ & $0.2 \%$ & $0.2 \%$ & $0.1 \%$ & $0.2 \%$ \\
\hline \% free lunch (gr 9) & $21.6 \%$ & $22.5 \%$ & $24.7 \%$ & $27.2 \%$ & $29.0 \%$ & $30.3 \%$ & $32.8 \%$ & $34.5 \%$ \\
\hline \% subdized lunch (gr 9) & $5.8 \%$ & $5.6 \%$ & $5.7 \%$ & $6.5 \%$ & $6.8 \%$ & $6.9 \%$ & $7.3 \%$ & $7.3 \%$ \\
\hline$\%$ in special education & $11.3 \%$ & $11.7 \%$ & $10.7 \%$ & $11.2 \%$ & $11.2 \%$ & $11.5 \%$ & $11.8 \%$ & $11.5 \%$ \\
\hline \% with limited English proficiency & $1.7 \%$ & $2.2 \%$ & $2.6 \%$ & $2.4 \%$ & $2.5 \%$ & $2.8 \%$ & $2.8 \%$ & $2.6 \%$ \\
\hline Average age & 14.50 & 14.49 & 14.49 & 14.50 & 14.51 & 14.50 & 14.50 & 14.51 \\
\hline \multicolumn{9}{|l|}{ School Characteristics } \\
\hline Enrollment & 273.36 & 292.47 & 308.34 & 302.40 & 294.71 & 290.76 & 279.05 & 281.47 \\
\hline$\%$ of students attending suburban school & $45.12 \%$ & $45.26 \%$ & $45.83 \%$ & $46.03 \%$ & $47.43 \%$ & $47.68 \%$ & $47.94 \%$ & $48.96 \%$ \\
\hline$\%$ of students attending school in a town & $9.00 \%$ & $8.91 \%$ & $8.70 \%$ & $8.59 \%$ & $8.53 \%$ & $8.48 \%$ & $8.44 \%$ & $8.30 \%$ \\
\hline$\%$ of students attending rural school & $26.21 \%$ & $26.14 \%$ & $25.60 \%$ & $25.76 \%$ & $25.88 \%$ & $26.28 \%$ & $26.20 \%$ & $26.13 \%$ \\
\hline$\%$ of students attending charter school & $1.29 \%$ & $1.88 \%$ & $2.16 \%$ & $2.50 \%$ & $2.69 \%$ & $2.99 \%$ & $3.50 \%$ & $3.76 \%$ \\
\hline$\%$ of students attending magnet school & $6.21 \%$ & $7.38 \%$ & $9.32 \%$ & $10.43 \%$ & $11.08 \%$ & $11.99 \%$ & $14.02 \%$ & $13.74 \%$ \\
\hline Unemp rate (\%) in county (grade 9) & 7.36 & 7.70 & 7.70 & 7.38 & 7.55 & 7.94 & 12.25 & 14.18 \\
\hline District pp expend (gr 9) & 10129.29 & 10152.35 & 10076.07 & 10006.60 & 10072.56 & 9877.53 & 10153.53 & 10080.25 \\
\hline school pp expend (gr 9) & 6376.35 & 6444.65 & 6376.83 & 6277.96 & 6349.03 & 6231.83 & 6555.39 & 6433.25 \\
\hline \multicolumn{9}{|l|}{ Prior Standardized Achievement } \\
\hline 8th grade std math score $*$ & -0.23 & -0.17 & 0.00 & 0.01 & 0.03 & 0.05 & 0.31 & 0.46 \\
\hline$\%$ missing 4 th grade math score & $17.89 \%$ & $19.55 \%$ & $20.40 \%$ & $20.70 \%$ & $20.10 \%$ & $15.96 \%$ & $13.50 \%$ & $12.00 \%$ \\
\hline 4th grade std math score * & -0.06 & -0.10 & 0.00 & -0.06 & 0.17 & 0.17 & 0.33 & 0.34 \\
\hline \multicolumn{9}{|l|}{ Sample } \\
\hline Total students & 112,201 & 120,853 & 126,974 & 126,443 & 122,890 & 120,770 & 116,208 & 114,491 \\
\hline
\end{tabular}

Notes: This table reports the mean of each variable for the sample including students who first attended a traditional high school in grade 9 during $2003-2010$ with non-missing 8th grade math test scores. *standardized equated exam scores are determined based on the 2005 cohort score. Scores are "equated" to account for differences in the number of possible points. 


\begin{tabular}{|c|c|c|c|c|c|c|c|c|}
\hline \multirow[b]{2}{*}{ Variable } & \multicolumn{8}{|c|}{$\underline{\text { Year of Grade } 9}$} \\
\hline & 2003 & 2004 & 2005 & 2006 & 2007 & 2008 & 2009 & 2010 \\
\hline \multicolumn{9}{|l|}{ High School Tests } \\
\hline \% that take the ACT & & & $83.46 \%$ & $84.66 \%$ & $85.48 \%$ & $86.33 \%$ & $87.52 \%$ & $87.59 \%$ \\
\hline Average ACT composite score & & & 18.88 & 18.92 & 19.08 & 19.31 & 19.38 & 19.61 \\
\hline Average ACT math score & & & 18.88 & 19.03 & 19.25 & 19.36 & 19.53 & 19.68 \\
\hline Average ACT science score & & & 19.48 & 19.52 & 19.44 & 19.71 & 19.91 & 19.99 \\
\hline Average ACT reading score & & & 17.64 & 17.71 & 18.07 & 18.32 & 18.35 & 18.73 \\
\hline Average ACT English score & & & 18.99 & 18.93 & 19.04 & 19.36 & 19.21 & 19.54 \\
\hline \multicolumn{9}{|l|}{ Advanced Placement Exam Outcomes } \\
\hline$\%$ took at least one exam $\dagger$ & $11.58 \%$ & $14.75 \%$ & $16.28 \%$ & $16.95 \%$ & $18.42 \%$ & $19.70 \%$ & $20.97 \%$ & $22.02 \%$ \\
\hline$\%$ took at least one exam (math) $\dagger$ & $5.09 \%$ & $6.08 \%$ & $6.47 \%$ & $6.66 \%$ & $7.20 \%$ & $8.06 \%$ & $8.29 \%$ & $8.85 \%$ \\
\hline$\%$ took at least one exam (science) $\dagger$ & $3.49 \%$ & $5.35 \%$ & $6.16 \%$ & $6.29 \%$ & $6.90 \%$ & $7.54 \%$ & $7.69 \%$ & $8.32 \%$ \\
\hline number of exams $\dagger$ & 0.20 & 0.32 & 0.38 & 0.40 & 0.44 & 0.50 & 0.53 & 0.59 \\
\hline number of exams (math) $\dagger$ & 0.05 & 0.07 & 0.07 & 0.08 & 0.08 & 0.09 & 0.10 & 0.10 \\
\hline number of exams (science) $\dagger$ & 0.04 & 0.07 & 0.08 & 0.08 & 0.09 & 0.10 & 0.10 & 0.11 \\
\hline Average score & 3.03 & 2.88 & 2.84 & 2.81 & 2.77 & 2.69 & 2.76 & 2.78 \\
\hline Average score (math) & 3.15 & 3.06 & 3.13 & 3.14 & 3.06 & 2.90 & 3.04 & 3.01 \\
\hline Average score (science) & 3.10 & 2.94 & 2.84 & 2.76 & 2.77 & 2.77 & 2.79 & 2.82 \\
\hline Maximum score & 3.16 & 3.06 & 3.04 & 3.02 & 2.98 & 2.92 & 2.98 & 3.01 \\
\hline Maximum score (math) & 3.16 & 3.09 & 3.17 & 3.18 & 3.11 & 2.96 & 3.10 & 3.08 \\
\hline Maximum score (science) & 3.15 & 3.03 & 2.94 & 2.87 & 2.88 & 2.88 & 2.91 & 2.94 \\
\hline Minimum score & 2.90 & 2.69 & 2.63 & 2.59 & 2.55 & 2.46 & 2.53 & 2.52 \\
\hline Minimum score (math) & 3.14 & 3.03 & 3.09 & 3.09 & 3.00 & 2.85 & 2.98 & 2.95 \\
\hline Minimum score (science) & 3.06 & 2.84 & 2.73 & 2.66 & 2.66 & 2.65 & 2.67 & 2.70 \\
\hline Score $3+$ on at least $1 \mathrm{AP}$ exam $\dagger$ & $4.59 \%$ & $5.59 \%$ & $5.94 \%$ & $5.95 \%$ & $6.40 \%$ & $6.83 \%$ & $7.14 \%$ & $7.83 \%$ \\
\hline Score $3+$ on at least 1 AP math exam $\dagger$ & $3.41 \%$ & $3.94 \%$ & $4.25 \%$ & $4.41 \%$ & $4.70 \%$ & $4.92 \%$ & $5.36 \%$ & $5.70 \%$ \\
\hline Score $3+$ on at least 1 AP science exam $\dagger$ & $2.34 \%$ & $3.38 \%$ & $3.71 \%$ & $3.60 \%$ & $3.95 \%$ & $4.35 \%$ & $4.46 \%$ & $5.14 \%$ \\
\hline \multicolumn{9}{|l|}{ High School Outcomes } \\
\hline$\%$ graduating in 4 years or fewer & $74.93 \%$ & $74.41 \%$ & $73.75 \%$ & $74.20 \%$ & $76.26 \%$ & $75.58 \%$ & $75.83 \%$ & $75.26 \%$ \\
\hline$\%$ enrolled in high school after 4 years & $9.18 \%$ & $9.31 \%$ & $9.45 \%$ & $9.48 \%$ & $8.91 \%$ & $9.86 \%$ & $9.14 \%$ & $7.83 \%$ \\
\hline$\%$ dropout within 4 years & $2.56 \%$ & $2.73 \%$ & $2.82 \%$ & $2.91 \%$ & $2.75 \%$ & $2.64 \%$ & $2.38 \%$ & $2.45 \%$ \\
\hline$\%$ left Michigan public within 4 years & $1.66 \%$ & $2.10 \%$ & $2.36 \%$ & $2.70 \%$ & $2.90 \%$ & $2.87 \%$ & $2.64 \%$ & $2.52 \%$ \\
\hline \% unknown within 4 years & $1.88 \%$ & $1.82 \%$ & $1.73 \%$ & $1.95 \%$ & $2.06 \%$ & $2.10 \%$ & $2.29 \%$ & $2.19 \%$ \\
\hline$\%$ other within 4 years & $9.79 \%$ & $9.63 \%$ & $9.89 \%$ & $8.76 \%$ & $7.13 \%$ & $6.95 \%$ & $7.73 \%$ & $9.75 \%$ \\
\hline$\%$ graduating in 5 years or fewer & $78.07 \%$ & $77.53 \%$ & $77.05 \%$ & $77.42 \%$ & $79.24 \%$ & $78.72 \%$ & $78.76 \%$ & $78.06 \%$ \\
\hline$\%$ enrolled in high school after 5 years $\ddagger$ & $2.17 \%$ & $2.25 \%$ & $2.34 \%$ & $2.28 \%$ & $2.33 \%$ & $2.46 \%$ & $1.97 \%$ & \\
\hline$\%$ dropout within 5 years $\ddagger$ & $3.67 \%$ & $3.80 \%$ & $3.94 \%$ & $4.06 \%$ & $3.58 \%$ & $3.75 \%$ & $3.52 \%$ & \\
\hline \% left Michigan public within 5 years $\ddagger$ & $1.77 \%$ & $2.24 \%$ & $2.43 \%$ & $2.76 \%$ & $2.95 \%$ & $2.99 \%$ & $2.68 \%$ & \\
\hline$\%$ unknown within 5 years $\ddagger$ & $2.57 \%$ & $2.78 \%$ & $2.85 \%$ & $3.07 \%$ & $3.12 \%$ & $3.48 \%$ & $3.45 \%$ & \\
\hline$\%$ other within 5 years $\ddagger$ & $11.75 \%$ & $11.41 \%$ & $11.38 \%$ & $10.41 \%$ & $8.78 \%$ & $8.60 \%$ & $9.62 \%$ & \\
\hline \multicolumn{9}{|l|}{ Sample } \\
\hline Total students & 112,201 & 120,853 & 126,974 & 126,443 & 122,890 & 120,770 & 116,208 & 114,491 \\
\hline Unique Schools & 705 & 706 & 698 & 711 & 674 & 717 & 701 & 705 \\
\hline
\end{tabular}

Notes: This table reports the mean of each variable for the sample including students who first attended a traditional high school in grade 9 during 2003-2010 with non-missing 8th grade math test scores. $†$ AP exam outcomes are unconditional, students who didn't take an AP exam are coded to have 0 exam and 0 score in one exam. AP score is $1-5$ point scale. $¥$ We don't have the high school graduation information (except graduation) within 5 years for the 2010 cohort. 
Table 2 - Impact of the MMC on ACT Scores

\begin{tabular}{|c|c|c|c|c|c|}
\hline Outcome & $\begin{array}{l}\text { Pre-Policy } \\
\text { Mean/S.D. }\end{array}$ & $(1)$ & $(2)$ & (3) & $(4)$ \\
\hline Composite ACT score & $\begin{array}{c}{[18.959]} \\
\{4.890\}\end{array}$ & $\begin{array}{c}0.400^{* * *} \\
(0.057)\end{array}$ & $\begin{array}{c}0.139 * * * \\
(0.053)\end{array}$ & $\begin{array}{c}0.167 * * * \\
(0.062)\end{array}$ & $\begin{array}{l}-0.096 \\
(0.059)\end{array}$ \\
\hline Number of Students & & 624,316 & 624,316 & 624,316 & 624,316 \\
\hline Math ACT Score & $\begin{array}{c}{[19.052]} \\
\{4.796\}\end{array}$ & $\begin{array}{c}0.373 * * * \\
(0.065)\end{array}$ & $\begin{array}{c}0.068 \\
(0.063)\end{array}$ & $\begin{array}{l}-0.018 \\
(0.072)\end{array}$ & $\begin{array}{c}-0.333 * * * \\
(0.069)\end{array}$ \\
\hline Number of Students & & 624,630 & 624,630 & 624,630 & 624,630 \\
\hline Science ACT Score & $\begin{array}{c}{[19.482]} \\
\{4.914\}\end{array}$ & $\begin{array}{c}0.407 * * * \\
(0.058)\end{array}$ & $\begin{array}{c}0.172 * * * \\
(0.060)\end{array}$ & $\begin{array}{c}0.432 * * * \\
(0.065)\end{array}$ & $\begin{array}{c}0.197 * * * \\
(0.065)\end{array}$ \\
\hline Number of Students & & 624,354 & 624,354 & 624,354 & 624,354 \\
\hline Reading ACT Score & $\begin{array}{c}{[18.984]} \\
\{5.902\}\end{array}$ & $\begin{array}{c}0.357 * * * \\
(0.062)\end{array}$ & $\begin{array}{c}0.128 * * \\
(0.061)\end{array}$ & $\begin{array}{c}0.295 * * * \\
(0.075)\end{array}$ & $\begin{array}{c}0.067 \\
(0.074)\end{array}$ \\
\hline Number of Students & & 624,494 & 624,494 & 624,494 & 624,494 \\
\hline English ACT Score & $\begin{array}{c}{[17.803]} \\
\{6.019\}\end{array}$ & $\begin{array}{c}0.465 * * * \\
(0.087)\end{array}$ & $\begin{array}{c}0.191 * * \\
(0.083)\end{array}$ & $\begin{array}{l}-0.046 \\
(0.090)\end{array}$ & $\begin{array}{c}-0.320 * * * \\
(0.087)\end{array}$ \\
\hline Number of Students & & 624,696 & 624,696 & 624,696 & 624,696 \\
\hline Took ACT Math & $\begin{array}{l}{[0.846]} \\
\{0.361\}\end{array}$ & $\begin{array}{c}-0.012 * * \\
(0.005)\end{array}$ & $\begin{array}{c}-0.013^{* *} \\
(0.005)\end{array}$ & $\begin{array}{c}-0.027 * * * \\
(0.006)\end{array}$ & $\begin{array}{c}-0.027 * * * \\
(0.006)\end{array}$ \\
\hline Number of Students & & 727,776 & 727,776 & 727,776 & 727,776 \\
\hline Pre-Policy Trend & & No & No & Yes & Yes \\
\hline Demographics, school characteristics and school FE & & Yes & Yes & Yes & Yes \\
\hline Prior 4th grade math test scores (individual and school level) & & Yes & Yes & Yes & Yes \\
\hline Prior 8th grade math test scores (individual and school level) & & No & Yes & No & Yes \\
\hline
\end{tabular}

Notes: This table reports the coefficients and standard errors from regressions of interrupted time series design of the impact of MMC on ACT outcomes. Each coefficient-standard error pair is from a separate regression. Students for 2005-2010 cohorts without imputed 8th grade test scores are included. "Took ACT math" is a dummy variable that is equal to one if a student has a nonmissing ACT composite score. All the ACT scores are the first time ACT exam raw scores of each subject. All the control variable groups (demographics, school characteristics, prior 4th and 8th grade test scores at both individual level and school level) are corresponding to those listed in Table 1, except not controlling for the unemployment rates and school/district expenditures in grades 11 and 12. Pre-policy mean reports the mean and s.d. of each outcome in 2005-2007. Robust standard errors in parentheses are clustered at high school level. ${ }^{*}$ significant at $10 \%$ level. ${ }^{* *}$ significant at $5 \%$ level. ${ }^{* * *}$ significant at $1 \%$ level. 
Table 3 - Impact of the MMC on ACT Scores, Relative to Illinois Score Trends

\begin{tabular}{|c|c|c|c|c|c|}
\hline Outcome & $\begin{array}{l}\text { Pre-Policy } \\
\text { Mean/S.D. }\end{array}$ & (1) & $(2)$ & $(3)$ & $(4)$ \\
\hline Composite ACT IL percentile & $\begin{array}{l}{[43.528]} \\
\{27.859\}\end{array}$ & $\begin{array}{c}1.310^{* * *} \\
(0.308)\end{array}$ & $\begin{array}{l}-0.064 \\
(0.294)\end{array}$ & $\begin{array}{c}2.223^{* * *} \\
(0.351)\end{array}$ & $\begin{array}{c}0.886^{* * *} \\
(0.331)\end{array}$ \\
\hline Number of Students & & 624,316 & 624,316 & 624,316 & 624,316 \\
\hline Math ACT Score IL percentile & $\begin{array}{l}{[45.220]} \\
\{26.608\}\end{array}$ & $\begin{array}{c}0.813^{* *} \\
(0.343)\end{array}$ & $\begin{array}{c}-0.737 * * \\
(0.324)\end{array}$ & $\begin{array}{c}0.878 * * \\
(0.388)\end{array}$ & $\begin{array}{l}-0.650 * \\
(0.370)\end{array}$ \\
\hline Number of Students & & 624,630 & 624,630 & 624,630 & 624,630 \\
\hline Science ACT Score IL percentile & $\begin{array}{l}{[47.391]} \\
\{28.573\}\end{array}$ & $\begin{array}{c}1.115^{* * *} \\
(0.338)\end{array}$ & $\begin{array}{l}-0.195 \\
(0.344)\end{array}$ & $\begin{array}{c}3.375^{* * *} \\
(0.373)\end{array}$ & $\begin{array}{c}2.111^{* * *} \\
(0.370)\end{array}$ \\
\hline Number of Students & & 624,354 & 624,354 & 624,354 & 624,354 \\
\hline Reading ACT Score IL percentile & $\begin{array}{l}{[44.559]} \\
\{28.215\}\end{array}$ & $\begin{array}{c}1.512^{* * *} \\
(0.295)\end{array}$ & $\begin{array}{c}0.402 \\
(0.291)\end{array}$ & $\begin{array}{c}2.913 * * * \\
(0.363)\end{array}$ & $\begin{array}{c}1.841^{* * *} \\
(0.356)\end{array}$ \\
\hline Number of Students & & 624,494 & 624,494 & 624,494 & 624,494 \\
\hline English ACT Score IL percentile & $\begin{array}{l}{[40.486]} \\
\{27.995\}\end{array}$ & $\begin{array}{c}1.812^{* * *} \\
(0.389)\end{array}$ & $\begin{array}{l}0.673^{*} \\
(0.374)\end{array}$ & $\begin{array}{c}0.644 \\
(0.412)\end{array}$ & $\begin{array}{c}-0.474 \\
(0.400)\end{array}$ \\
\hline Number of Students & & 624,696 & 624,696 & 624,696 & 624,696 \\
\hline Pre-Policy Trend & & No & No & Yes & Yes \\
\hline Demographics, school characteristics and school FE & & Yes & Yes & Yes & Yes \\
\hline Prior 4th grade math test scores (individual and school level) & & Yes & Yes & Yes & Yes \\
\hline Prior 8th grade math test scores (individual and school level) & & No & Yes & No & Yes \\
\hline
\end{tabular}

Notes: This table reports the coefficients and standard errors from regressions of interrupted time series design of the impact of MMC on ACT outcomes. Each coefficient-standard error pair is from a separate regression. Students for 2005-2010 cohorts without imputed 8th grade test scores are included. The ACT outcome measures correspond to the percentile that the student's raw score would be in the distribution of Illinois test takers in the given year. See text for more discussion of this. All the control variable groups (demographics, school characteristics, prior 4th and 8th grade test scores at both individual level and school level) are corresponding to those listed in Table 1, except not controlling for the unemployment rates and school/district expenditures in grades 11 and 12. Pre-policy mean reports the mean and s.d. of each outcome in 2005-2007. Robust standard errors in parentheses are clustered at high school level. * significant at $10 \%$ level. ${ }^{* *}$ significant at $5 \%$ level. ${ }^{* * *}$ significant at $1 \%$ level. 
Table 4 - Impact of the MMC on ACT Outcomes by Student 8th Grade Math Score Quintile

\begin{tabular}{|c|c|c|c|c|c|c|}
\hline \multirow{2}{*}{ Outcome } & \multicolumn{5}{|c|}{ Student 8th Grade Math Score Quintile } & \multirow{2}{*}{$\begin{array}{c}\text { Diff: } \\
\text { Q1 - Q5 } \\
\end{array}$} \\
\hline & $1($ Low $)$ & 2 & 3 & 4 & 5 (High) & \\
\hline \multicolumn{7}{|l|}{ ACT composite score } \\
\hline All covariates, but no pre-policy trend & $\begin{array}{c}0.361^{* * *} \\
(0.062) \\
{[14.108]} \\
\{2.295\}\end{array}$ & $\begin{array}{c}0.120 \\
(0.073) \\
{[16.060]} \\
\{2.696\}\end{array}$ & $\begin{array}{c}0.122 \\
(0.081) \\
{[18.004]} \\
\{3.092\}\end{array}$ & $\begin{array}{c}0.148 * \\
(0.086) \\
{[20.481]} \\
\{3.459\}\end{array}$ & $\begin{array}{c}0.196^{*} \\
(0.112) \\
{[24.718]} \\
\{4.125\}\end{array}$ & $\begin{array}{c}0.165 \\
(0.122)\end{array}$ \\
\hline All covariates, and pre-policy trend & $\begin{array}{c}0.354^{* * *} \\
(0.073)\end{array}$ & $\begin{array}{c}0.105 \\
(0.085)\end{array}$ & $\begin{array}{c}-0.035 \\
(0.093)\end{array}$ & $\begin{array}{c}-0.261^{* * *} \\
(0.101)\end{array}$ & $\begin{array}{l}-0.239 * \\
(0.129)\end{array}$ & $\begin{array}{c}0.593 * * * \\
(0.143)\end{array}$ \\
\hline Number of Students & 112,294 & 119,788 & 124,796 & 137,931 & 129,507 & 241,801 \\
\hline \multicolumn{7}{|l|}{ ACT math score } \\
\hline All covariates, but no pre-policy trend & $\begin{array}{c}0.211^{* * *} \\
(0.051) \\
{[14.766]} \\
\{1.709\}\end{array}$ & $\begin{array}{c}0.094 \\
(0.064) \\
{[16.042]} \\
\{2.061\}\end{array}$ & $\begin{array}{c}0.184^{* *} \\
(0.076) \\
{[17.698]} \\
\{2.734\}\end{array}$ & $\begin{array}{c}0.058 \\
(0.100) \\
{[20.304]} \\
\{3.479\}\end{array}$ & $\begin{array}{c}0.111 \\
(0.140) \\
{[25.128]} \\
\{4.337\}\end{array}$ & $\begin{array}{c}0.100 \\
(0.148)\end{array}$ \\
\hline All covariates, and pre-policy trend & $\begin{array}{c}-0.119 * * \\
(0.055)\end{array}$ & $\begin{array}{c}-0.084 \\
(0.074)\end{array}$ & $\begin{array}{l}-0.047 \\
(0.090)\end{array}$ & $\begin{array}{c}-0.428^{* * *} \\
(0.113)\end{array}$ & $\begin{array}{c}-0.562 * * * \\
(0.147)\end{array}$ & $\begin{array}{c}0.443^{* * *} \\
(0.153)\end{array}$ \\
\hline Number of Students & 112,429 & 119,861 & 124,850 & 137,965 & 129,525 & 241,954 \\
\hline \multicolumn{7}{|l|}{ ACT Science score } \\
\hline All covariates, but no pre-policy trend & $\begin{array}{c}0.391 * * * \\
(0.081) \\
{[14.939]} \\
\{3.307\}\end{array}$ & $\begin{array}{c}0.170^{*} \\
(0.096) \\
{[16.884]} \\
\{3.459\}\end{array}$ & $\begin{array}{c}0.105 \\
(0.090) \\
{[18.758]} \\
\{3.525\}\end{array}$ & $\begin{array}{c}0.168 * \\
(0.096) \\
{[20.940]} \\
\{3.597\}\end{array}$ & $\begin{array}{c}0.249 * * \\
(0.122) \\
{[24.574]} \\
\{4.150\}\end{array}$ & $\begin{array}{c}0.142 \\
(0.142)\end{array}$ \\
\hline All covariates, and pre-policy trend & $\begin{array}{c}0.726 * * * \\
(0.099)\end{array}$ & $\begin{array}{c}0.647 * * * \\
(0.111)\end{array}$ & $\begin{array}{c}0.337 * * * \\
(0.104)\end{array}$ & $\begin{array}{c}0.034 \\
(0.110)\end{array}$ & $\begin{array}{c}-0.314 * * \\
(0.133)\end{array}$ & $\begin{array}{c}1.040 * * * \\
(0.163)\end{array}$ \\
\hline Number of Students & 112,312 & 119,799 & 124,800 & 137,934 & 129,509 & 241,821 \\
\hline \multicolumn{7}{|l|}{ ACT Reading score } \\
\hline All covariates, but no pre-policy trend & $\begin{array}{c}0.409 * * * \\
(0.084) \\
{[14.140]} \\
\{3.413\}\end{array}$ & $\begin{array}{c}0.147 \\
(0.100) \\
{[16.153]} \\
\{4.071\}\end{array}$ & $\begin{array}{c}0.072 \\
(0.116) \\
{[18.106]} \\
\{4.627\}\end{array}$ & $\begin{array}{c}0.210 * \\
(0.122) \\
{[20.528]} \\
\{5.093\}\end{array}$ & $\begin{array}{c}0.152 \\
(0.139) \\
{[24.587]} \\
\{5.577\}\end{array}$ & $\begin{array}{c}0.257 \\
(0.159)\end{array}$ \\
\hline All covariates, and pre-policy trend & $\begin{array}{c}0.660^{* * *} \\
(0.104)\end{array}$ & $\begin{array}{c}0.154 \\
(0.117)\end{array}$ & $\begin{array}{c}-0.074 \\
(0.135)\end{array}$ & $\begin{array}{l}-0.119 \\
(0.149)\end{array}$ & $\begin{array}{c}0.145 \\
(0.169)\end{array}$ & $\begin{array}{c}0.515^{* * *} \\
(0.195)\end{array}$ \\
\hline Number of Students & 112,368 & 119,838 & 124,823 & 137,949 & 129,516 & 241,884 \\
\hline \multicolumn{7}{|l|}{ ACT English score } \\
\hline All covariates, but no pre-policy trend & $\begin{array}{c}0.449 * * * \\
(0.113) \\
{[12.079]} \\
\{3.569\}\end{array}$ & $\begin{array}{c}0.015 \\
(0.110) \\
{[14.652]} \\
\{4.025\}\end{array}$ & $\begin{array}{c}0.137 \\
(0.126) \\
{[16.946]} \\
\{4.337\}\end{array}$ & $\begin{array}{c}0.175 \\
(0.118) \\
{[19.642]} \\
\{4.589\}\end{array}$ & $\begin{array}{c}0.288 * * \\
(0.143) \\
{[24.066]} \\
\{5.168\}\end{array}$ & $\begin{array}{c}0.161 \\
(0.165)\end{array}$ \\
\hline All covariates, and pre-policy trend & $\begin{array}{c}0.154 \\
(0.124)\end{array}$ & $\begin{array}{c}-0.346^{* * *} \\
(0.126)\end{array}$ & $\begin{array}{c}-0.367 * * * \\
(0.136)\end{array}$ & $\begin{array}{c}-0.512 * * * \\
(0.138)\end{array}$ & $\begin{array}{l}-0.217 \\
(0.168)\end{array}$ & $\begin{array}{l}0.371^{*} \\
(0.194)\end{array}$ \\
\hline
\end{tabular}


Took ACT Math

\begin{tabular}{|c|c|c|c|c|c|c|}
\hline All covariates, but no pre-policy trend & $\begin{array}{l}-0.014 \\
(0.011) \\
{[0.675]} \\
\{0.468\}\end{array}$ & $\begin{array}{c}-0.014^{*} \\
(0.008) \\
{[0.812]} \\
\{0.391\}\end{array}$ & $\begin{array}{l}-0.011 \\
(0.007) \\
{[0.879]} \\
\{0.326\}\end{array}$ & $\begin{array}{c}-0.011 * \\
(0.006) \\
{[0.925]} \\
\{0.264\}\end{array}$ & $\begin{array}{l}-0.003 \\
(0.005) \\
{[0.955]} \\
\{0.207\}\end{array}$ & $\begin{array}{c}-0.011 \\
(0.012)\end{array}$ \\
\hline All covariates, and pre-policy trend & $\begin{array}{c}-0.048 * * * \\
(0.012)\end{array}$ & $\begin{array}{c}-0.028 * * * \\
(0.010)\end{array}$ & $\begin{array}{c}-0.024 * * * \\
(0.009)\end{array}$ & $\begin{array}{c}-0.018^{* *} \\
(0.007)\end{array}$ & $\begin{array}{c}-0.002 \\
(0.006)\end{array}$ & $\begin{array}{c}-0.046^{* * *} \\
(0.013)\end{array}$ \\
\hline Number of Students & 159,770 & 144,618 & 140,088 & 148,056 & 135,244 & 295,014 \\
\hline
\end{tabular}

Notes: This table reports the coefficients and standard errors from regressions identical to columns (2) and (4) shown in Table 2, but estimated separately for students in quintiles of 8th grade math achievement. Each coefficient-standard error pair is from a separate regression. Students for 2005-2010 cohorts with non-missing 8th grade test scores are included. The pre-policy mean (standard deviation) of the outcomes is reported in square brackets (braces). Robust standard errors in parentheses are clustered at high school level. * significant at $10 \%$ level. ** significant at $5 \%$ level. *** significant at $1 \%$ level. 
Table 5 - Impact of the MMC on MME outcomes by Student 8th Grade Math Score Quintile

\begin{tabular}{|c|c|c|c|c|c|}
\hline \multirow{2}{*}{ Outcome } & \multicolumn{5}{|c|}{ 8th grade math quintile } \\
\hline & 1 (Low) & 2 & 3 & 4 & 5 (High) \\
\hline MME Math Score & $\begin{array}{c}0.067 \\
(0.041)\end{array}$ & $\begin{array}{l}-0.035 \\
(0.027)\end{array}$ & $\begin{array}{l}-0.032 \\
(0.019)\end{array}$ & $\begin{array}{c}-0.090 * * * \\
(0.016)\end{array}$ & $\begin{array}{c}-0.073^{* * *} \\
(0.019)\end{array}$ \\
\hline MME Science Score & $\begin{array}{c}0.107 * * * \\
(0.033)\end{array}$ & $\begin{array}{c}0.058 * * \\
(0.027)\end{array}$ & $\begin{array}{c}0.006 \\
(0.022)\end{array}$ & $\begin{array}{l}-0.014 \\
(0.019)\end{array}$ & $\begin{array}{l}-0.008 \\
(0.017)\end{array}$ \\
\hline MME Reading Score & $\begin{array}{l}-0.004 \\
(0.031)\end{array}$ & $\begin{array}{c}-0.058 * * * \\
(0.022)\end{array}$ & $\begin{array}{c}-0.074 * * * \\
(0.022)\end{array}$ & $\begin{array}{c}-0.063^{* * *} \\
(0.021)\end{array}$ & $\begin{array}{l}-0.006 \\
(0.022)\end{array}$ \\
\hline MME Social Studies Score & $\begin{array}{c}0.020 \\
(0.023)\end{array}$ & $\begin{array}{c}-0.081^{* * *} \\
(0.024)\end{array}$ & $\begin{array}{c}-0.182 * * * \\
(0.027)\end{array}$ & $\begin{array}{c}-0.353^{* * *} \\
(0.029)\end{array}$ & $\begin{array}{c}-0.543^{* * *} \\
(0.034)\end{array}$ \\
\hline Number of Students Had Math Score & 108,786 & 117,598 & 123,356 & 136,890 & 128,953 \\
\hline
\end{tabular}

Notes: This table reports the coefficients and standard errors from regressions of interrupted time series design of the impact of MMC on MME outcomes with full controls that are listed in Table 2, but estimated separately for students in quintiles of 8th grade math achievement. Students for 2005-2010 cohorts with non-missing 8th grade test scores are included. Each coefficient-standard error pair is from a separate regression. MME outcomes are standardized based on cohort 2005 MME test scores. The pre-policy mean (standard deviation) of the outcomes is reported in square brackets (braces). Robust standard errors in parentheses are clustered at high school level. * significant at $10 \%$ level. ${ }^{* *}$ significant at $5 \%$ level. $* * *$ significant at $1 \%$ level. 
Table 6: Effect of MMC on Advanced Placement Course-taking and Scores by Student 8th Grade Math Score Quintile

\begin{tabular}{|c|c|c|c|}
\hline \multirow{2}{*}{ Outcome } & \multicolumn{3}{|c|}{ " Grade 8 Math Quintile } \\
\hline & 3 & 4 & 5 (High) \\
\hline \multirow[t]{4}{*}{ Number of AP exams taken } & 0.028 & -0.023 & $0.172^{* *}$ \\
\hline & $(0.020)$ & $(0.037)$ & $(0.081)$ \\
\hline & {$[0.166]$} & [0.429] & [1.434] \\
\hline & $\{0.583\}$ & $\{0.992\}$ & $\{2.003\}$ \\
\hline \multirow[t]{4}{*}{ Number of AP science exams taken } & 0.000 & -0.014 & 0.047 \\
\hline & $(0.006)$ & $(0.011)$ & $(0.031)$ \\
\hline & {$[0.028]$} & {$[0.076]$} & [0.321] \\
\hline & $\{0.178\}$ & $\{0.300\}$ & $\{0.680\}$ \\
\hline \multirow[t]{4}{*}{ Average score on AP exams taken } & 0.096 & 0.047 & $0.154^{* *}$ \\
\hline & $(0.144)$ & $(0.106)$ & $(0.071)$ \\
\hline & [1.738] & [2.195] & [3.179] \\
\hline & $\{1.000\}$ & $\{1.159\}$ & $\{1.280\}$ \\
\hline \multirow[t]{3}{*}{ Score $3+$ on at least $1 \mathrm{AP}$ exam } & 0.004 & -0.005 & 0.022 \\
\hline & $(0.003)$ & $(0.007)$ & $(0.015)$ \\
\hline & [0.009] & {$[0.044]$} & {$[0.264]$} \\
\hline \multirow[t]{3}{*}{ Score $3+$ on at least 1 AP science exam } & $0.005^{* *}$ & 0.001 & $0.036 * * *$ \\
\hline & $(0.002)$ & $(0.005)$ & $(0.014)$ \\
\hline & {$[0.006]$} & {$[0.026]$} & [0.163] \\
\hline
\end{tabular}

Notes: This table reports the coefficients and standard errors from regressions of interrupted time series design of the impact of MMC on Advanced Placement exam outcomes with full controls that are listed in column 4 of Table 2, but estimated separately for students in quintiles of 8th grade math achievement. Students for 2005-2010 cohorts with non-missing 8th grade test scores are included. Each coefficient-standard error pair is from a separate regression. Robust standard errors in parentheses are clustered at high school level. * significant at $10 \%$ level. ** significant at $5 \%$ level. *** significant at $1 \%$ level. 
Table 7 - Impact of the MMC on 5-Year High School Completion Outcomes

\begin{tabular}{|c|c|c|c|c|c|c|}
\hline \multirow[b]{2}{*}{ Approach } & \multicolumn{3}{|c|}{ Outcome $=$ Graduated } & \multicolumn{3}{|c|}{ Outcome $=$ Still enrolled } \\
\hline & $\begin{array}{c}2003-10 \\
(1)\end{array}$ & $\begin{array}{c}2004-10 \\
(2)\end{array}$ & $\begin{array}{c}2005-10 \\
(3)\end{array}$ & $\begin{array}{c}2003-10 \\
(4) \\
\end{array}$ & $\begin{array}{c}2004-10 \\
(5) \\
\end{array}$ & $\begin{array}{c}2005-10 \\
(6) \\
\end{array}$ \\
\hline Difference-in-Differences & $\begin{array}{c}0.005 \\
(0.011)\end{array}$ & $\begin{array}{c}0.008 \\
(0.011)\end{array}$ & $\begin{array}{l}-0.002 \\
(0.011)\end{array}$ & $\begin{array}{l}0.006^{* * *} \\
(0.002)\end{array}$ & $\begin{array}{c}0.006^{* * *} \\
(0.002)\end{array}$ & $\begin{array}{c}0.005^{* * *} \\
(0.002)\end{array}$ \\
\hline Interrupted Time Series & $\begin{array}{c}0.033^{* *} \\
(0.002)\end{array}$ & $\begin{array}{c}0.013 \\
(0.003)\end{array}$ & $\begin{array}{c}-0.050 * * \\
(0.004)\end{array}$ & $\begin{array}{l}0.004^{*} \\
(0.002)\end{array}$ & $\begin{array}{c}0.002 \\
(0.003)\end{array}$ & $\begin{array}{c}0.003 \\
(0.004)\end{array}$ \\
\hline $\begin{array}{l}\text { Pre-policy mean } \\
\text { Number of Students }\end{array}$ & $\begin{array}{c}0.779 \\
960,830 \\
\end{array}$ & $\begin{array}{c}0.778 \\
848,629 \\
\end{array}$ & $\begin{array}{c}0.779 \\
727,776 \\
\end{array}$ & $\begin{array}{c}0.023 \\
960,830 \\
\end{array}$ & $\begin{array}{c}0.023 \\
848,629 \\
\end{array}$ & $\begin{array}{c}0.023 \\
727,776 \\
\end{array}$ \\
\hline
\end{tabular}

Notes: This table reports the coefficients and standard errors from difference-in-differences and interrupted time series models, where the outcomes of graduation or enrollment are measured five years after high school entry. Each coefficient-standard error pair is from a separate regression. Students with missing 8th grade test scores are excluded. All regressions include the full set of control variables shown in Table 1, including demographics, school characteristics, prior 4th and 8th grade test scores at both individual level and school level. Pre-policy mean reports the mean of each outcome in 2005-2007. Robust standard errors in parentheses are clustered by high school. * significant at $10 \%$ level. ** significant at $5 \%$ level. *** significant at $1 \%$ level. 
Table 8 - Impact of the MMC on High School Outcomes by Student 8th Grade Math Score Quintile, 2003-2010 Cohorts

\begin{tabular}{|c|c|c|c|c|c|c|}
\hline \multirow{2}{*}{ Outcome } & \multicolumn{5}{|c|}{ Student 8th Grade Math Score Quintile } & \multirow{2}{*}{$\begin{array}{c}\text { Diff: } \\
\text { Q1 - Q5 } \\
\end{array}$} \\
\hline & 1 (Low) & 2 & 3 & 4 & 5 (High) & \\
\hline \multicolumn{7}{|l|}{ Graduated within 5 years } \\
\hline All covariates, but no pre-policy trend & $\begin{array}{l}-0.010 \\
(0.015) \\
{[0.586]}\end{array}$ & $\begin{array}{l}-0.004 \\
(0.013) \\
{[0.726]}\end{array}$ & $\begin{array}{c}0.005 \\
(0.013) \\
{[0.809]}\end{array}$ & $\begin{array}{c}0.006 \\
(0.014) \\
{[0.870]}\end{array}$ & $\begin{array}{c}0.020 \\
(0.014) \\
{[0.918]}\end{array}$ & $\begin{array}{l}-0.029 * \\
(0.018)\end{array}$ \\
\hline All covariates, and pre-policy trend & $\begin{array}{l}-0.000 \\
(0.016)\end{array}$ & $\begin{array}{c}0.022 \\
(0.017)\end{array}$ & $\begin{array}{c}0.038^{* *} \\
(0.019)\end{array}$ & $\begin{array}{c}0.050^{* *} \\
(0.021)\end{array}$ & $\begin{array}{c}0.048 * * \\
(0.021)\end{array}$ & $\begin{array}{c}-0.049 * * \\
(0.021)\end{array}$ \\
\hline \multicolumn{7}{|l|}{ Still enrolled within 5 years } \\
\hline All covariates, but no pre-policy trend & $\begin{array}{c}0.017 * * * \\
(0.004) \\
{[0.057]}\end{array}$ & $\begin{array}{c}0.010 * * * \\
(0.003) \\
{[0.029]}\end{array}$ & $\begin{array}{c}0.003 \\
(0.003) \\
{[0.015]}\end{array}$ & $\begin{array}{c}0.001 \\
(0.002) \\
{[0.007]}\end{array}$ & $\begin{array}{c}0.001 \\
(0.001) \\
{[0.003]}\end{array}$ & $\begin{array}{c}0.016^{* * *} \\
(0.004)\end{array}$ \\
\hline All covariates, and pre-policy trend & $\begin{array}{c}0.013^{* *} \\
(0.006)\end{array}$ & $\begin{array}{c}0.005 \\
(0.004)\end{array}$ & $\begin{array}{c}-0.002 \\
(0.003)\end{array}$ & $\begin{array}{c}-0.001 \\
(0.002)\end{array}$ & $\begin{array}{c}0.000 \\
(0.002)\end{array}$ & $\begin{array}{c}0.013^{* *} \\
(0.006)\end{array}$ \\
\hline Number of Students & 207058 & 192876 & 186639 & 195378 & 178879 & 385,937 \\
\hline
\end{tabular}

Notes: This table reports the coefficients and standard errors from regressions identical to those shown in Column (1) of Table 7, but estimated separately for students in quintiles of 8th grade math achievement. Each coefficient-standard error pair is from a separate regression. Students for 2003-2010 cohorts with non-missing 8th grade test scores are included. The pre-policy mean of the outcomes is reported in square brackets. Robust standard errors in parentheses are clustered at high school level. ${ }^{*}$ significant at $10 \%$ level. ${ }^{* *}$ significant at $5 \%$ level. ${ }^{* * *}$ significant at $1 \%$ level. 


\begin{tabular}{|c|c|c|c|c|c|c|}
\hline & \multicolumn{6}{|c|}{ Outcome = log (Average Freshman Graduation Rate) } \\
\hline & \multicolumn{3}{|c|}{$\begin{array}{c}\text { States selected using synthetic } \\
\text { control method }\end{array}$} & \multicolumn{3}{|c|}{ All non-reform states } \\
\hline & $(1)$ & $(2)$ & $(3)$ & $(4)$ & $(5)$ & $(6)$ \\
\hline MMC Requirement & -0.045 & -0.045 & -0.053 & -0.073 & -0.086 & -0.031 \\
\hline RMSPE of control & 0.012 & & & & & \\
\hline No. of valid placebos & 29 & 29 & 29 & 29 & 29 & 29 \\
\hline Implied p-value from placebo test & 0.000 & 0.000 & 0.170 & 0.100 & 0.100 & 0.000 \\
\hline State and year fixed effects & Yes & Yes & Yes & Yes & Yes & Yes \\
\hline State-year covariates & No & Yes & Yes & No & Yes & Yes \\
\hline Prior trend & No & No & Yes & No & No & Yes \\
\hline Control states (weight) & \multicolumn{3}{|c|}{$\begin{array}{c}\text { Alabama (0.42), Alaska (0.12), } \\
\text { Connecticut }(0.28), \\
\text { Vermont }(0.18) .\end{array}$} & \multicolumn{3}{|c|}{$\begin{array}{c}\text { All } 29 \text { non-reform states listed in } \\
\text { Appendix Table 6, weighted } \\
\text { equally. }\end{array}$} \\
\hline
\end{tabular}

Notes: The AFGR is collected by the National Center of Education Statistics (NCES) and reported in the Common Core of Data. RMSPE = root mean squared prediction error. Synthetic control method described in Abadie et al. (2010). Covariates include all of the variables listed in Appendix Table 7. 
Appendix Figure 1: Impact of MMC on ACT scores (Quintile 1)

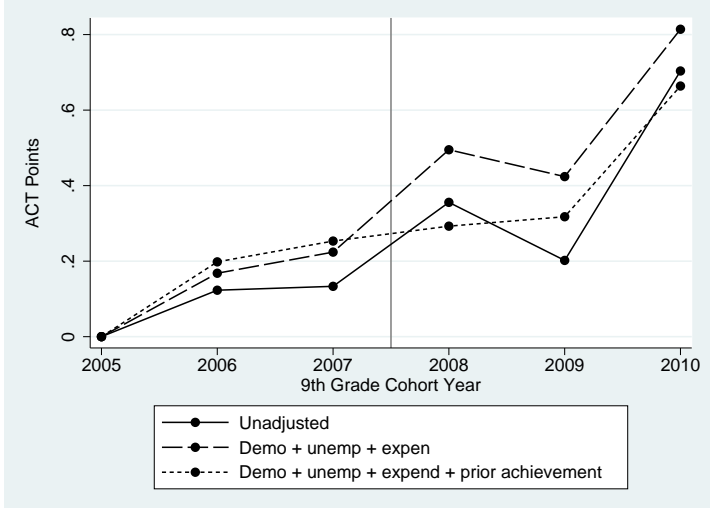

(a) Math

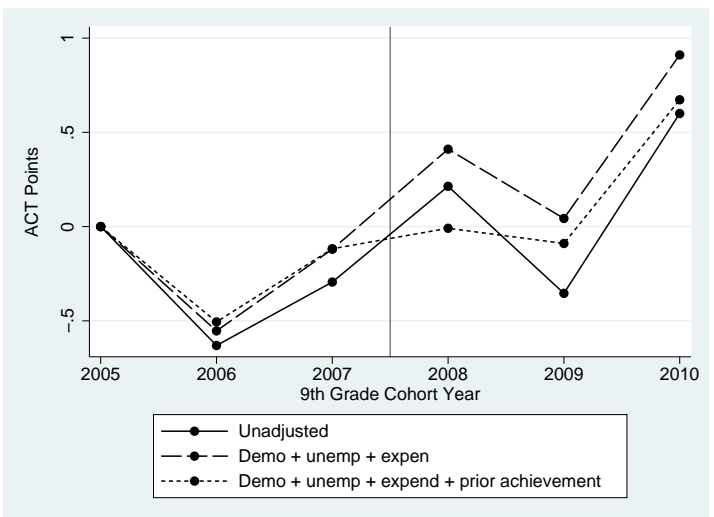

(c) Reading

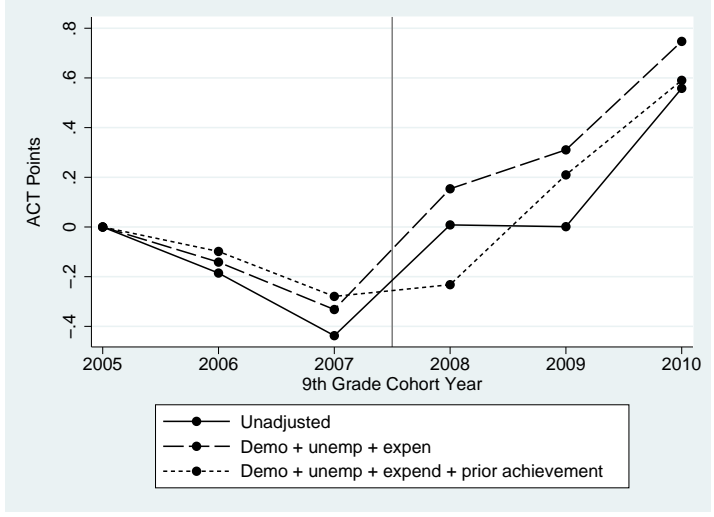

(b) Science

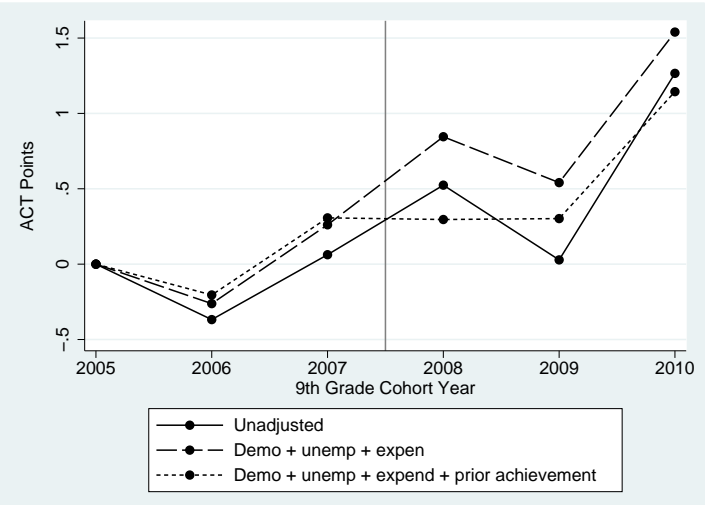

(d) English 
Appendix Figure 2: Impact of MMC on ACT scores (Quintile 2)

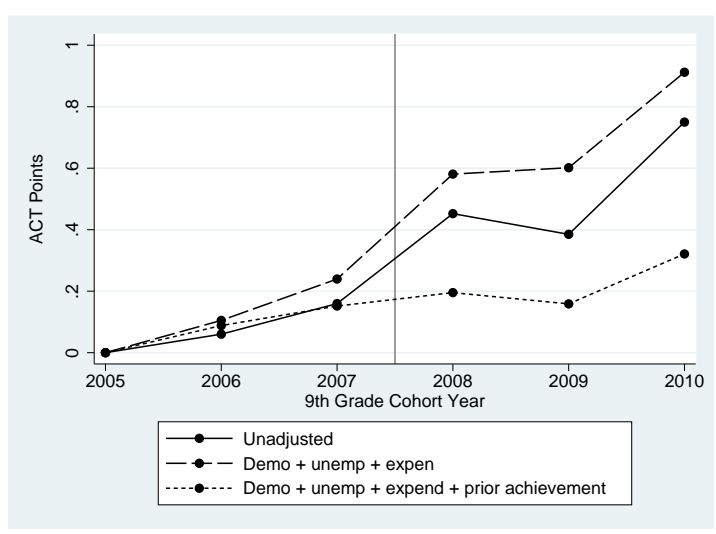

(a) Math

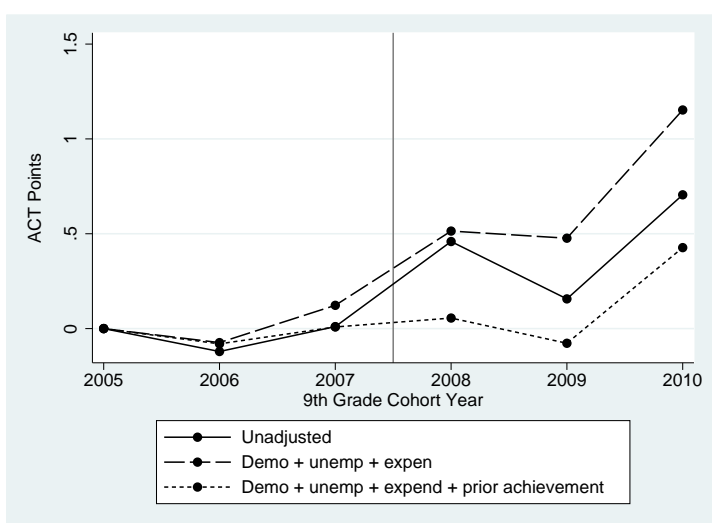

(c) Reading

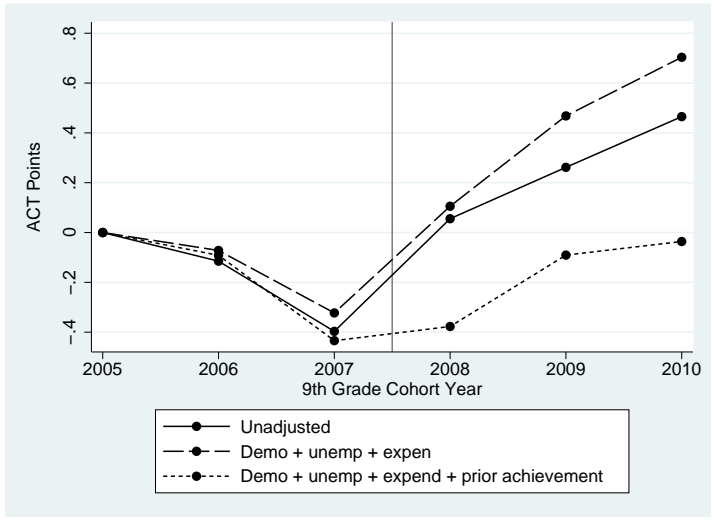

(b) Science

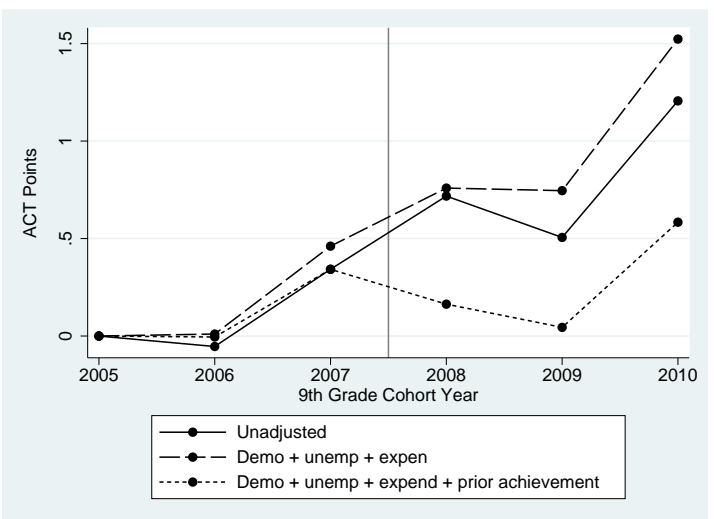

(d) English 
Appendix Figure 3: Impact of MMC on ACT scores (Quintile 3)

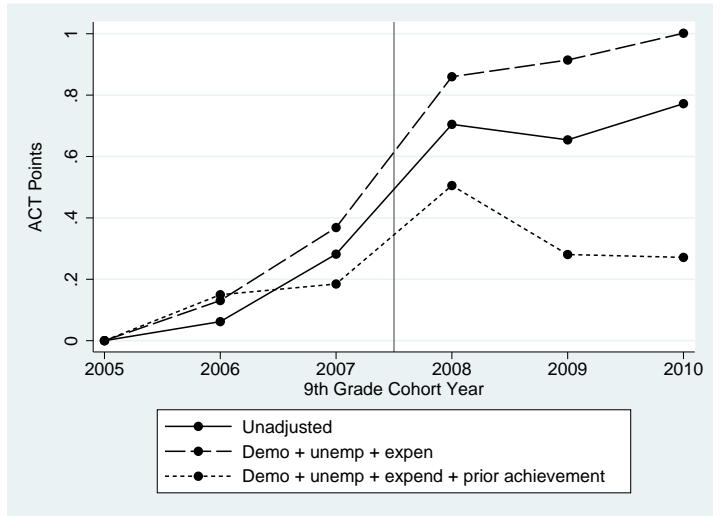

(a) Math

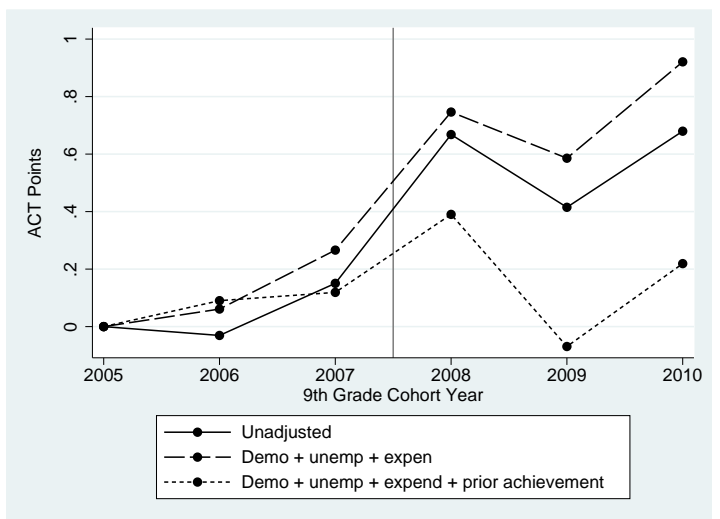

(c) Reading

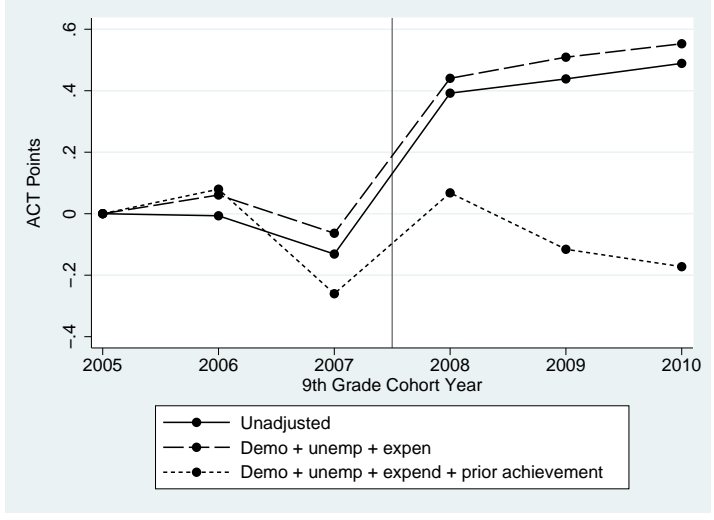

(b) Science

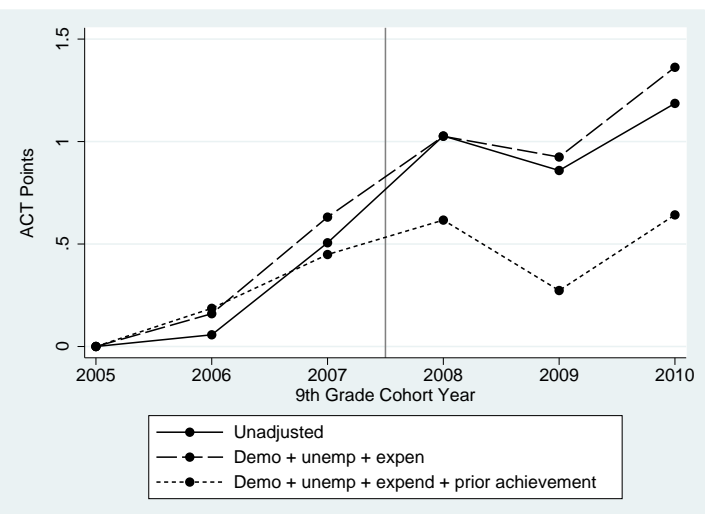

(d) English 
Appendix Figure 4: Impact of MMC on ACT scores (Quintile 4)

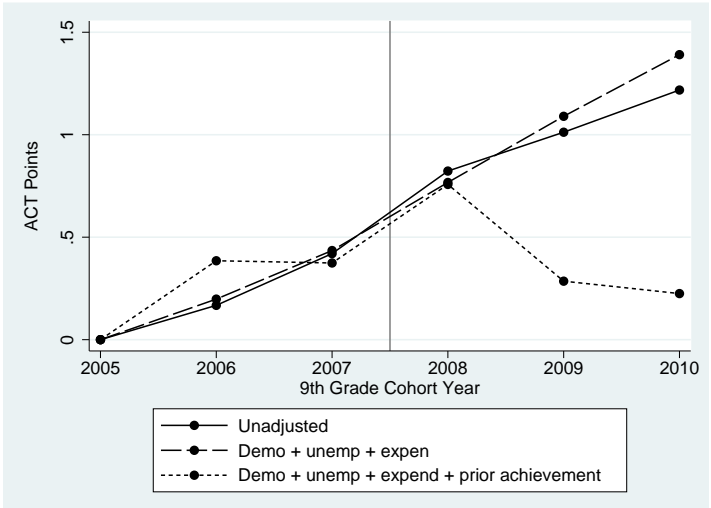

(a) Math

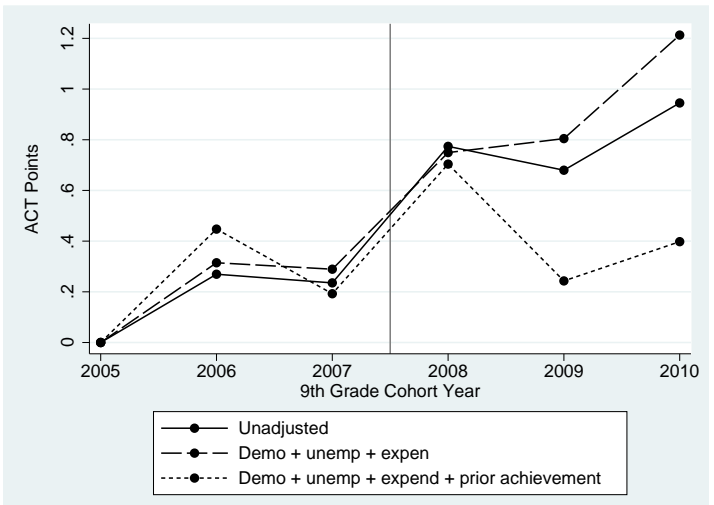

(c) Reading

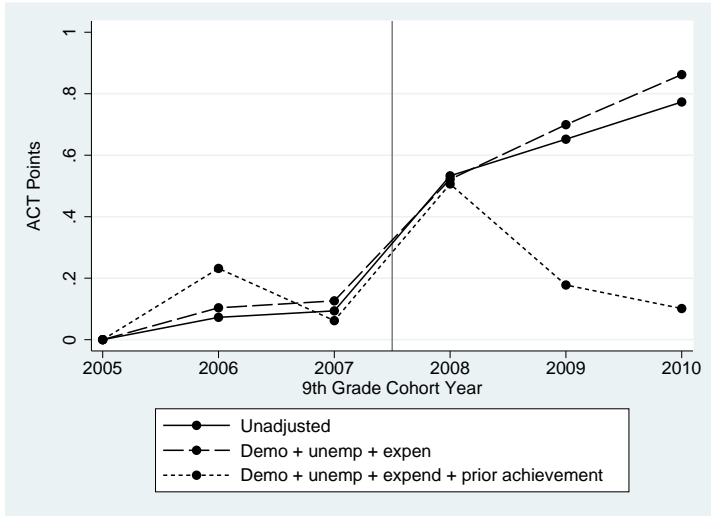

(b) Science

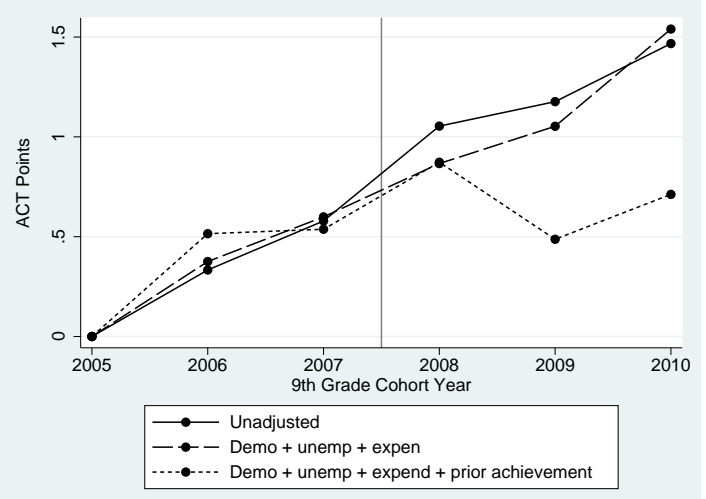

(d) English 
Appendix Figure 5: Impact of MMC on ACT scores (Quintile 5)

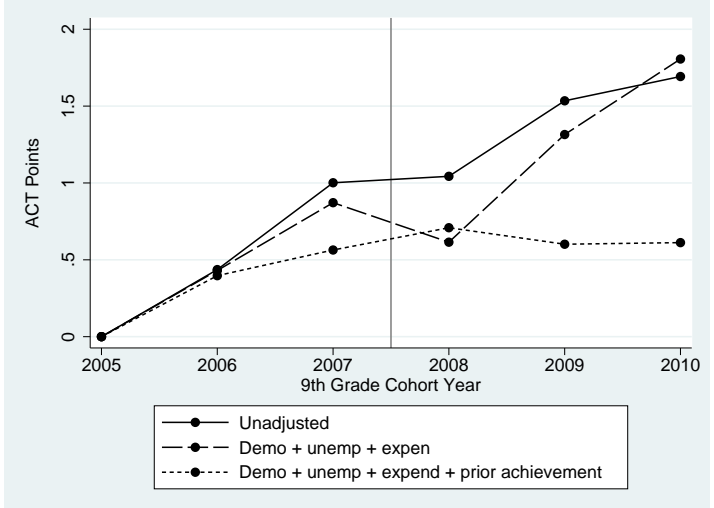

(a) Math

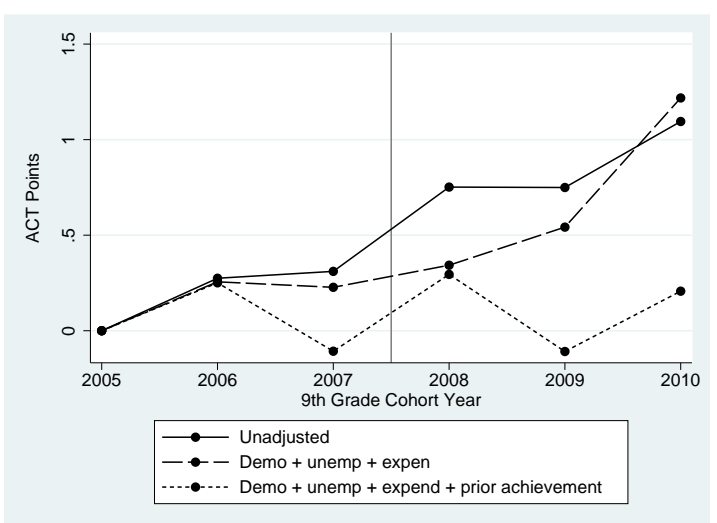

(c) Reading

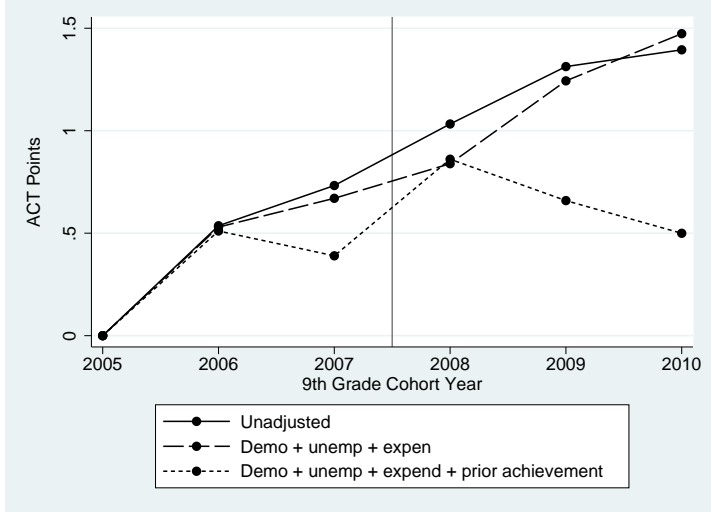

(b) Science

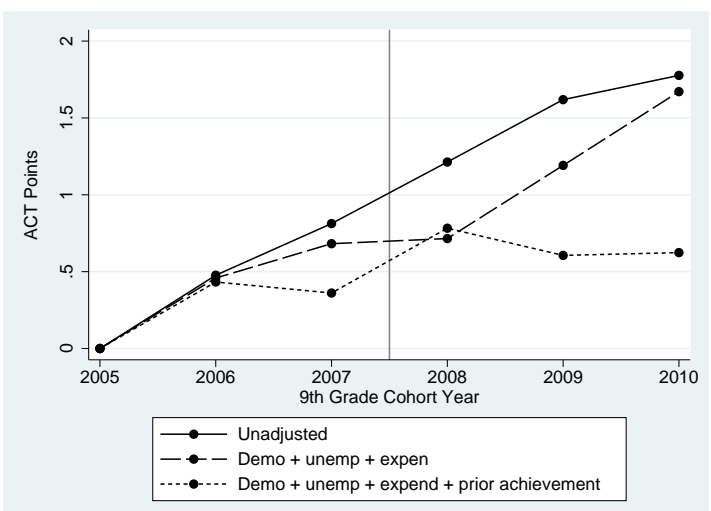

(d) English 
Appendix Figure 6: Impact of MMC on ACT math scores

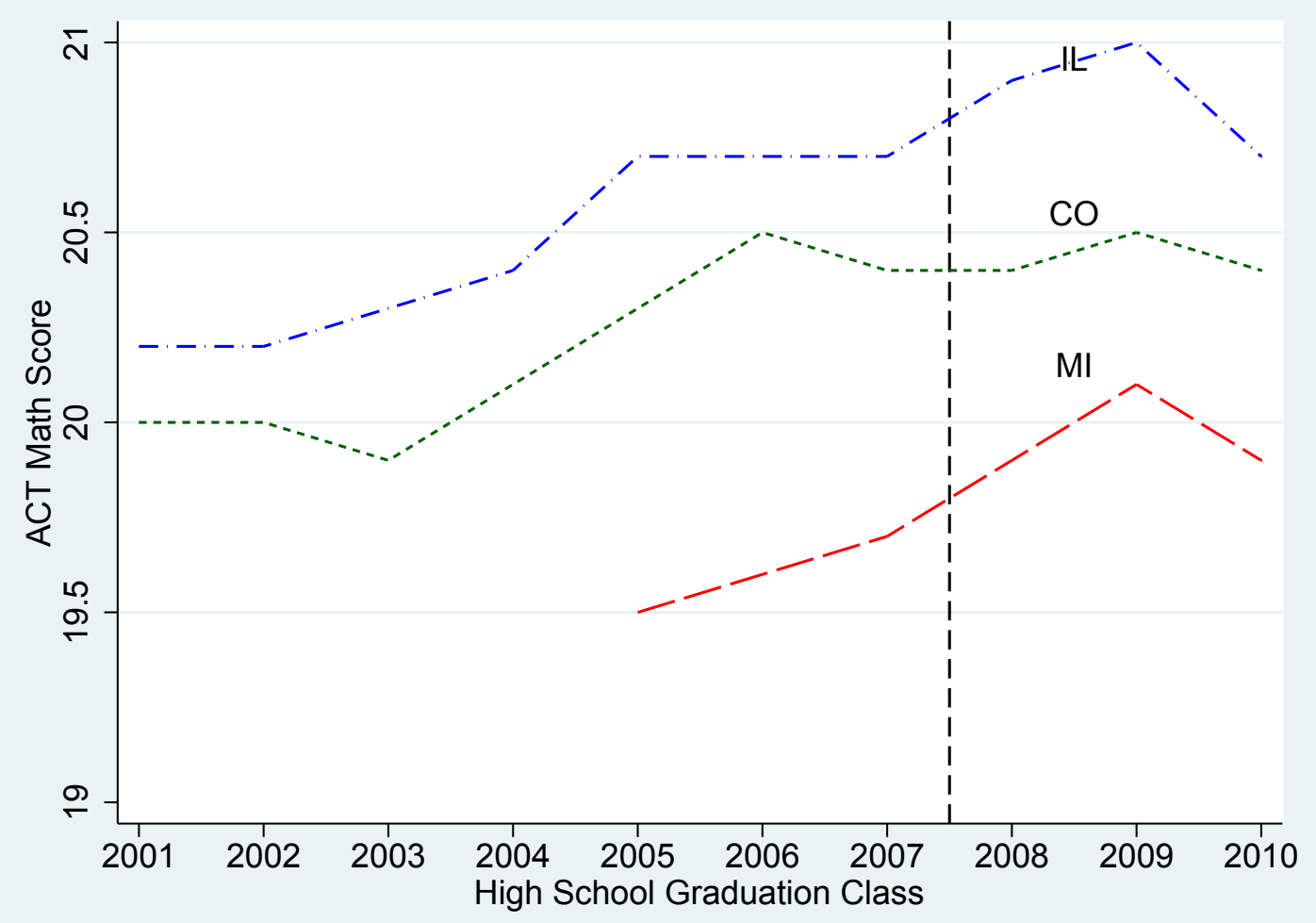

Appendix Figure 7: Impact of MMC on ACT English scores

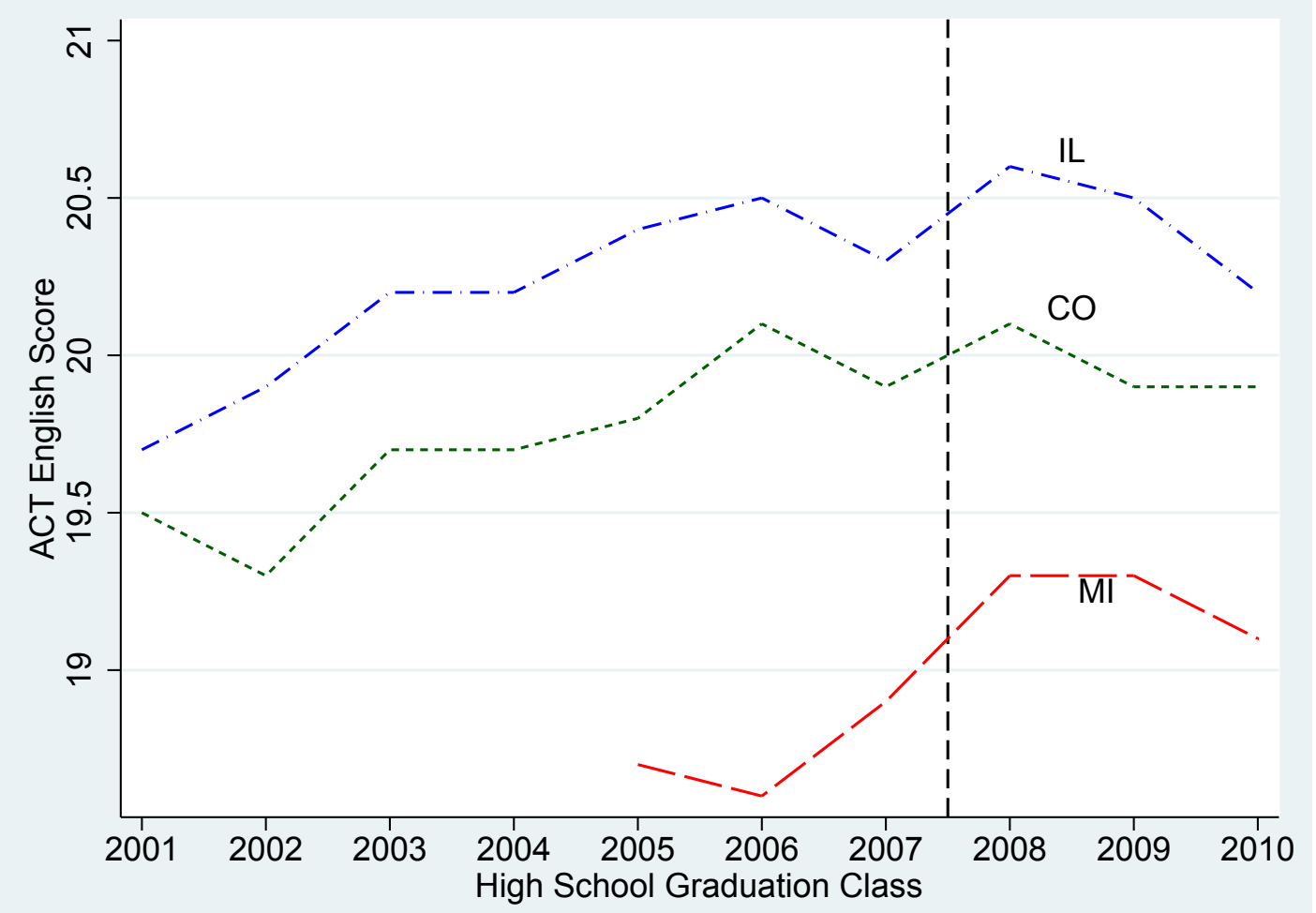


Appendix Figure 8: Impact of MMC on ACT science scores

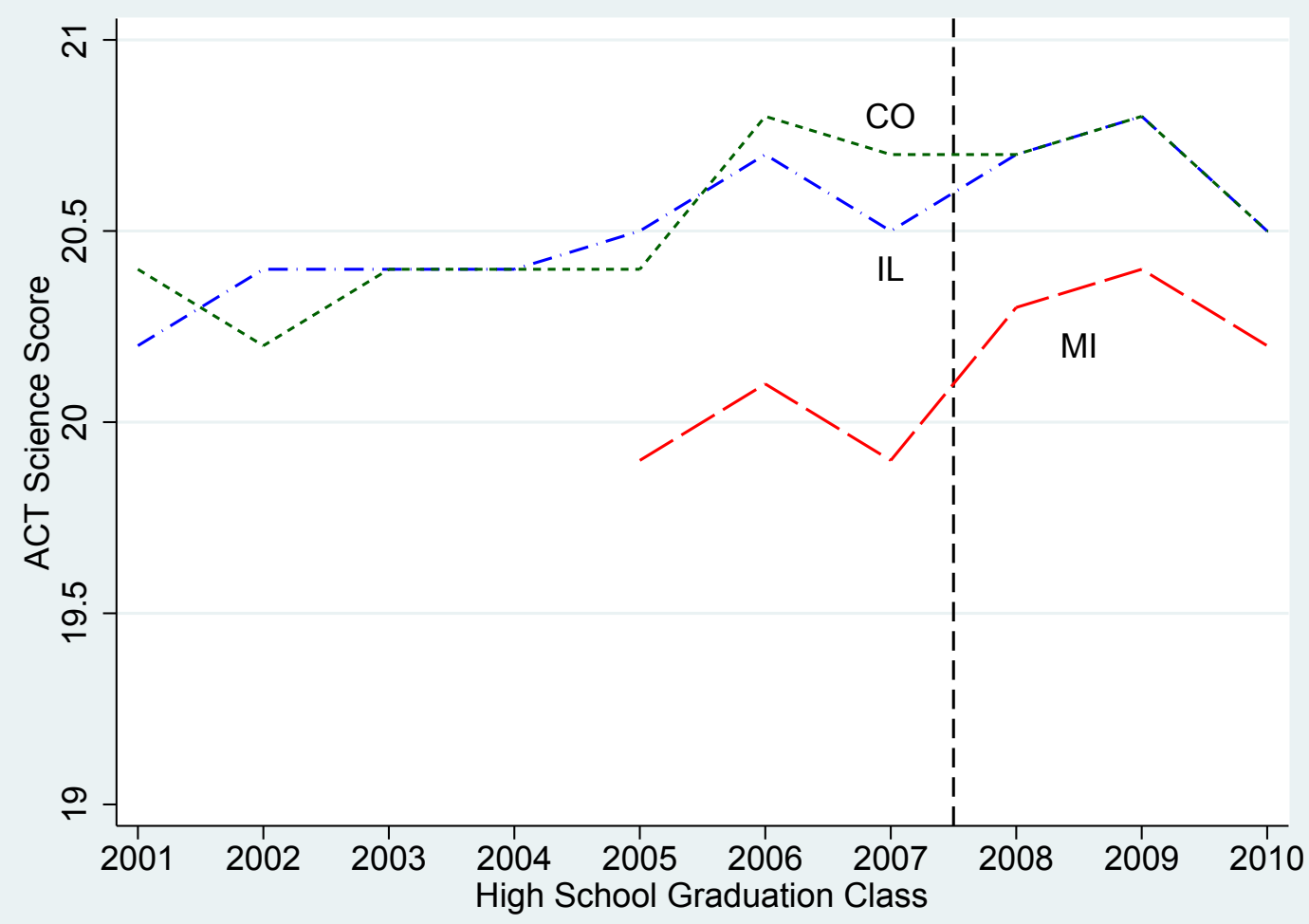

Appendix Figure 9: Impact of MMC on ACT reading scores

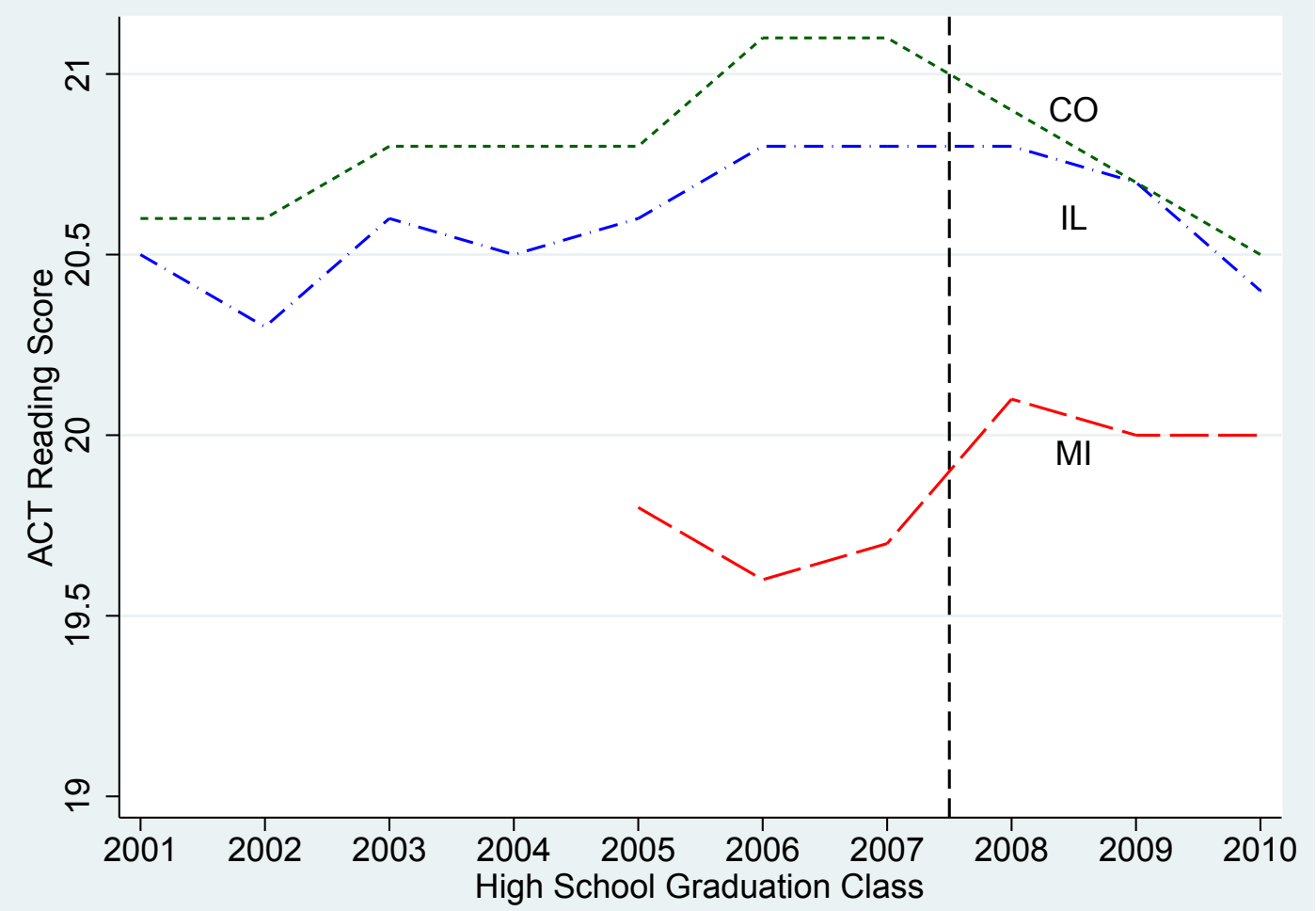




\begin{tabular}{|c|c|c|c|c|c|c|c|c|c|c|}
\hline \multirow{3}{*}{ Outcome } & \multicolumn{5}{|c|}{ Controls for Grade 4 Math Scores } & \multirow{2}{*}{\multicolumn{5}{|c|}{$\begin{array}{l}\text { Controls for Grade } 4 \text { \& } 8 \text { Math Scores } \\
\text { Student 8th Grade Math Score Quintile }\end{array}$}} \\
\hline & \multicolumn{5}{|c|}{ Student 8th Grade Math Score Quintile } & & & & & \\
\hline & 1 (Low) & 2 & 3 & 4 & 5 (High) & 1 (Low) & 2 & 3 & 4 & 5 (High) \\
\hline \multicolumn{11}{|l|}{ ACT composite score } \\
\hline All covariates, but no pre-policy trend & $\begin{array}{c}0.439 * * * \\
(0.059) \\
{[14.108]} \\
\{2.295\}\end{array}$ & $\begin{array}{c}0.473 * * * \\
(0.071) \\
{[16.060]} \\
\{2.696\}\end{array}$ & $\begin{array}{c}0.471 * * * \\
(0.081) \\
{[18.004]} \\
\{3.092\}\end{array}$ & $\begin{array}{c}0.525 * * * \\
(0.094) \\
{[20.481]} \\
\{3.459\}\end{array}$ & $\begin{array}{c}0.534 * * * \\
(0.115) \\
{[24.718]} \\
\{4.125\}\end{array}$ & $\begin{array}{c}0.361 * * * \\
(0.062) \\
{[14.108]} \\
\{2.295\}\end{array}$ & $\begin{array}{c}0.120 \\
(0.073) \\
{[16.060]} \\
\{2.696\}\end{array}$ & $\begin{array}{c}0.122 \\
(0.081) \\
{[18.004]} \\
\{3.092\}\end{array}$ & $\begin{array}{c}0.148 * \\
(0.086) \\
{[20.481]} \\
\{3.459\}\end{array}$ & $\begin{array}{c}0.196^{*} \\
(0.112) \\
{[24.718]} \\
\{4.125\}\end{array}$ \\
\hline All covariates, and pre-policy trend & $\begin{array}{c}0.409 * * * \\
(0.071)\end{array}$ & $\begin{array}{c}0.357 * * * \\
(0.084)\end{array}$ & $\begin{array}{l}0.228 * * \\
(0.094)\end{array}$ & $\begin{array}{l}0.213^{* *} \\
(0.105)\end{array}$ & $\begin{array}{c}0.013 \\
(0.126)\end{array}$ & $\begin{array}{c}0.354 * * * \\
(0.073)\end{array}$ & $\begin{array}{c}0.105 \\
(0.085)\end{array}$ & $\begin{array}{l}-0.035 \\
(0.093)\end{array}$ & $\begin{array}{c}-0.261 * * * \\
(0.101)\end{array}$ & $\begin{array}{l}-0.239 * \\
(0.129)\end{array}$ \\
\hline Number of Students & 112,294 & 119,788 & 124,796 & 137,931 & 129,507 & 112,294 & 119,788 & 124,796 & 137,931 & 129,507 \\
\hline \multicolumn{11}{|l|}{ ACT math score } \\
\hline All covariates, and pre-policy trend & $\begin{array}{l}-0.076 \\
(0.052)\end{array}$ & $\begin{array}{l}0.125^{*} \\
(0.071)\end{array}$ & $\begin{array}{l}0.228 * * \\
(0.090)\end{array}$ & $\begin{array}{c}0.193 \\
(0.121)\end{array}$ & $\begin{array}{l}-0.260 * \\
(0.146)\end{array}$ & $\begin{array}{c}-0.119 * * \\
(0.055)\end{array}$ & $\begin{array}{l}-0.084 \\
(0.074)\end{array}$ & $\begin{array}{l}-0.047 \\
(0.090)\end{array}$ & $\begin{array}{c}-0.428 * * * \\
(0.113)\end{array}$ & $\begin{array}{c}-0.562 * * * \\
(0.147)\end{array}$ \\
\hline Number of Students & 112,429 & 119,861 & 124,850 & 137,965 & 129,525 & 112,429 & 119,861 & 124,850 & 137,965 & 129,525 \\
\hline \multicolumn{11}{|l|}{ ACT Science Score } \\
\hline All covariates, but no pre-policy trend & $\begin{array}{c}0.445 * * * \\
(0.080) \\
{[14.939]} \\
\{3.307\}\end{array}$ & $\begin{array}{c}0.529 * * * \\
(0.096) \\
{[16.884]} \\
\{3.459\}\end{array}$ & $\begin{array}{c}0.458 * * * \\
(0.088) \\
{[18.758]} \\
\{3.525\}\end{array}$ & $\begin{array}{c}0.492 * * * \\
(0.098) \\
{[20.940]} \\
\{3.597\}\end{array}$ & $\begin{array}{c}0.567 * * * \\
(0.123) \\
{[24.574]} \\
\{4.150\}\end{array}$ & $\begin{array}{c}0.391 * * * \\
(0.081) \\
{[14.939]} \\
\{3.307\}\end{array}$ & $\begin{array}{c}0.170 * \\
(0.096) \\
{[16.884]} \\
\{3.459\}\end{array}$ & $\begin{array}{c}0.105 \\
(0.090) \\
{[18.758]} \\
\{3.525\}\end{array}$ & $\begin{array}{c}0.168 * \\
(0.096) \\
{[20.940]} \\
\{3.597\}\end{array}$ & $\begin{array}{c}0.249 * * \\
(0.122) \\
{[24.574]} \\
\{4.150\}\end{array}$ \\
\hline Number of Students & 112,312 & 119,799 & 124,800 & 137,934 & 129,509 & 112,312 & 119,799 & 124,800 & 137,934 & 129,509 \\
\hline \multicolumn{11}{|l|}{ ACT Reading Score } \\
\hline All covariates, but no pre-policy trend & $\begin{array}{c}0.480 * * * \\
(0.078)\end{array}$ & $\begin{array}{c}0.469 * * * \\
(0.096)\end{array}$ & $\begin{array}{c}0.397 * * * \\
(0.110)\end{array}$ & $\begin{array}{c}0.547 * * * \\
(0.123)\end{array}$ & $\begin{array}{c}0.428 * * * \\
(0.132)\end{array}$ & $\begin{array}{c}0.409 * * * \\
(0.084)\end{array}$ & $\begin{array}{c}0.147 \\
(0.100)\end{array}$ & $\begin{array}{c}0.072 \\
(0.116)\end{array}$ & $\begin{array}{l}0.210^{*} \\
(0.122)\end{array}$ & $\begin{array}{c}0.152 \\
(0.139)\end{array}$ \\
\hline
\end{tabular}




\begin{tabular}{|c|c|c|c|c|c|c|c|c|c|c|}
\hline & $\begin{array}{c}{[14.140]} \\
\{3.413\}\end{array}$ & $\begin{array}{c}{[16.153]} \\
\{4.071\}\end{array}$ & $\begin{array}{c}{[18.106]} \\
\{4.627\}\end{array}$ & $\begin{array}{c}{[20.528]} \\
\{5.093\}\end{array}$ & $\begin{array}{c}{[24.587]} \\
\{5.577\}\end{array}$ & $\begin{array}{c}{[14.140]} \\
\{3.413\}\end{array}$ & $\begin{array}{c}{[16.153]} \\
\{4.071\}\end{array}$ & $\begin{array}{c}{[18.106]} \\
\{4.627\}\end{array}$ & $\begin{array}{c}{[20.528]} \\
\{5.093\}\end{array}$ & $\begin{array}{c}{[24.587]} \\
\{5.577\}\end{array}$ \\
\hline All covariates, and pre-policy trend & $\begin{array}{c}0.705^{* * *} \\
(0.099)\end{array}$ & $\begin{array}{c}0.382 * * * \\
(0.115)\end{array}$ & $\begin{array}{c}0.166 \\
(0.132)\end{array}$ & $\begin{array}{c}0.307^{* *} \\
(0.146)\end{array}$ & $\begin{array}{c}0.338 * * \\
(0.161)\end{array}$ & $\begin{array}{c}0.660 * * * \\
(0.104)\end{array}$ & $\begin{array}{c}0.154 \\
(0.117)\end{array}$ & $\begin{array}{c}-0.074 \\
(0.135)\end{array}$ & $\begin{array}{l}-0.119 \\
(0.149)\end{array}$ & $\begin{array}{c}0.145 \\
(0.169)\end{array}$ \\
\hline Number of Students & 112,368 & 119,838 & 124,823 & 137,949 & 129,516 & 112,368 & 119,838 & 124,823 & 137,949 & 129,516 \\
\hline \multicolumn{11}{|l|}{ ACT English Score } \\
\hline All covariates, but no pre-policy trend & $\begin{array}{c}0.599 * * * \\
(0.111) \\
{[12.079]} \\
\{3.569\}\end{array}$ & $\begin{array}{c}0.449 * * * \\
(0.104) \\
{[14.652]} \\
\{4.025\}\end{array}$ & $\begin{array}{c}0.488 * * * \\
(0.126) \\
{[16.946]} \\
\{4.337\}\end{array}$ & $\begin{array}{c}0.518 * * * \\
(0.123) \\
{[19.642]} \\
\{4.589\}\end{array}$ & $\begin{array}{c}0.640 * * * \\
(0.145) \\
{[24.066]} \\
\{5.168\}\end{array}$ & $\begin{array}{c}0.449 * * * \\
(0.113) \\
{[12.079]} \\
\{3.569\}\end{array}$ & $\begin{array}{c}0.015 \\
(0.110) \\
{[14.652]} \\
\{4.025\}\end{array}$ & $\begin{array}{c}0.137 \\
(0.126) \\
{[16.946]} \\
\{4.337\}\end{array}$ & $\begin{array}{c}0.175 \\
(0.118) \\
{[19.642]} \\
\{4.589\}\end{array}$ & $\begin{array}{c}0.288 * * \\
(0.143) \\
{[24.066]} \\
\{5.168\}\end{array}$ \\
\hline All covariates, and pre-policy trend & $\begin{array}{c}0.265 * * \\
(0.123)\end{array}$ & $\begin{array}{c}-0.041 \\
(0.121)\end{array}$ & $\begin{array}{l}-0.113 \\
(0.136)\end{array}$ & $\begin{array}{c}-0.063 \\
(0.138)\end{array}$ & $\begin{array}{c}0.047 \\
(0.162)\end{array}$ & $\begin{array}{c}0.154 \\
(0.124)\end{array}$ & $\begin{array}{c}-0.346^{* * *} \\
(0.126)\end{array}$ & $\begin{array}{c}-0.367 * * * \\
(0.136)\end{array}$ & $\begin{array}{c}-0.512 * * * \\
(0.138)\end{array}$ & $\begin{array}{c}-0.217 \\
(0.168)\end{array}$ \\
\hline Number of Students & 112,465 & 119,868 & 124,865 & 137,970 & 129,528 & 112,465 & 119,868 & 124,865 & 137,970 & 129,528 \\
\hline \multicolumn{11}{|l|}{ Took ACT Math } \\
\hline All covariates, but no pre-policy trend & $\begin{array}{c}-0.001 \\
(0.010) \\
{[0.675]} \\
\{0.468\}\end{array}$ & $\begin{array}{c}-0.001 \\
(0.008) \\
{[0.812]} \\
\{0.391\}\end{array}$ & $\begin{array}{l}-0.003 \\
(0.007) \\
{[0.879]} \\
\{0.326\}\end{array}$ & $\begin{array}{l}-0.010^{*} \\
(0.005) \\
{[0.925]} \\
\{0.264\}\end{array}$ & $\begin{array}{c}-0.004 \\
(0.005) \\
{[0.955]} \\
\{0.207\}\end{array}$ & $\begin{array}{c}-0.014 \\
(0.011) \\
{[0.675]} \\
\{0.468\}\end{array}$ & $\begin{array}{c}-0.014 * \\
(0.008) \\
{[0.812]} \\
\{0.391\}\end{array}$ & $\begin{array}{l}-0.011 \\
(0.007) \\
{[0.879]} \\
\{0.326\}\end{array}$ & $\begin{array}{c}-0.011^{*} \\
(0.006) \\
{[0.925]} \\
\{0.264\}\end{array}$ & $\begin{array}{c}-0.003 \\
(0.005) \\
{[0.955]} \\
\{0.207\}\end{array}$ \\
\hline All covariates, and pre-policy trend & $\begin{array}{c}-0.037 * * * \\
(0.011)\end{array}$ & $\begin{array}{c}-0.019 * * \\
(0.010)\end{array}$ & $\begin{array}{c}-0.018 * * \\
(0.008)\end{array}$ & $\begin{array}{c}-0.017 * * \\
(0.007)\end{array}$ & $\begin{array}{c}-0.003 \\
(0.006)\end{array}$ & $\begin{array}{c}-0.048^{* * *} \\
(0.012)\end{array}$ & $\begin{array}{c}-0.028 * * * \\
(0.010)\end{array}$ & $\begin{array}{c}-0.024 * * * \\
(0.009)\end{array}$ & $\begin{array}{c}-0.018 * * \\
(0.007)\end{array}$ & $\begin{array}{c}-0.002 \\
(0.006)\end{array}$ \\
\hline Number of Students & 159,770 & 144,618 & 140,088 & 148,056 & 135,244 & 159,770 & 144,618 & 140,088 & 148,056 & 135,244 \\
\hline
\end{tabular}

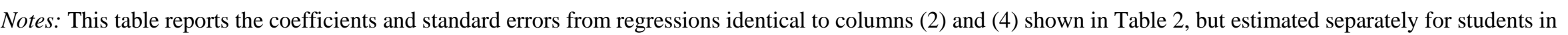

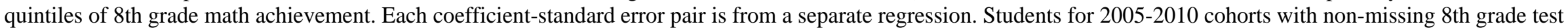

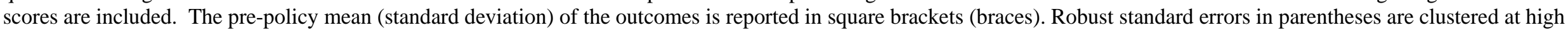
school level. * significant at $10 \%$ level. $* *$ significant at $5 \%$ level. ${ }^{* * *}$ significant at $1 \%$ level. 
Appendix Table 2 - Impact of the MMC on ACT Outcomes by Student 8th Grade Math Score Quintile

\begin{tabular}{|c|c|c|c|c|c|c|c|c|c|c|}
\hline \multirow{2}{*}{ Outcome } & \multicolumn{5}{|c|}{ Controls for Grade 4 Math Scores } & \multicolumn{5}{|c|}{$\begin{array}{l}\text { Controls for Grade } 4 \text { \& } 8 \text { Math Scores } \\
\text { Student 8th Grade Math Score Quintile }\end{array}$} \\
\hline & 1 (Low) & 2 & 3 & 4 & 5 (High) & 1 (Low) & 2 & 3 & 4 & 5 (High) \\
\hline \multicolumn{11}{|l|}{ ACT composite IL percentile } \\
\hline All covariates, but no pre-policy trend & $\begin{array}{c}2.848 * * * \\
(0.322) \\
{[14.679]} \\
\{13.133\}\end{array}$ & $\begin{array}{c}2.765 * * * \\
(0.443) \\
{[26.281]} \\
\{17.064\}\end{array}$ & $\begin{array}{c}2.297 * * * \\
(0.504) \\
{[38.784]} \\
\{19.707\}\end{array}$ & $\begin{array}{c}2.098 * * * \\
(0.543) \\
{[54.095]} \\
\{20.666\}\end{array}$ & $\begin{array}{c}1.107 * * \\
(0.487) \\
{[75.298]} \\
\{18.610\}\end{array}$ & $\begin{array}{c}2.615^{* * *} \\
(0.344) \\
{[14.679]} \\
\{13.133\}\end{array}$ & $\begin{array}{c}0.608 \\
(0.456) \\
{[26.281]} \\
\{17.064\}\end{array}$ & $\begin{array}{c}0.069 \\
(0.513) \\
{[38.784]} \\
\{19.707\}\end{array}$ & $\begin{array}{c}-0.082 \\
(0.510) \\
{[54.095]} \\
\{20.666\}\end{array}$ & $\begin{array}{c}0.284 \\
(0.471) \\
{[75.298]} \\
\{18.610\}\end{array}$ \\
\hline All covariates, and pre-policy trend & $\begin{array}{c}4.981 * * * \\
(0.394)\end{array}$ & $\begin{array}{c}4.217 * * * \\
(0.521)\end{array}$ & $\begin{array}{c}2.903 * * * \\
(0.593)\end{array}$ & $\begin{array}{c}2.187 * * * \\
(0.622)\end{array}$ & $\begin{array}{c}0.511 \\
(0.568)\end{array}$ & $\begin{array}{c}4.838 * * * \\
(0.411)\end{array}$ & $\begin{array}{c}2.674 * * * \\
(0.529)\end{array}$ & $\begin{array}{l}1.223 * * \\
(0.584)\end{array}$ & $\begin{array}{l}-0.504 \\
(0.596)\end{array}$ & $\begin{array}{c}0.015 \\
(0.558)\end{array}$ \\
\hline Number of Students & 112,294 & 119,788 & 124,796 & 137,931 & 129,507 & 112,294 & 119,788 & 124,796 & 137,931 & 129,507 \\
\hline \multicolumn{11}{|l|}{ ACT math IL percentile } \\
\hline All covariates, but no pre-policy trend & $\begin{array}{c}1.074 * * * \\
(0.357) \\
{[17.691]} \\
\{13.283\}\end{array}$ & $\begin{array}{c}1.664 * * * \\
(0.442) \\
{[28.149]} \\
\{15.867\}\end{array}$ & $\begin{array}{c}1.922 * * * \\
(0.471) \\
{[40.091]} \\
\{17.827\}\end{array}$ & $\begin{array}{c}1.787 * * * \\
(0.552) \\
{[55.319]} \\
\{18.770\}\end{array}$ & $\begin{array}{c}1.214 * * \\
(0.523) \\
{[76.676]} \\
\{17.209\}\end{array}$ & $\begin{array}{c}0.719 * \\
(0.386) \\
{[17.691]} \\
\{13.283\}\end{array}$ & $\begin{array}{c}-0.640 \\
(0.461) \\
{[28.149]} \\
\{15.867\}\end{array}$ & $\begin{array}{c}-0.386 \\
(0.469) \\
{[40.091]} \\
\{17.827\}\end{array}$ & $\begin{array}{c}-0.804 \\
(0.506) \\
{[55.319]} \\
\{18.770\}\end{array}$ & $\begin{array}{c}0.411 \\
(0.501) \\
{[76.676]} \\
\{17.209\}\end{array}$ \\
\hline All covariates, and pre-policy trend & $\begin{array}{c}0.275 \\
(0.402)\end{array}$ & $\begin{array}{l}1.345^{* *} \\
(0.524)\end{array}$ & $\begin{array}{l}1.945 * * * \\
(0.567)\end{array}$ & $\begin{array}{c}2.145^{* * * *} \\
(0.635)\end{array}$ & $\begin{array}{c}0.856 \\
(0.590)\end{array}$ & $\begin{array}{l}-0.025 \\
(0.426)\end{array}$ & $\begin{array}{l}-0.324 \\
(0.544)\end{array}$ & $\begin{array}{c}0.193 \\
(0.564)\end{array}$ & $\begin{array}{l}-0.999 * \\
(0.590)\end{array}$ & $\begin{array}{c}0.399 \\
(0.569)\end{array}$ \\
\hline Number of Students & 112,429 & 119,861 & 124,850 & 137,965 & 129,525 & 112,429 & 119,861 & 124,850 & 137,965 & 129,525 \\
\hline \multicolumn{11}{|l|}{ ACT Science IL percentile } \\
\hline All covariates, but no pre-policy trend & $\begin{array}{c}2.744 * * * \\
(0.420) \\
{[20.204]} \\
\{16.821\}\end{array}$ & $\begin{array}{c}3.188 * * * \\
(0.584) \\
{[31.156]} \\
\{20.513\}\end{array}$ & $\begin{array}{c}2.262 * * * \\
(0.567) \\
{[43.247]} \\
\{22.609\}\end{array}$ & $\begin{array}{c}1.675 * * * \\
(0.604) \\
{[57.572]} \\
\{22.907\}\end{array}$ & $\begin{array}{c}0.847 * \\
(0.512) \\
{[76.772]} \\
\{19.426\}\end{array}$ & $\begin{array}{c}2.722 * * * \\
(0.419) \\
{[20.204]} \\
\{16.821\}\end{array}$ & $\begin{array}{c}1.083 * \\
(0.587) \\
{[31.156]} \\
\{20.513\}\end{array}$ & $\begin{array}{c}-0.061 \\
(0.582) \\
{[43.247]} \\
\{22.609\}\end{array}$ & $\begin{array}{c}-0.368 \\
(0.598) \\
{[57.572]} \\
\{22.907\}\end{array}$ & $\begin{array}{c}0.085 \\
(0.488) \\
{[76.772]} \\
\{19.426\}\end{array}$ \\
\hline All covariates, and pre-policy trend & $\begin{array}{c}6.323 * * * \\
(0.491)\end{array}$ & $\begin{array}{l}7.321 * * * \\
(0.665)\end{array}$ & $\begin{array}{l}5.173 * * * \\
(0.667)\end{array}$ & $\begin{array}{c}3.240 * * * \\
(0.680)\end{array}$ & $\begin{array}{c}-0.725 \\
(0.584)\end{array}$ & $\begin{array}{c}6.349 * * * \\
(0.501)\end{array}$ & $\begin{array}{c}5.773 * * * \\
(0.675)\end{array}$ & $\begin{array}{c}3.378 * * * \\
(0.663)\end{array}$ & $\begin{array}{c}0.763 \\
(0.679)\end{array}$ & $\begin{array}{c}-1.203 * * \\
(0.571)\end{array}$ \\
\hline Number of Students & 112,312 & 119,799 & 124,800 & 137,934 & 129,509 & 112,312 & 119,799 & 124,800 & 137,934 & 129,509 \\
\hline \multicolumn{11}{|l|}{ ACT Reading IL percentile } \\
\hline All covariates, but no pre-policy trend & $\begin{array}{c}2.344 * * * \\
(0.398)\end{array}$ & $\begin{array}{c}2.211 * * * \\
(0.501)\end{array}$ & $\begin{array}{c}1.916 * * * \\
(0.561)\end{array}$ & $\begin{array}{c}2.463 * * * \\
(0.586)\end{array}$ & $\begin{array}{c}1.481^{* * *} \\
(0.532)\end{array}$ & $\begin{array}{c}2.071^{* * *} \\
(0.428)\end{array}$ & $\begin{array}{c}0.508 \\
(0.525)\end{array}$ & $\begin{array}{c}0.171 \\
(0.595)\end{array}$ & $\begin{array}{c}0.885 \\
(0.589)\end{array}$ & $\begin{array}{c}0.627 \\
(0.562)\end{array}$ \\
\hline
\end{tabular}




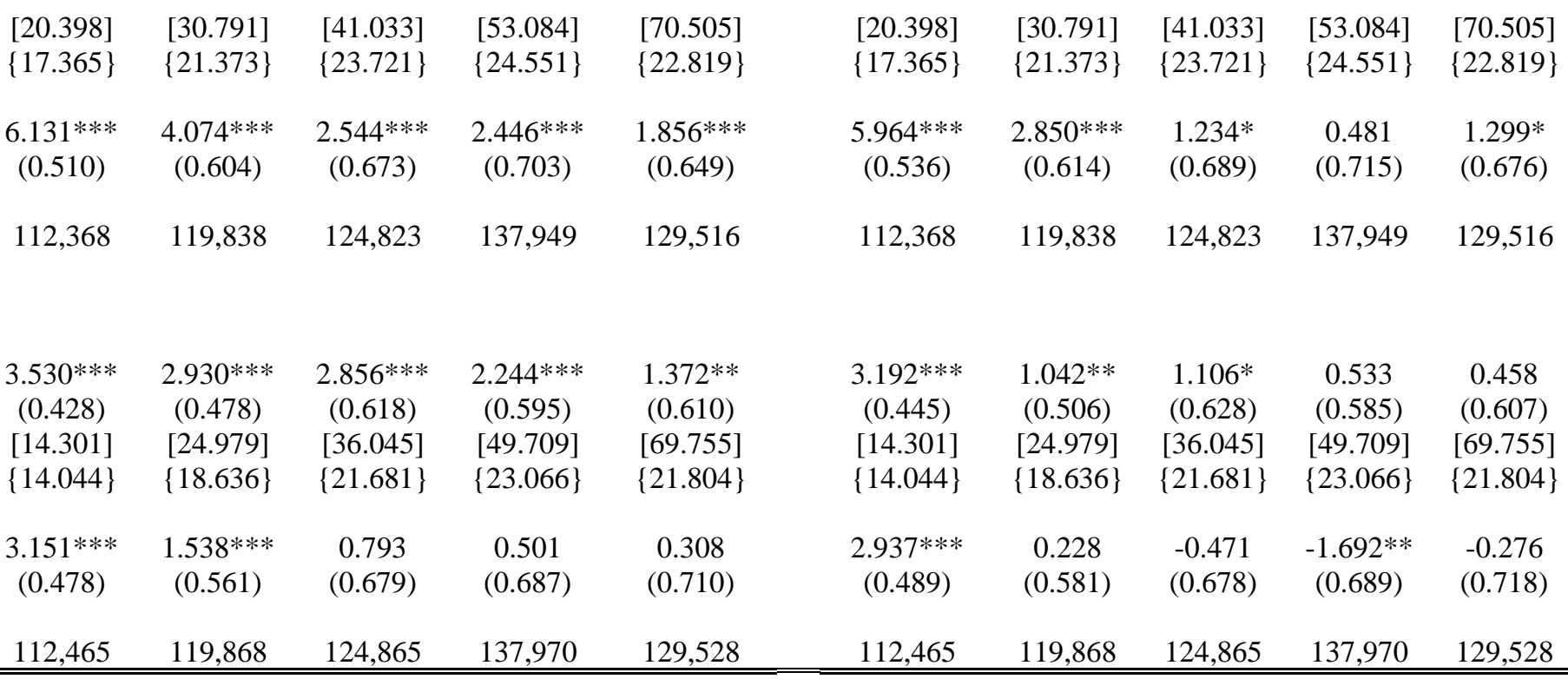

All covariates, and pre-policy trend

Number of Students

\section{ACT English IL percentile}

All covariates, but no pre-policy trend

All covariates, and pre-policy trend

Number of Students

$112,465 \quad 119,868$

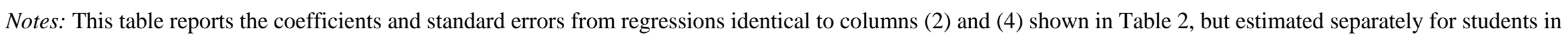

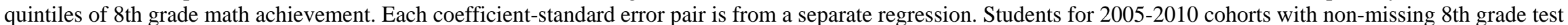

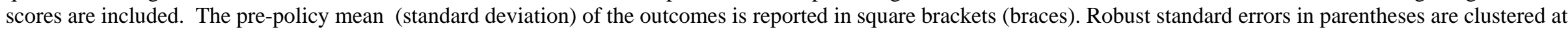
high school level. * significant at $10 \%$ level. ** significant at 5\% level. *** significant at $1 \%$ level. 


\begin{tabular}{|c|c|c|c|c|}
\hline & $\begin{array}{c}\text { Estimate from } \\
\text { primary } \\
\text { specification } \\
\text { (1) }\end{array}$ & $\begin{array}{c}\text { Analagous } \\
\text { estimate using } \\
10 \text { "tightening" } \\
\text { bins } \\
(2)\end{array}$ & (3) & (4) \\
\hline \multicolumn{5}{|c|}{ Dependent Variable $=$ ACT Composite Score } \\
\hline Estimate & $-0.1027^{*}$ & $-0.0979 * * *$ & $-0.1563 * * *$ & $-0.0480 * *$ \\
\hline Conventional s.e. & $(0.033)$ & $(0.007)$ & $(0.024)$ & $(0.023)$ \\
\hline S.E. clustered by high school & $(0.059)$ & $(0.017)$ & & \\
\hline Control Mean & 18.959 & 18.959 & 18.959 & 18.959 \\
\hline Number of Students & 617,241 & 617,241 & & \\
\hline \multicolumn{5}{|c|}{ Dependent Variable = ACT Math Score } \\
\hline Estimate & $-0.3434 * * *$ & $-0.2370 * * *$ & $-0.2305^{* * *}$ & $-0.2075^{* * *}$ \\
\hline Conventional s.e. & $(0.032)$ & $(0.007)$ & $(0.023)$ & $(0.023)$ \\
\hline S.E. clustered by high school & $(0.069)$ & $(0.019)$ & & \\
\hline Control Mean & 19.052 & 19.0522 & 19.0522 & 19.0522 \\
\hline Number of Students & 617,550 & 617,550 & & \\
\hline \multicolumn{5}{|c|}{ Dependent Variable = ACT Science Score } \\
\hline Estimate & $0.1911 * * *$ & $0.4774 * * *$ & $0.2668 * * *$ & $0.6887 * * *$ \\
\hline Conventional s.e. & $(0.040)$ & $(0.009)$ & $(0.024)$ & $(0.023)$ \\
\hline S.E. clustered by high school & $(0.066)$ & $(0.019)$ & & \\
\hline Control Mean & 19.482 & 19.4818 & 19.4818 & 19.4818 \\
\hline Number of Students & 617,279 & 617279 & & \\
\hline \multicolumn{5}{|c|}{ Dependent Variable $=$ ACT Reading Score } \\
\hline Estimate & 0.0631 & -0.0127 & $-0.1561 * * *$ & $0.0975^{* * *}$ \\
\hline Conventional s.e. & $(0.051)$ & $(0.011)$ & $(0.026)$ & $(0.025)$ \\
\hline S.E. clustered by high school & $(0.075)$ & $(0.019)$ & & \\
\hline Control Mean & 18.985 & 18.9845 & 18.9845 & 18.9845 \\
\hline Number of Students & 617,415 & 617,415 & & \\
\hline \multicolumn{5}{|c|}{ Dependent Variable = ACT English Score } \\
\hline Estimate & $-0.3258 * * *$ & $-0.6794 * * *$ & $-0.4307 * * *$ & $-0.7973 * * *$ \\
\hline Conventional s.e. & $(0.047)$ & $(0.010)$ & $(0.030)$ & $(0.028)$ \\
\hline S.E. clustered by high school & $(0.087)$ & $(0.026)$ & & \\
\hline Control Mean & 17.803 & 17.8027 & 17.8027 & 17.8027 \\
\hline Number of Students & 617,616 & 617,616 & & \\
\hline
\end{tabular}

Notes: The sample for the analysis shown in this table is identical to the sample used to create the estimates in Table 2, with the exception that we exclude schools that did not exist before or after the introduction of the policy. See the text for more detail on the estimates in each column. 


\begin{tabular}{|c|c|c|c|c|c|}
\hline \multirow{2}{*}{ Outcome } & \multicolumn{5}{|c|}{ Student 8th Grade Math Score Quintile } \\
\hline & 1 (Low) & 2 & 3 & 4 & 5 (High) \\
\hline \multicolumn{6}{|l|}{ Graduated within 5 Years } \\
\hline All covariates, but no pre-policy trend & $\begin{array}{l}-0.020 \\
(0.015) \\
{[0.592]}\end{array}$ & $\begin{array}{l}-0.021 \\
(0.014) \\
{[0.728]}\end{array}$ & $\begin{array}{l}-0.002 \\
(0.014) \\
{[0.807]}\end{array}$ & $\begin{array}{l}-0.001 \\
(0.015) \\
{[0.869]}\end{array}$ & $\begin{array}{c}0.019 \\
(0.015) \\
{[0.918]}\end{array}$ \\
\hline All covariates, and pre-policy trend & $\begin{array}{c}-0.086 * * * \\
(0.027)\end{array}$ & $\begin{array}{c}-0.041 \\
(0.028)\end{array}$ & $\begin{array}{l}-0.055^{*} \\
(0.029)\end{array}$ & $\begin{array}{c}-0.063 * * \\
(0.026)\end{array}$ & $\begin{array}{l}-0.016 \\
(0.025)\end{array}$ \\
\hline \multicolumn{6}{|l|}{ Still Enrolled within 5 Years } \\
\hline All covariates, but no pre-policy trend & $\begin{array}{c}0.015 * * * \\
(0.005) \\
{[0.057]}\end{array}$ & $\begin{array}{c}0.011^{* * *} \\
(0.004) \\
{[0.029]}\end{array}$ & $\begin{array}{c}0.002 \\
(0.003) \\
{[0.016]}\end{array}$ & $\begin{array}{c}0.000 \\
(0.002) \\
{[0.008]}\end{array}$ & $\begin{array}{l}0.002 * \\
(0.001) \\
{[0.003]}\end{array}$ \\
\hline All covariates, and pre-policy trend & $\begin{array}{c}0.009 \\
(0.012)\end{array}$ & $\begin{array}{c}0.000 \\
(0.008)\end{array}$ & $\begin{array}{c}-0.002 \\
(0.006)\end{array}$ & $\begin{array}{c}0.004 \\
(0.004)\end{array}$ & $\begin{array}{c}0.001 \\
(0.003)\end{array}$ \\
\hline Number of Students & 159,770 & 144,618 & 140,088 & 148,056 & 135,244 \\
\hline
\end{tabular}

Notes: This table reports the coefficients and standard errors from regressions identical to those shown in Table 7, but estimated separately for students in quintiles of 8th grade math achievement. Each coefficient-standard error pair is from a separate regression. Students for 2005-2010 cohorts with non-missing 8th grade test scores are included. The pre-policy mean of the outcomes is reported in square brackets. Robust standard errors in parentheses are clustered at high school level. * significant at $10 \%$ level. ${ }^{* *}$ significant at $5 \%$ level. *** significant at $1 \%$ level. 


Outcome $\quad$ Student 8th Grade Math Score Quintile

\section{Dropout within 5 Years}

All covariates, but no pre-policy trend

All covariates, and pre-policy trend

Left MI Public Schools within 5 Years

All covariates, but no pre-policy trend

All covariates, and pre-policy trend

Unknown within 5 Years

All covariates, but no pre-policy trend

All covariates, and pre-policy trend

Other within 5 Years

All covariates, but no pre-policy trend

All covariates, and pre-policy trend

Number of Students

\section{Dropout within 4 Years}

All covariates, but no pre-policy trend

All covariates, and pre-policy trend

Left MI Public Schools within 4 Years

All covariates, but no pre-policy trend

All covariates, and pre-policy trend

\section{Unknown within 4 Years}

All covariates, but no pre-policy trend

All covariates, and pre-policy trend

1 (Low)

2

3

$0.020^{* *}$
$(0.009)$
$[0.083]$

$$
\begin{gathered}
0.007 \\
(0.015)
\end{gathered}
$$

$0.011^{*}$
$(0.006)$
$[0.050]$

$0.017 * * *$
$(0.005)$
$[0.031]$

$-0.005$

(0.011)

$$
0.003
$$

(0.009)

$-0.000$

(0.004)

[0.030]

0.006
$(0.004)$
$[0.026]$

0.001

(0.008)

$$
0.001
$$

(0.008)

-0.001
$(0.005)$
$[0.039]$

$-0.008^{*}$
$(0.004)$
$[0.023]$

$-0.001$

(0.011)

0.000

(0.009)

0.001

$(0.012)$

[0.125]

-0.015
$(0.012)$
$[0.097]$

$0.047^{*}$

(0.025)

$0.052^{* *}$

(0.026)

144,618

140,088

$0.011^{* * *}$
$(0.004)$
$[0.023]$

0.011

(0.007)

-0.004
$(0.009)$

(0.011)

$-0.005$

(0.004)

[0.034]

0.000

(0.004)

[0.029]

$-0.020 * *$

(0.009)

$-0.003$

(0.008)

$0.007^{*}$
$(0.004)$
$[0.026]$

0.002

(0.008)

$-0.004$

(0.004)

[0.025]

$-0.006 *$

(0.003)

[0.015]

$-0.006$

(0.009)

(0.011)
$-0.000$

(0.008)

$\begin{array}{cc}0.006^{* *} & 0.001 \\ (0.003) & (0.002) \\ {[0.018]} & {[0.007]} \\ & \\ 0.010 & 0.005 \\ (0.007) & (0.004)\end{array}$

$0.007^{* *}$

(0.004)

[0.023]

$0.007 * *$

(0.003)

[0.020]

0.003

(0.007)

0.006

(0.009)

$-0.002$

(0.003)

[0.013]

$-0.003$

(0.003)

[0.005]

$-0.003$

(0.007)

0.000

(0.005)

$-0.026 *$

(0.015)

[0.048]

$(0.013)$

[0.070]

0.003

$0.048^{* *}$

(0.023)

135,244

148,056

$0.006 * *$

$(0.002)$

[0.013]

$0.003^{* *}$

(0.001)

[0.005]

$0.009 *$

(0.005)

$0.009 * * *$

(0.003)

$0.009 * *$

$0.007^{* *}$

$(0.004)$

[0.022]

(0.003)

[0.020]

0.002

(0.007)

0.005

(0.009)
$-0.003$

(0.002)

[0.009]

$-0.003$

(0.006)
$-0.004 *$

(0.002)

[0.004]

0.001

(0.004) 
Other within 4 Years

All covariates, but no pre-policy trend $-0.001$

[0.131]

$-0.001$

(0.011)

[0.103]

$-0.015$

$-0.013$

$-0.027 *$

$[0.131$

$(0.012)$

(0.013)

$(0.015)$

[0.083]

[0.063]

[0.045]

All covariates, and pre-policy trend

$0.082 * * *$

$0.051^{* *}$

$0.057 * *$

$0.052^{* *}$

$-0.000$

$(0.022)$

(0.024)

(0.025)

(0.023)

(0.023)

Number of Students

159,770

144,618

140,088

148,056

135,244

Notes: This table reports the coefficients and standard errors from regressions identical to those shown in Table 7, but estimated separately for students in quintiles of 8th grade math achievement. Each coefficient-standard error pair is from a separate regression. Students for 2005-2010 cohorts with non-missing 8th grade test scores are included. Pre-policy means are in square brackets. Robust standard errors in parentheses are clustered at high school level. * significant at $10 \%$ level. ** significant at $5 \%$ level. *** significant at $1 \%$ level. 


\begin{tabular}{|c|c|c|c|c|c|c|c|c|}
\hline \multirow[b]{2}{*}{ State } & \multirow[b]{2}{*}{$\begin{array}{l}\text { Treat } \\
\text { State }\end{array}$} & \multicolumn{3}{|c|}{$\begin{array}{c}\frac{\text { Earliest high school graduating class to which }}{\text { the requirement applied }} \\
\text { the }\end{array}$} & \multicolumn{4}{|c|}{$\begin{array}{c}\frac{\# \text { of courses required for graduation (CGRs) for the }}{\text { class of } 2006 \text { (and 2012) }} \\
\text { (a) }\end{array}$} \\
\hline & & $\begin{array}{c}\text { Exit exam } \\
\text { with content } \\
\text { at or above } \\
\text { 9th grade } \\
\text { level }\end{array}$ & $\begin{array}{c}\text { At least } \\
\text { Algebra } 1 \\
\text { and } \\
\text { Geometry }\end{array}$ & $\begin{array}{c}\text { At least } 2 \text { of } \\
3 \text { core } \\
\text { science } \\
\text { courses (Bio, } \\
\text { Chem, Phy) }\end{array}$ & Math & English & Science & $\begin{array}{l}\text { Social } \\
\text { Studies }\end{array}$ \\
\hline AK & No & 2004 & & & $2(2)$ & $4(4)$ & $2(2)$ & $3(3)$ \\
\hline $\mathrm{AL}$ & No & 2001 & 2013 & & $4(4)$ & $4(4)$ & $4(4)$ & $4(4)$ \\
\hline CA & No & 2006 & & & $2(2)$ & $3(3)$ & $2(2)$ & $3(3)$ \\
\hline $\mathrm{CO}$ & No & & & & $0(0)$ & $0(0)$ & $0(0)$ & $0(.5)$ \\
\hline CT & No & & 2018 & 2018 & $3(3)$ & $4(4)$ & $2(2)$ & $3(3)$ \\
\hline FL & No & 1993 & 2014 & 2017 & $3(4)$ & $4(4)$ & $3(3)$ & $3(3)$ \\
\hline HI & No & & 2016 & 2016 & $3(3)$ & $4(4)$ & $3(3)$ & $4(4)$ \\
\hline IA & No & & & & $0(3)$ & $0(4)$ & $0(3)$ & $1.5(3)$ \\
\hline MA & No & 2003 & & & $0(0)$ & $0(0)$ & $0(0)$ & $1(1)$ \\
\hline MD & No & 2009 & & & $3(3)$ & $4(4)$ & $3(3)$ & $3(3)$ \\
\hline $\mathrm{ME}$ & No & & & & $2(2)$ & $4(4)$ & $2(2)$ & $2(2)$ \\
\hline MO & No & & & & $2(3)$ & $4(4)$ & $2(3)$ & $2(3)$ \\
\hline MT & No & & & & $2(2)$ & $4(4)$ & $2(2)$ & $2(2)$ \\
\hline NC & No & & 2013 & & $3(4)$ & $4(4)$ & $3(3)$ & $3(3)$ \\
\hline ND & No & & & & $2(3)$ & $4(4)$ & $2(3)$ & $3(3)$ \\
\hline $\mathrm{NE}$ & No & & 2018 & 2018 & $0(0)$ & $0(0)$ & $0(0)$ & $0(0)$ \\
\hline NH & No & & & & $2(2)^{b}$ & $4(4)$ & $2(2)$ & $2.5(2.5)$ \\
\hline NJ & No & 1985 & & & $3(3)$ & $4(4)$ & $3(3)$ & 3 (3) \\
\hline NM & No & & 2013 & 2013* & $3(3)^{c}$ & $4(4)$ & $2(3)$ & $3(3.5)$ \\
\hline $\mathrm{NV}$ & No & 2003 & & & $3(3)$ & $4(4)$ & $2(2)$ & $2(2)$ \\
\hline NY & No & 2000 & & & $3(3)$ & $4(4)$ & $3(3)$ & $4(4)$ \\
\hline $\mathrm{OH}$ & No & 2007 & 2014 & 2014 & $3(3)$ & $4(4)$ & $3(3)$ & $3(3)$ \\
\hline OR & No & 2012 & & & $2(3)$ & $3(4)$ & $2(2)$ & $3(3)$ \\
\hline PA & No & & & & $0(0)$ & $0(0)$ & $0(0)$ & $0(0)$ \\
\hline RI & No & & & & $2(4)$ & $4(4)$ & $2(3)$ & $2(3)$ \\
\hline SC & No & 2006 & & & $4(4)$ & $4(4)$ & $3(3)$ & $3(3)$ \\
\hline VA & No & 2004 & & & $3(3)$ & $4(4)$ & $3(3)$ & $3(3)$ \\
\hline VT & No & & & & $3(3)$ & $4(4)$ & $3(3)$ & $3(3)$ \\
\hline WA & No & 2008 & & & $2(2)$ & $3(3)$ & $2(2)$ & $2.5(2.5)$ \\
\hline WI & No & & & & $2(2)$ & $4(4)$ & $2(2)$ & $3(3)$ \\
\hline WY & No & & & & $3(3)$ & $4(4)$ & $3(3)$ & $3(3)$ \\
\hline AR & Yes & 2010 & 2009 & 2010 & $3(4)$ & $4(4)$ & $3(3)$ & 3 (3) \\
\hline AZ & Yes & 2006 & 2013 & 2012 & $2(2)^{\mathrm{a}}$ & $4(4)$ & $2(2)$ & $2.5(2.5)$ \\
\hline DC & Yes & & 2011 & 2011 & $3(4)$ & $4(4)$ & $3(4)$ & $3.5(4)$ \\
\hline $\mathrm{DE}$ & Yes & & 2011 & & $3(4)$ & $4(4)$ & $3(3)$ & $3(3)$ \\
\hline GA & Yes & 1995 & & 2012 & $3(4)$ & $4(4)$ & $3(3)$ & $3(3)$ \\
\hline ID & Yes & 2007 & 2014 & 2012 & $2(2)$ & $4(4.5)$ & $2(2)$ & $2.5(2.5)$ \\
\hline $\mathrm{IL}$ & Yes & & 2010 & & $2(3)$ & $3(3)$ & $1(2)$ & $2(2)$ \\
\hline IN & Yes & 2000 & 2011 & 2011 & $2(3)$ & $4(4)$ & $2(3)$ & $2(3)$ \\
\hline KS & Yes & & 2009 & 2009 & $2(3)$ & $4(4)$ & $2(3)$ & $3(3)$ \\
\hline KY & Yes & & 2012 & 2012 & $3(3)$ & $4(4)$ & $3(3)$ & $3(3)$ \\
\hline LA & Yes & 1991 & 2012 & & $3(3)$ & $4(4)$ & $3(3)$ & $3(3)$ \\
\hline MI & Yes & & 2011 & 2011 & $0(4)$ & $0(4)$ & $0(3)$ & $.5(3)$ \\
\hline MN & Yes & & 2008 & 2015 & $3(3)$ & $4(4)$ & $3(3)$ & $3.5(3.5)$ \\
\hline MS & Yes & 2003 & 2012 & 2012 & $3(4)$ & $4(4)$ & $3(3)$ & $4(3)$ \\
\hline OK & Yes & 2012 & 2010 & 2010 & $3(3)$ & $4(4)$ & $3(3)$ & 3 (3) \\
\hline SD & Yes & & 2010 & 2010 & $2.5(3)$ & $4(4)$ & $2.5(3)$ & $3(3)$ \\
\hline $\mathrm{TN}$ & Yes & 2005 & 2012 & 2012 & $3(3)$ & $4(4)$ & $3(3)$ & $3(3)$ \\
\hline $\mathrm{TX}$ & Yes & 1993 & 2011 & 2011 & $3(4)$ & $4(4)$ & $2(4)$ & $3(4)$ \\
\hline UT & Yes & & 2011 & 2011 & $2(3)$ & $3(4)$ & $2(3)$ & $2.5(3)$ \\
\hline WV & Yes & & $2012 * *$ & 2012 & $3(4)$ & $4(4)$ & $3(3)$ & $3(4)$ \\
\hline
\end{tabular}


Notes: * $=3$ lab sciences required. ** $=3$ units Algebra 1 and above. (a) Arizona required three math courses for cohorts graduating in 2008, 2009, and 2010. (b) New Hampshire required three math courses for cohorts graduating in 2008, 2009, and 2010. (c) New Mexico required four courses of math for the cohorts graduating in 2008, 2009, and 2010. 
All states except those that implement MMC

All States

Number of states

Outcomes

Average Freshman Graduate Rate (AFGR)

ACT Composite

Fraction of students taking the ACT

Policies

Exit exam, low level

Exit exam, higher level

Any End-of-Course (EOC) exams

\# of EOC exams (including zeros)

Math CGR (course graduation requirements)

English CGR

Science CGR

Social Studies CGR

Covariates

Log(population)

Fraction $<18$ years old

Fraction Asian

Fraction Black

Fraction Hispanic

Fraction population with BA or higher

Median HH income (\$2013)

Unemployment rate

Fraction enrolled in private schools

Per pupil expenditures (\$2013)
0.07

0.38

0.27

1.48

2.54

3.49

2.35

2.69

15.14

0.25

0.04

0.10

0.06

0.27

51,429

6.29

0.10

11,123
Michigan

like policies as of 2012
30

0.78

21.79

41.10

86.00

0.05

0.38

0.19

1.08

2.31

3.26

2.14

2.53

1.88

16.12

15.06

0.26

0.25

0.05

0.09

0.14

0.07

0.29

54,187

6.17

0.11

12,125

Notes: See text for details on the data and sample. 